\title{
HUMAN HEALTH RISK ASSESSMENT OF AMBIENT AIR IN A DISPUTE OVER PETROCHEMICAL EMISSIONS
}

\begin{abstract}
A case study in the application of science and risk assessment in an ongoing environmental conflict
\end{abstract}

By

Douglas Theodore Cousins, BA, University of Guelph, 2009

\author{
A thesis \\ presented to Ryerson University \\ in partial fulfillment of the \\ requirements for the degree of \\ Master of Applied Science \\ in the program of \\ Environmental Applied Science and Management
}

Toronto, Ontario, Canada 2018

(C) Douglas Cousins 2018 


\section{AUTHOR'S DECLARATION FOR ELECTRONIC SUBMISSION OF A THESIS}

I hereby declare that I am the sole author of this thesis. This is a true copy of the thesis, including any required final revisions, as accepted by my examiners. I authorize Ryerson University to lend this thesis to other institutions or individuals for the purpose of scholarly research. I further authorize Ryerson University to reproduce this thesis by photocopying or by other means, in total or in part, at the request of other institutions or individuals for the purpose of scholarly research. I understand that my thesis may be made electronically available to the public. 


\title{
Abstract \\ HUMAN HEALTH RISK ASSESSMENT OF AMBIENT AIR IN A DISPUTE OVER PETROCHEMICAL EMISSIONS
}

\author{
Master of Applied Science \\ 2018 \\ Douglas Theodore Cousins \\ Environmental Applied Science and Management \\ Ryerson University
}

Combined air emissions from multiple petrochemical facilities operating in the area known as Chemical Valley in Sarnia, Ontario, Canada, have led to escalating concerns over health effects to nearby residents. By conducting a quantitative health risk assessment of ambient air data collected from 2008-2014, this thesis investigated whether current emissions are resulting in increased health risk for the population living near Chemical Valley. The results of this analysis are that health risks are slightly higher than levels considered acceptable for large populations, but are within levels often accepted for smaller groups based on the traditional risk assessment - risk management paradigm. Interpreting these results in the context of the literature about the science-policy interface, and environmental dispute resolution, this thesis highlights several problems with using the traditional risk assessment - risk management paradigm as the basis for decision-making in environmental disputes - particularly when the affected population is Indigenous. 
Table of Contents

AUTHOR'S DECLARATION FOR ELECTRONIC SUBMISSION OF A THESIS.......................... ii

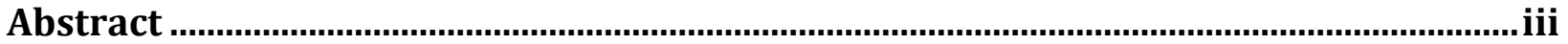

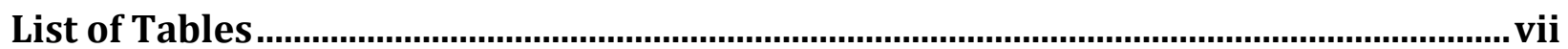

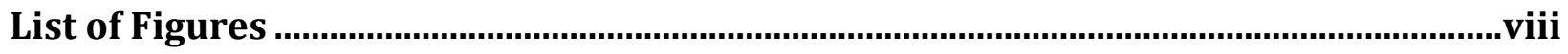

Chapter 1: Introduction ........................................................................................... 1

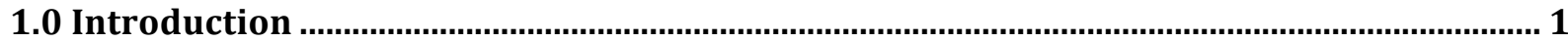

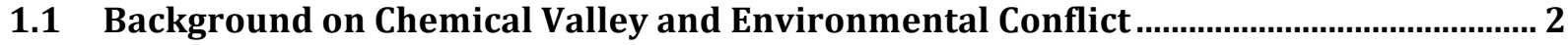

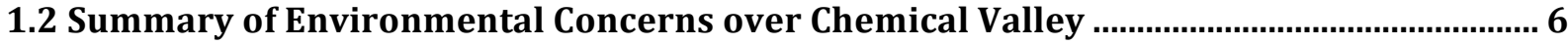

1.2.1 Expansion in Chemical Valley ................................................................................................................. 6

1.2.2 Leaks, Spills and Community Warnings ..................................................................................................

1.2.3 Legal Action over Environmental Regulation and Health Effects................................................... 9

1.2.4 Efforts to Assess Health Impacts of Chemical Valley ...................................................................... 10

1.2.5 Legal Challenge Arguing Ontario Regulatory System Discriminates against Aamjiwnaang

Residents and Other Accusations of Racism ......................................................................................12

1.2.6 Renewed Scrutiny of MOECC Regulation, Enforcement- Delays and Accusations of

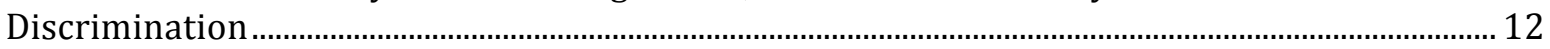

1.3 Environmental Regulation in Chemical Valley ………………………………………….....13

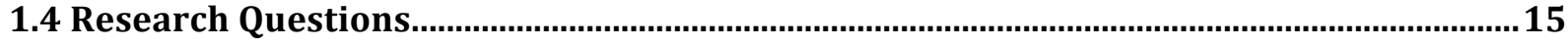

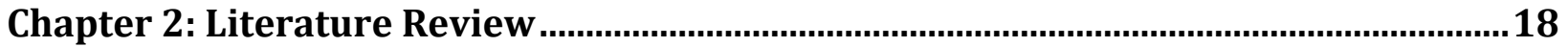

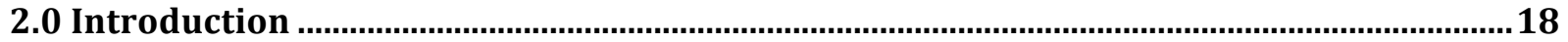

2.1 VOC Emissions from Petrochemical Facilities ………...................................................19

2.1.1 VOCs in the Local Environment near Petrochemical Industry.....................................................21

2.1.2 Health Risks in VOC hotspots...................................................................................................................22

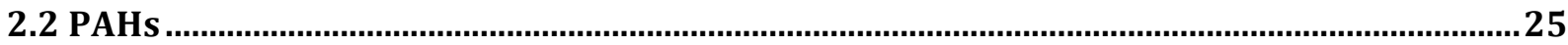

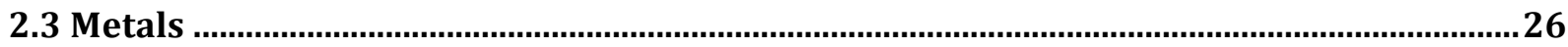

2.4 Criteria Air Contaminants...........................................................................................27

2.5 Regulating Emissions from Facilities..........................................................................28

2.6 Connecting Empirical Studies to the Dispute at Chemical Valley .......................................29

2.7 Scientific Background on Risk Assessment ............................................................................30

2.8 Transforming Risk Estimates into Policy …………........................................................33

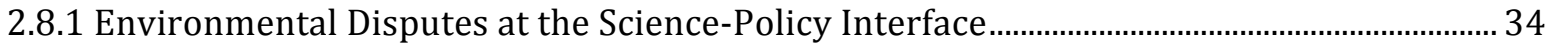

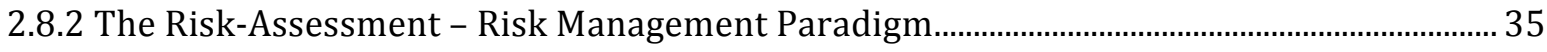

2.8.3 Risk Assessment, Uncertainty and the Penetration of Politics in Science..................................36

2.8.4 Risk Management and Acceptability of Risk ………………………………………………….... 39

2.8.5 Risk Assessment, Risk Management and Defining Health ………………………………….... 42

Chapter 3: Quantitative Health Risk Assessment Methods................................................43

3.0 Study Area and Monitoring Location and Equipment .........................................................43

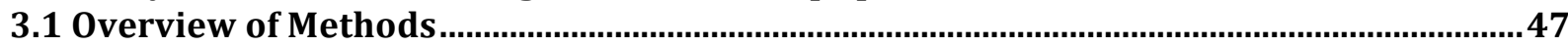

3.1.1 Identification of Chemicals of Concern.................................................................................... 49

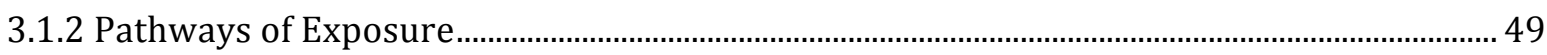

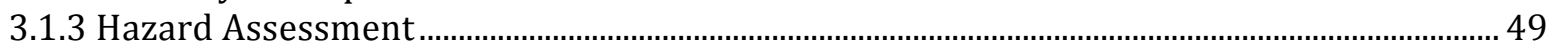

3.1.4 Exposure and Dose-Response Assumptions ……………………………………………………. 50

3.1.5 Dose-Response Assessment ...................................................................................................... 50 


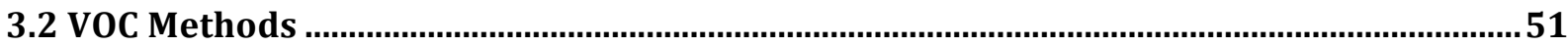

3.2.1 Identification of Contaminants of Concern ............................................................................ 51

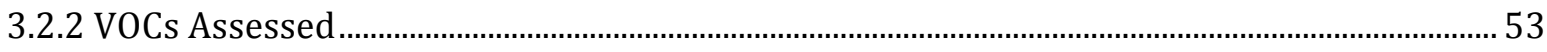

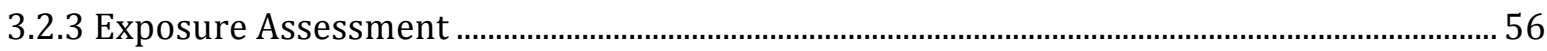

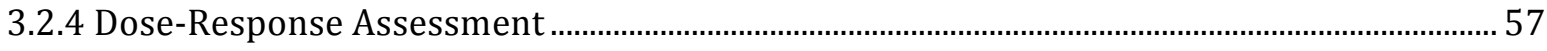

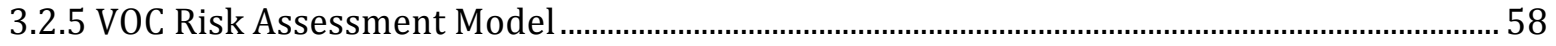

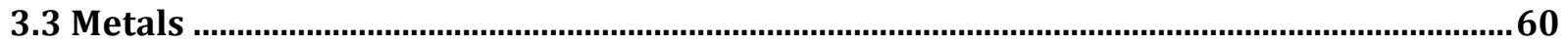

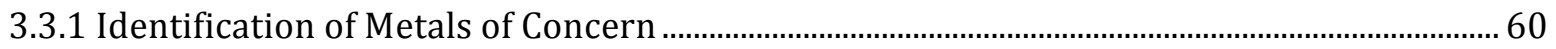

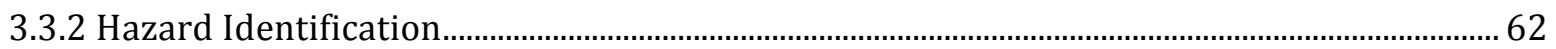

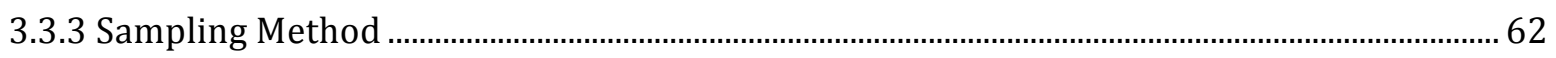

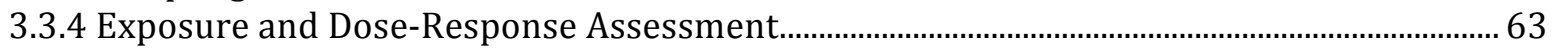

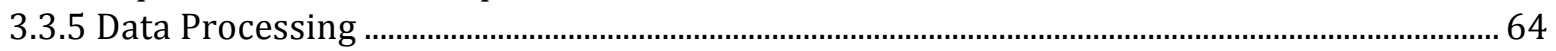

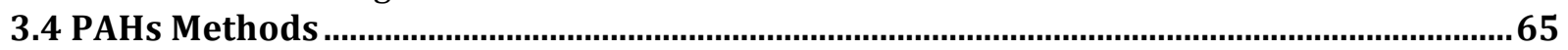

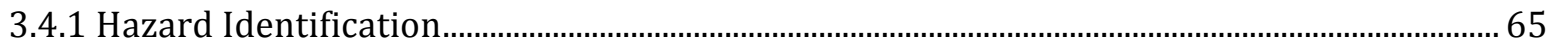

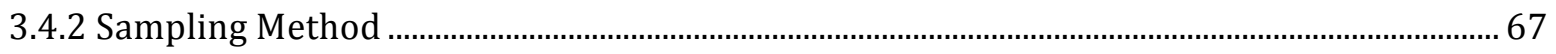

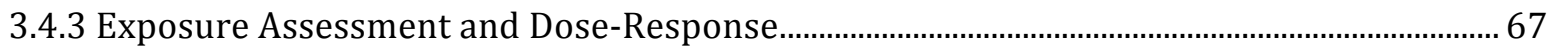

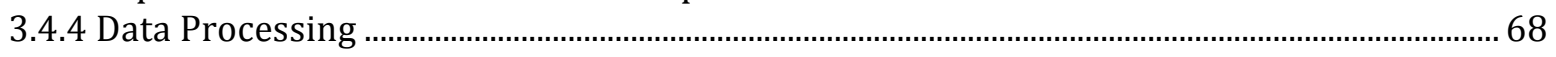

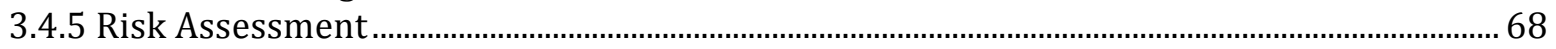

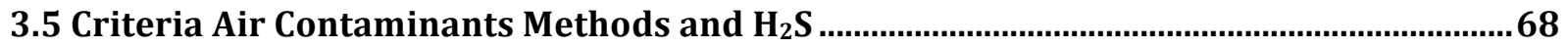

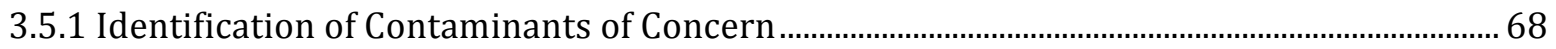

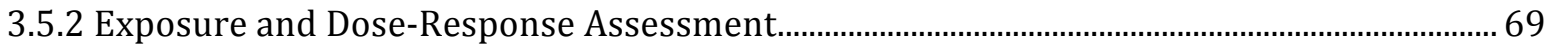

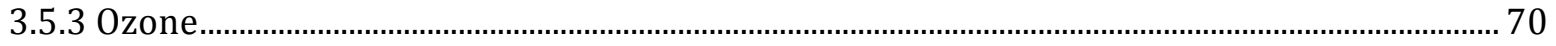

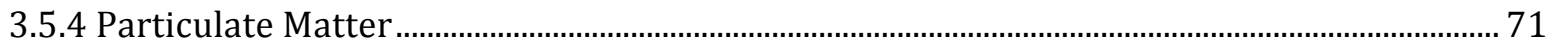

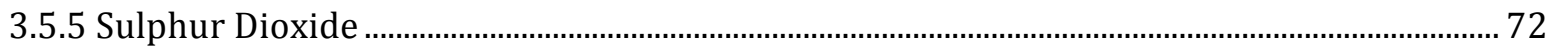

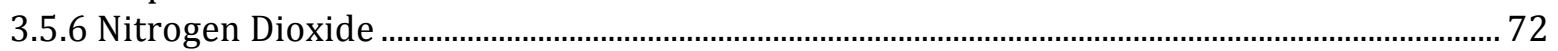

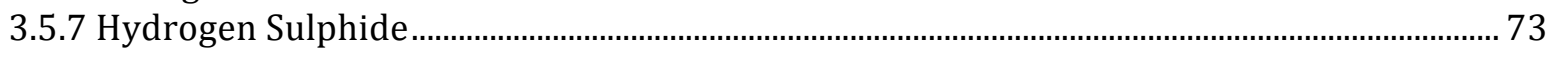

3.5.8 Sampling methods and Data Processing ....................................................................................... 73

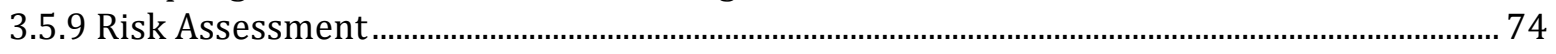

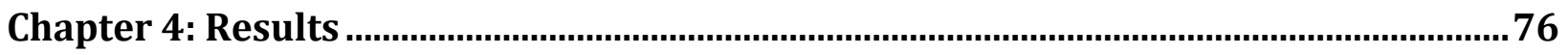

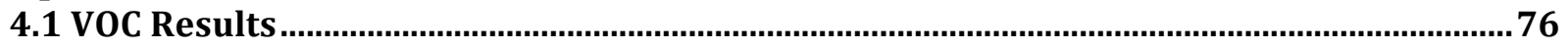

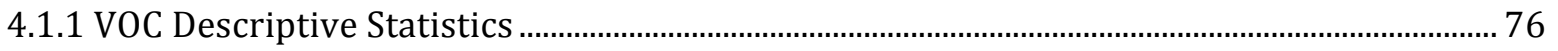

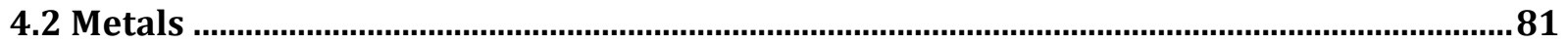

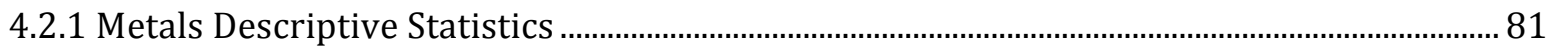

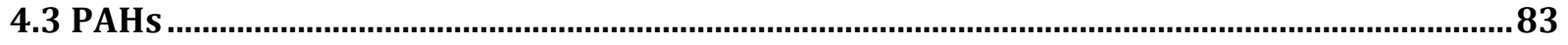

4.4 Cumulative Chronic and Cancer Risk from VOCs, Metals and PAHs ..................................... 84

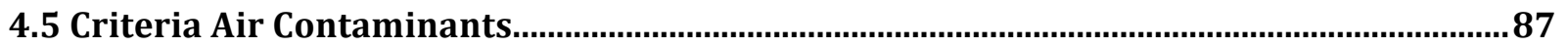

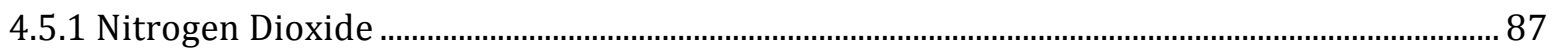

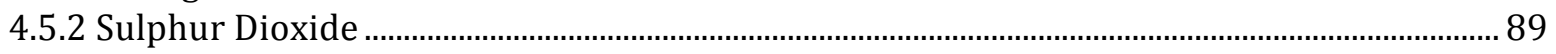

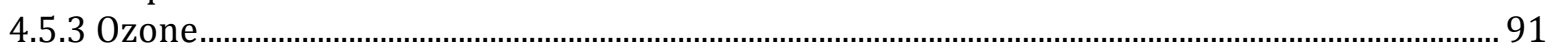

4.5.4 Fine Particulate Matter.................................................................................................................... 92

4.5.5 Total Reduced Sulphur/Hydrogren Sulphide............................................................................ 93

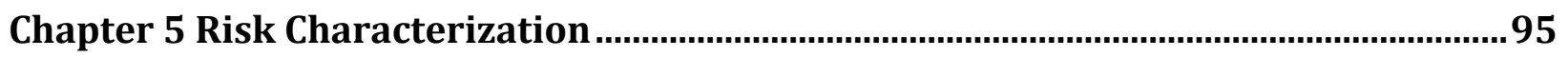

5.1 Major Assumptions and Uncertainties and Variability .....................................................95

5.1.1 Exposure Assumptions, Uncertainty and Variability affecting all Chemicals ....................... 95

5.1.2 Dose Response Assumptions, Uncertainty and Variability affecting all Chemicals ...........100

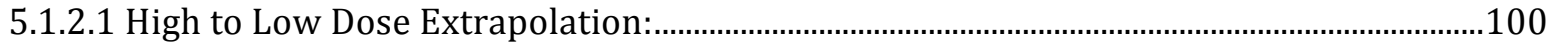

5.1.2.2 Uncertainty in Exposure Assessment, Statistical Methods and Treatment of Confounders in Occupational Studies 


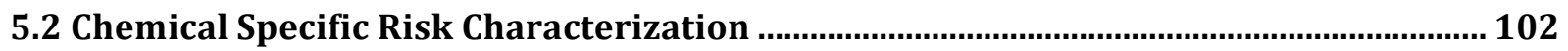

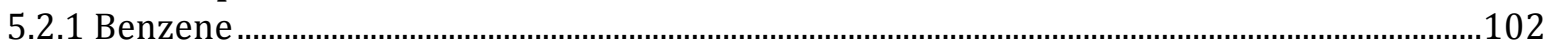

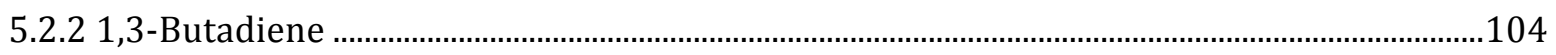

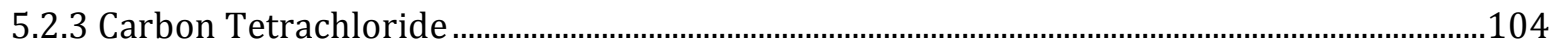

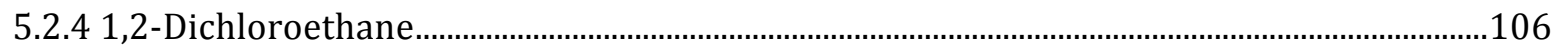

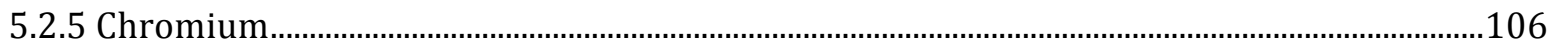

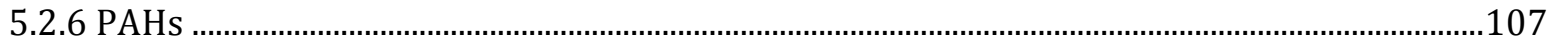

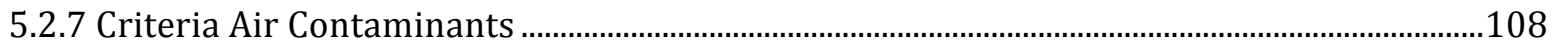

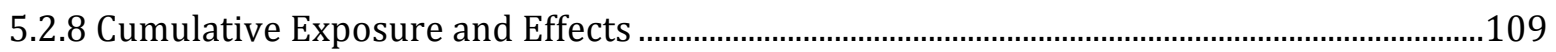

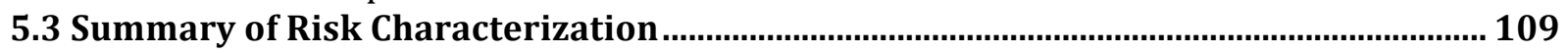

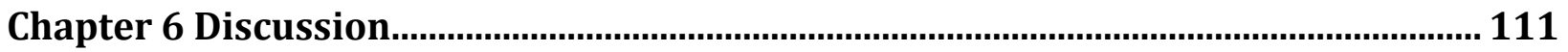

6.1 Summary, Response to Research Question \# 1 .................................................................... 111

6.1.1 Thesis Results relative to other Hotspots: ............................................................................112

6.2 Response to Research Question \# 2: Comparing Results to Ontario's Acceptable Risk

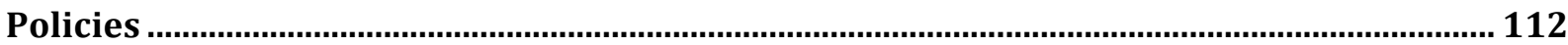

6.2.1 Emissions Reductions under Existing Regulations .................................................................114

6.3 Response to Research Questions \#2, \#3: Discussing Results Relative to Value-Concerns

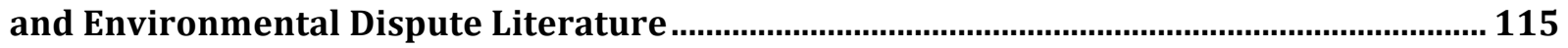

6.3.1 Discussion of Results Within Criticism of the Risk Assessment - Risk Management

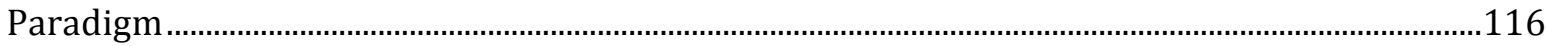

6.3.2 Managing uncertainty, fear and their impact on how to evaluate environmental policy118

6.4 Environmental Racism and Indigenous Rights ............................................................. 119

6.5 Further Discussion and Improvements in MOECC Regulation in Chemical Valley....... 121

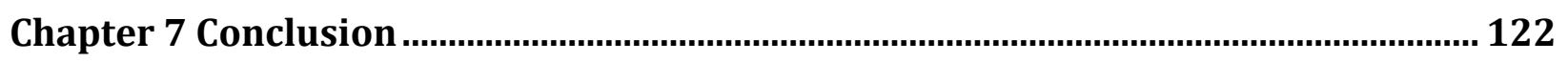

Appendix 1: Assessment of continuous VOC monitor Data........................................... 125

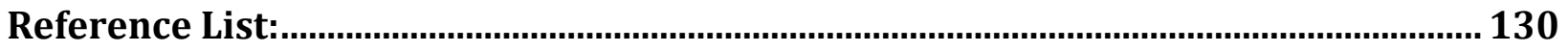

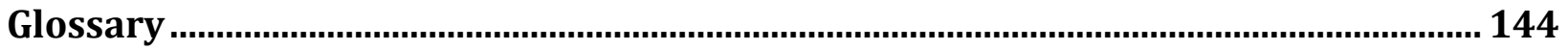




\section{List of Tables}

Table 1: Industrial Facilities in Chemical Valley 3

Table 2: Maximum concentrations of toxic and carcinogenic VOCs observed in short-term studies inside or near petroleum industry facilities $\quad 20$

Table 3. Monitoring Equipment at the Aamjiwnaang Monitor 45

Table 4. VOCs identified in literature review or NPRI database not monitored at Aamjiwnaang Monitor $\quad 52$

Table 5 VOCs assessed with chronic effects $\quad 54$

Table 6 VOCs assessed with USEPA carcinogenic classification and type 55

Table 7: Metals found in literature, NPRI and monitored at Aamjiwnaang monitor $\quad 62$

Table 8. List of PAHs monitored and their cancer classification 66

$\begin{array}{ll}\text { Table 9 VOC Descriptive Statistics } & 77\end{array}$

Table 10: VOC 95\% Upper Confidence Level of Mean $\quad 78$

Table 11 VOCs Chronic Risk Assessment using mean and 95\% UCL of mean 79

Table 12: VOCs Cancer Risk Assessment $\quad 80$

Table 13: VOCs Cancer Risk Assessment Exposure from birth 80

Table 14: Metals descriptive statistics $\quad 82$

Table 15: Metals Chronic Risk Assessment $\quad 82$

Table 16: Metals Cancer Risk Assessment $\quad 82$

Table 17: Summary Statistics for Benzo[a]Pyrene 83

Table 18: Cancer Risk Assessment for PAH mixture 84

Table 19: Cancer Risk Assessment for PAH mixture exposure from childbirth scenario 84

Table 20: Cumulative Hazard Index for Chronic Effects 85

Table 21: Cumulative Cancer Risk $\quad 86$

Table 22 Nitrogen Dioxide Assessment using CCME guidelines- Acute 87

Table 23 Nitrogen Dioxide Assessment using CCME guidelines— long-term 87

Table 24: Sulphur Dioxide Assessment using CCME guidelines-Acute 89

Table 25: Sulphur Dioxide Assessment using CCME guidelines— Long-term 89

Table 26 Ozone assessment using CCME guidelines- Acute 91

Table 26: Fine Particulate assessment using CCME guidelines- Acute 92

Table 27: Fine Particulate assessment using CCME guidelines — Long-term 92

Table 28: Total Reduced Sulphur / Hydrogen Sulphide 94

Table A1: benzene concentrations measured in Ontario Ministry of the Environment and

Climate Change, $2017 \quad 128$ 


\section{List of Figures}

Figure 1. Map of Chemical Valley Facilities $\quad 5$

Figure 2. Representation of Observable Risks and High to Low dose Extrapolation 31

Figure 3. Map of Chemical Valley Facilities 46

Figure 4. Wind Rose 2014 Aamjiwnaang Air Monitor $\quad 47$

Figure 5: CCME CAAQS management levels $\quad 69$

Figure 6: Nitrogen Dioxide Assessment using CCME guidelines- Acute 88

Figure 7: Sulphur Dioxide Assessment using CCME guidelines- Acute 90

Figure 8: Ozone assessment using CCME guidelines- Acute 91

Figure 9: Fine Particulate assessment using CCME guidelines-Acute 93

Figure A1: 2014 Hourly Benzene Concentrations Recorded Aamjiwnaang Continuous VOC Monitor

Figure A2: 2013 Hourly Benzene Concentrations Recorded Aamjiwnaang Continuous VOC Monitor

Figure A3: 2012 Hourly Benzene Concentrations Recorded Aamjiwnaang Continuous VOC Monitor

Figure A4: 2014 and 2013 Hourly 1,3-butadiene Concentrations Recorded Aamjiwnaang Continuous VOC Monitor

Figure A5: MOECC 2015 mobile monitoring survey locations. 


\section{Chapter 1: Introduction}

\subsection{Introduction}

Potential health effects due to contaminants are frequently a flashpoint in conflicts over industrial development. In Sarnia, Ontario, Canada, a petrochemical and refining complex, referred to as Chemical Valley, has been involved in conflict over the health impacts of emissions and, the efficacy of environmental regulation over the past two decades. Like many environmental disputes, the conflict over Chemical Valley emissions is a multi-faceted social conflict about how land, water, air, and people are transformed by industrial development - and in which science plays a defining role in how outcomes are decided. By conducting a quantitative health risk assessment of ambient air near Chemical Valley, this thesis therefore evaluates the scientific validity of criticisms of Ontario's regulatory system in Chemical Valley, with special attention to the relationship between the practice of science and the multidimensional nature of environmental disputes.

The way in which science is practiced, in relationship to other concerns in environmental disputes, is of particular importance for this case study because Chemical Valley nearly surrounds the Aamjiwnaang First Nation— a community subject to historic oppression by the Canadian state. By conducting a quantitative health risk assessment of government air monitoring data collected on the Aamjiwnaang reserve, the objective of this thesis is to determine whether current emissions from multiple facilities in Chemical Valley are resulting in increased risk to the population living near facilities, and compare health risk estimates to Ontario's policy of acceptable risk. 
The outcome of this analysis will show that health risks resulting from facility emissions are above what Ontario describes as negligible risk, but are not at levels that require immediate reductions in risk within Ontario's policy framework. Placing this result within the larger context of environmental disputes as social conflicts about how the physical environment ought to be, this thesis will show how the risk-assessment - risk management paradigm, as practiced in Ontario, excludes important problem aspects from consideration, and that particularly in the context of Indigenous populations and land, this poses ethical problems.

\subsection{Background on Chemical Valley and Environmental Conflict}

Chemical Valley is located in Sarnia Ontario along the shore of the St. Claire River and across from Port Huron, Michigan. The significant industrialization of Chemical Valley dates back to the 1940s, when the Canadian government established synthetic rubber plants. Growth in the refining and petrochemical industries took place over the next several decades, and the area is now considered a hub for industry with a network of pipelines, rail, road and power generating infrastructure (Sarnia-Lambton Econmic Partnership, 2015, 2017). There are currently 36 petrochemical or refined petroleum related facilities operating in Sarnia Lambton County, employing roughly 4500 people (Sarnia-Lambton Econmic Partnership, 2017). Facilities include three petroleum refineries with combined refining capacity of 274,000 barrels of crude oil per day, as well as numerous chemical manufacturing facilities producing a large number of organic and inorganic chemical products. Table 1 lists the significant industrial facilities in Chemical Valley along with some of the feedstocks they use, or products they produce. This list is not inclusive of all 
feedstocks and products as it is gathered from industry marketing materials. These facilities either border, or are in close proximity to the Aamjiwnaang First Nation, as well as residential neighbourhoods (see figure 1).

Table 1: Industrial Facilities in Chemical Valley

\begin{tabular}{|c|c|c|}
\hline Facility & $\begin{array}{l}\text { Feedstock and } \\
\text { Intermediaries }\end{array}$ & Products \\
\hline $\begin{array}{l}\text { NOVA Chemicals } \\
\text { (Corunna site) }\end{array}$ & $\begin{array}{l}\text { Crude Oil } \\
\text { Natural Gas Liquids } \\
\text { C4's, Mixed }\end{array}$ & $\begin{array}{l}\text { Ethylene, Butylene, } \\
\text { Iso-Butylene, 1,3-butadiene, } \\
\text { Benzene, Butane (mixed), } \\
\text { Fuel Oil, Toluene/Xylene } \\
\text { Natural Gas, Hydrogen gas }\end{array}$ \\
\hline $\begin{array}{l}\text { NOVA Chemicals } \\
\text { (Moore Site - } \\
\text { Located just South } \\
\text { of map boundary) }\end{array}$ & $\begin{array}{l}\text { Cyclohexane } \\
\text { Octene } \\
\text { Ethylene }\end{array}$ & Polyethylene \\
\hline $\begin{array}{l}\text { NOVA Chemicals } \\
\text { (St. Claire Site) }\end{array}$ & & Polyethylene \\
\hline Imperial Oil & $\begin{array}{l}\text { Crude Oil } \\
\text { Ethylene Propylene } \\
\text { Phenol } \\
\text { Ketone, Methyl Ethyl } \\
\text { Ketone, Methyl Isobutyl } \\
\text { C4's, Mixed }\end{array}$ & $\begin{array}{l}\text { Ethylene, Propylene, Benzene, } \\
\text { Butane (mixed), Hexane, } \\
\text { Gasolines, Nonene, Tetramer, } \\
\text { Propylene, Solvents, Petroleum } \\
\text { kerosene, fuel oil, lubricating oil, } \\
\text { petroleum waxes, } \\
\text { Lube Oil Additives, petroleum } \\
\text { coke, toluene, xylenes, } \\
\text { cyclopentane, polyethylene, } \\
\text { sulphur }\end{array}$ \\
\hline Cabot & & Carbon Black \\
\hline $\begin{array}{l}\text { ARLANXEO/ } \\
\text { LANXESS }\end{array}$ & $\begin{array}{l}\text { Butylene, Iso-Butylene, } \\
\text { 1,3-butadiene, Styrene, } \\
\text { Chlorine, Methyl Chloride, } \\
\text { Cyclohexane, Octene } \\
\text { Bromine, Acetonitrile, } \\
\text { Isoprene C4's, Mixed }\end{array}$ & $\begin{array}{l}\text { Iso-Butylene, } \\
\text { Butylene } \\
\text { 1,3-butadiene } \\
\text { Rubber, Polybutadiene, Butyl, } \\
\text { Halobutyl }\end{array}$ \\
\hline Shell Refinery & $\begin{array}{l}\text { Crude Oil } \\
\text { Natural Gas Liquids }\end{array}$ & $\begin{array}{l}\text { Benzene, Propane, Butane (Iso and } \\
\text { normal), Gasolines, Solvents, } \\
\text { Petroleum fuel Oil, } \\
\text { Toluene, Xylene, Isopropyl Alcohol, } \\
\text { Sulphur }\end{array}$ \\
\hline
\end{tabular}




\begin{tabular}{|l|l|l|}
\hline Suncor & $\begin{array}{l}\text { Crude Oil } \\
\text { Hydrofluoric Acid } \\
\text { Natural Gas Liquids }\end{array}$ & $\begin{array}{l}\text { Benzene, Propane, Butane (Iso and } \\
\text { normal), Gasolines, Kerosene, Fuel } \\
\text { Oil, Toluene, Xylene, Sulphur }\end{array}$ \\
\hline Styrolution & Benzene, Ethyl benzene & Ethyl benzene, Styrene \\
\hline Plains Midstream & Natural Gas Liquids & $\begin{array}{l}\text { Propane, Butane (Iso and normal) } \\
\text { C5's+, Mixed }\end{array}$ \\
\hline DuPont & & Reactive Polymers \\
\hline $\begin{array}{l}\text { HC Stark / Toda } \\
\text { Kogyo }\end{array}$ & $\begin{array}{l}\text { Tungsten carbide } \\
\text { Nickel hydroxide }\end{array}$ \\
\hline $\begin{array}{l}\text { TransAlta } \\
\begin{array}{l}\text { Cogeneration Plant } \\
\text { Located Beside } \\
\text { Suncor) }\end{array}\end{array}$ & Natural gas & Heat, electricity \\
\hline Sourc: (Sartide & & \\
\hline
\end{tabular}

Source: (Sarnia-Lambton Econmic Partnership, 2015)

This list of facilities is less comprehensive than MacDonald and Rang's 2007 review, published by the environmental advocacy law firm Eco-Justice, which found 62 facilities within a $25 \mathrm{~km}$ radius of the Aamjiwnaang First Nation with air emissions reportable to Canada's National Pollutant Release Inventory (NPRI) or the United States Toxic Release Inventory (TRI). However, while it is important to consider all facilities with the potential to influence air quality in the area, this thesis focuses on the smaller number of facilities listed above, within $5 \mathrm{~km}$ of the Aamjiwnaang reserve because they are most central to the environmental dispute. 
Figure 1. Map of Chemical Valley Facilities

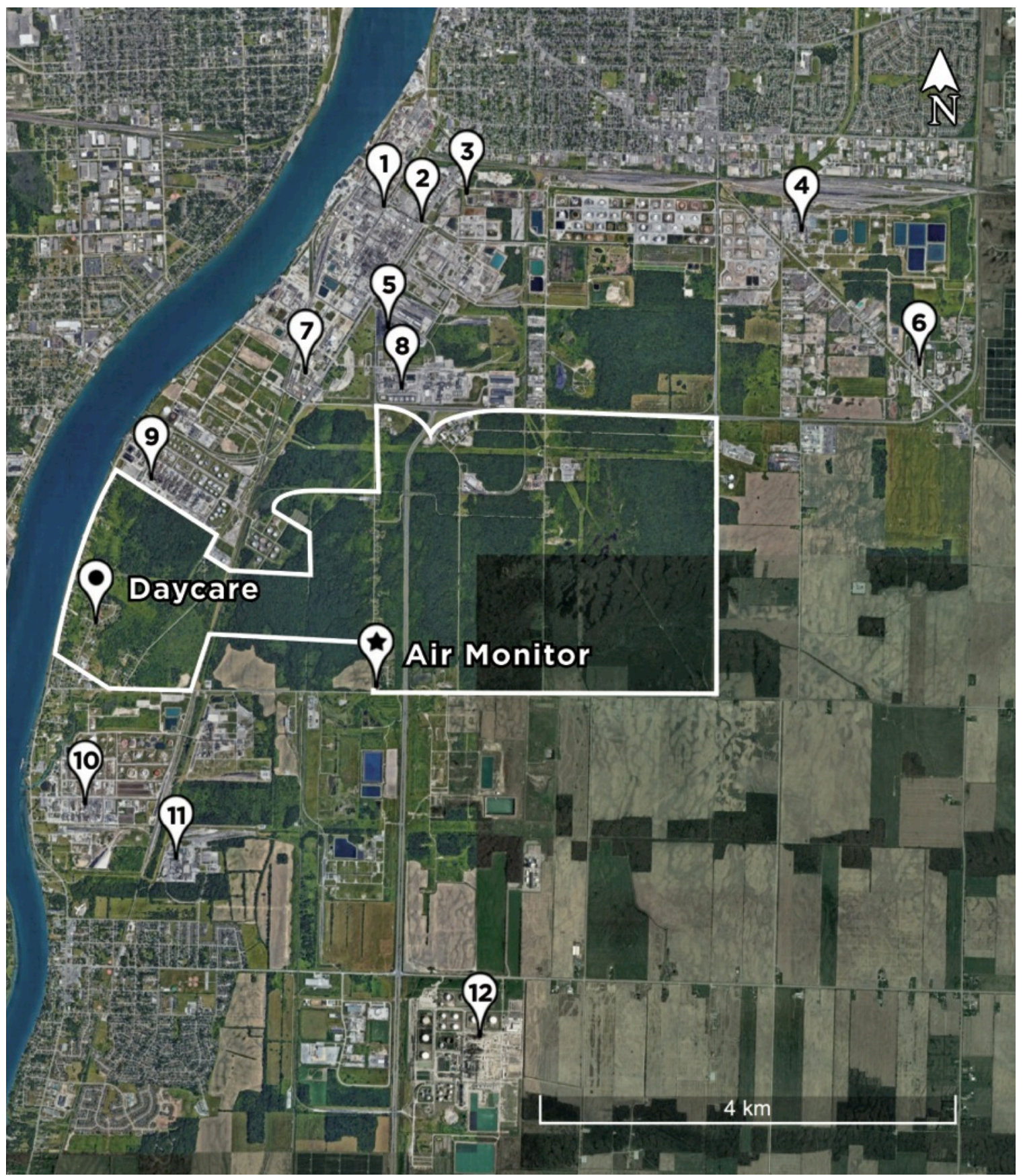

Legend:

1. Imperial Oil

2. HC Stark / Toda Kogyo

3. Sarnia Water Pollution Control

4. Plains Midstream
5. Cabot Canada

6. Enbridge Pipelines

7. LANXESS West

8. Styrolution

9. Suncor Refinery

10. Shell Refinery
11. NOVA Chemicals St. Claire/ DuPont

12. NOVA Chemicals Corunna Site 


\subsection{Summary of Environmental Concerns over Chemical Valley}

The key concerns driving the activism over Chemical Valley have been expansion of facilities and infrastructure in Chemical Valley, large spills and leaks, insufficient community warning procedures, insufficient environmental regulation, and fear of health effects from both acute and long-term exposure to emissions from facilities.

\subsubsection{Expansion in Chemical Valley}

Residents in Aamjiwnaang formed the Aamjiwnaang Health and Environmental Committee in 2002 in response to the announcement of Suncor ethanol refinery planned adjacent to the reserve, (Aamjiwnaang Environment, 2010). The chief and council formally supported the committee at the time, and protesters blockaded a private road used by Suncor for six weeks. Eventually the ethanol plant was sited in an alternative location. In 2009, however, expansion to the existing Suncor refinery operating beside the reserve was approved by the Ontario Ministry of Environment and Climate Change (MOECC) without direct notice to community members (Wiebe, 2016a).

In 2010, two residents from the reserve filed an application for judicial review of an administrative decision by the director of the MOECC. The Director's order had reinstated Suncor's operating permit for a sulphur recovery unit after a control order had previously restricted the unit's production so that it would meet Point Of Impingement (POI) standards ${ }^{1}$ (Lockridge et al. v. Ontario). The application for judicial review argued that this

\footnotetext{
${ }^{1}$ Point of Impingement (POI) is a term in Ontario's air emissions regulatory framework meaning any point on the ground or on a building located beyond an emitting facility's property boundary where either the
} 
decision put resident's health at risk and was discriminatory under Canada's Charter of Rights and Freedoms because the permitting decisions put a disproportionate burden of risk on the First Nation residents of the reserve.

\subsubsection{Leaks, Spills and Community Warnings}

Spills and leaks are recurring issues reported in media as well as in qualitative academic research (see Jackson, 2010; Oiamo, Luginaah, Atari, \& Gorey, 2011; Wiebe, 2016 for detailed accounts of personal experiences of living in Aamjiwnaang). From $2001-2005$ there were a number of high profile leaks and spills reported in local newspapers including:

- A 44,000 litre spill of crude oil at the Suncor refinery, which caused the reserve's daycare to be evacuated and a shelter in place advisory for other parts of the reserve (Mathewson, 2004).

- Massive flaring at several locations in Chemical Valley facilities, which sent four residents to hospital with nausea. (Sarnia Observer, 2003)

- A benzene spill at Nova Chemicals, which forced evacuation of parts of Aamjiwnaang. Band members described it as the twelfth time that summer that they were downwind from a leak at petrochemical factories next to their land. (Spears, 2005).

- A styrene spill at the now closed Dow Chemical facility which sent thousands seeking shelter (Mathewson, 2001).

maximum concentration of a given pollutant is expected to occur, or where the concentration of a given pollutant is expected to exceed Ontario's general air quality standards (Ontario Ministry of the Environment and Climate Change, 2017d) 
- A Benzene Spill at Nova Chemicals Coruna site which cost the company $\$ 400,000$ in fines (Mathewson, 2004).

- Complaints that the emergency warning system did not work after a benzene spill in 2001. (Plain, W, 2001)

Although reports of leaks and spills are now less frequent in local media, concerns over leaks and the emergency warning system have continued. In 2013, two residents of the reserve applied under Ontario's Environmental Bill of Rights (EBR) for an investigation of leaks which took place at Shell's refinery on January 11th 2013 and April 26, 2013 (Environmental Commissioner of Ontario, 2014a). The request alleged that strong rottenegg and gasoline odours were apparent for several hours and that residents experienced red eyes; headaches; nausea; throat irritation; dizziness; shortness of breath; coughing; and skin irritation. Further, they claimed that the emergency sirens, which alert the community when a shelter-in-place advisory is in effect, did not sound until almost an hour after the advisory was issued.

The MOECC denied the request to investigate under the EBR, citing that they were already conducting their own investigation, but confirmed that Shell reported a pipeline leak of sour water and that roads were closed and a shelter-in-place advisory had been issued for the entire Aamjiwnaang reserve (Environmental Commissioner of Ontario, 2014a). Eventually the MOECCs investigation led to charges laid, to which Shell pleaded guilty incurring fines totalling \$ 825,000 (Miron \& MacDonald, 2015). Despite this outcome, one of the applicants, Ada Lockridge, expressed concern that the spill occurred close to the reserve's daycare and community centre (shown in figure 1) where most community 
events occur, and that there is no air monitoring at this location (Miron \& MacDonald, 2015).

\subsubsection{Legal Action over Environmental Regulation and Health Effects}

Two residents of Aamjiwnaang have taken legal actions due to concerns that Ontario's regulatory system has failed to protect them from the health impacts of combined emissions from the facilities near and bordering the reserve (Lockridge et. al. vs. Ontario 2010). Although Lockridge et. al. vs. Ontario centred on an administrative decision concerning one facility, the central argument was that permits issued to the Suncor facility based on facility-specific standards did not take into consideration the combined emissions from neighbouring facilities, which could lead to concentrations putting residents' health at risk. Additionally, the application addressed clauses in Ontario's Environmental Protection Act that allow facilities to operate above regulatory standards at the Director's discretion, as well as the lack of updated science based benzene and sulphur dioxide air quality standards at the time.

The same two applicants from Lockridge et. al. vs. Ontario (2010) had already filed an application for review in 2009 under Ontario's Environmental Bill of Rights. The application requested that the MOECC review the need for a new regulatory framework to fill gaps in Ontario's air pollution laws related to cumulative impacts of pollution, particularly air pollution hot spots (Environmental Commissioner of Ontario, 2014b). In addition to several demands, the application requested that the MOECC require that any assessment, report or estimate of emissions and/or pollutant concentrations used regulatory permitting include background levels of pollution. The MOECC agreed to 
undertake this review in 2009, and in July 2017, the MOECC had still not completed the review. This prompted Ada Lockridge, one of the original review applicants, to file an application with Ontario's Superior Court of Justice to compel the MOECC to complete the review. In November 2017, the MOECC proposed a regulatory framework for cumulative benzene emissions in Chemical Valley.

\subsubsection{Efforts to Assess Health Impacts of Chemical Valley}

In addition to the legal actions related to cumulative emissions and health effects, community concerns over health effects have been documented in several studies and reports. A 2005, birth sex-ratio study published in Environmental Health Perspectives found that from 1994-2003 the proportion of male births showed a statistically significant decline (Mackenzie, Lockridge, \& Keith, 2005). This study drew widespread media and academic attention due to the potential link between these results and exposure to endocrine disrupting contaminants on the reserve- despite the fact that the study used birth records that included band members potentially living off-reserve and did not include any form of quantitative exposure assessment (Wiebe, 2016a).

Around this time, in partnership with Sarnia's Occupational Health Clinic for Ontario Workers, Aamjiwnaang's Health and Environment Committee conducted a voluntary health survey of 411 residents living on reserve, and found that:

- 26 percent of adults experienced high blood pressure,

- 26 percent of adults and 9 percent of children experienced chronic headaches, 
- 23 percent of children aged five to sixteen had learning and behavioural problems,

- 27 percent of children experienced skin rashes, and

- 39 percent of women had experienced a miscarriage or stillbirth

- 40 percent of residents interviewed required an inhaler

- 17 percent of adults and 22 percent of children had asthma

These results were published by MacDonald \& Rang (2007), in a report released by the law firm Eco-Justice, and the methodology used is unclear. Additionally, self-reported results are not comparable to illness rates reported by health authorities-despite some of these results appearing to be high.

As a result of the birth-ratio study, and the Aamjiwnaang voluntary health study, there were calls from stakeholders, including the industry funded Sarnia Lambton Environmental Association to conduct a multi-stakeholder-led, countywide health study. Problems over jurisdiction, funding, study methods, and control over study-design prevented this from moving beyond the literature review stage (Wiebe, 2016a). The literature review commissioned by the health study, concluded that because the population living in areas of higher exposure (Aamjiwnaang and South-western Sarnia) is too small to generate reliable statistical results for an epidemiology study, there are limited robust options available for assessing potential health effects actually occurring in the population (Lambton Community Health Study Board, 2010). The literature review recommended that only a cohort study would avoid the statistical problems caused by a small exposure population, however reconstruction of exposure would pose significant challenges since 
there was no long-term monitoring near Chemical Valley before the Aamjiwnaang air monitor was established in 2008.

\subsubsection{Legal Challenge Arguing Ontario Regulatory System Discriminates against Aamjiwnaang Residents and Other Accusations of Racism}

Part of Lockridge et. al. vs. Ontario (2010) was an argument under section 15(1) of Canada's Charter of Rights and Freedoms, that the Aamjiwnaang first nation is bearing a disproportionate burden of significant adverse health effects from pollution, because the MOECC regulatory system sanctions the disproportionate siting of facilities, and their associated pollution around the First Nation. Additionally, the case argued that as First Nations people, the applicant's cultural and community identity is tied to the reserve lands at Aamjiwnaang and that pollution from the facilities has disrupted the applicants' ability to carry out traditional activities such as hunting, fishing, medicine gathering and ceremonial activities. Further they argued that moving to avoid pollution constitutes a profound cultural dislocation (Lockridge et. al. vs. Ontario).

\subsubsection{Renewed Scrutiny of MOECC Regulation, Enforcement- Delays and Accusations of Discrimination}

Through the summer and fall of 2017, The Toronto Star, Global News, Vice and other news outlets published stories critical of the MOECCs regulation of emissions in Chemical Valley, its response to leaks, and its delay in completing its review of cumulative effects under the EBR. Included in this coverage were reports that an MOECC engineer, Scott Grant, had written a letter to the chief of the Aamjiwnaang First Nation questioning "whether or not discriminatory attitudes by some senior managers of the [environment ministry] may have played a role in the substantive delays in addressing concerns with air 
quality" (Graf, 2017). Also reported was that Grant had written a letter to Chief Commissioner of the Ontario Human Rights Commission to request an investigation of systemic discriminatory practices by the MOECC towards the Aamjiwnaang First Nation (Graf, 2017). Additionally, the union representing the Professional Engineers Government of Ontario (PEGO), was reported as having presented the MOECC's minister's office with a report alleging that the MOECC ignored concerns from the First Nations community of Aamjiwnaang and dismissed engineers' worries about the risk of industrial leaks with possibly irreversible health impacts (McIntosh, 2017b). Under public and media scrutiny, MOECC minister Chris Ballard announced the MOECC would fund a "science-based approach to understanding the localized impact of air pollution on the health of Sarnia residents." (McIntosh, 2017a).

\subsection{Environmental Regulation in Chemical Valley}

Up until 2005, the facilities in Chemical Valley were regulated based on air quality standards which incorporated technical and economic considerations, a process criticized for lack of transparency and less protective standards (Grant and Bloxam, 2009). In 2005, the MOECC overhauled the province's regulatory system, setting out a risk-based framework for regulating air emissions. Under the policy, the MOECC's objective for air standards for chemicals with carcinogenic effects is to set the standard equal to the air concentration that corresponds to an incremental lifetime cancer risk (ILCR) of 1 in a 
million $\left(1 \times 10^{-6}\right)$. For non-carcinogens, the policy is to set the ambient standard at the air concentration that corresponds with a hazard quotient (HQ) of $1 .{ }^{2}$

For a facility to obtain an operating permit, it must demonstrate, using dispersion modeling, that the highest concentration beyond the facility's fence line, (called a point of impingement (POI)), will meet the air quality standard. Facilities that cannot meet the air quality standard, but can achieve a POI concentration within either an HQ of 10 or an ILCR of 1 in ten thousand $\left(1 \times 10^{-4}\right)$ can apply for a site-specific standard, which can be granted by the director of the MOECC, and involves conditions requiring the facility to make efforts to reduce its emissions. If a facility's point of impingement concentration falls above an HQ of 10 or ILCR of $1 \times 10^{-4}$, it must take immediate measures to reduce its emissions.

In addition to this risk-based regulatory framework, the MOECC also introduced 59 new or updated health and environment-based air quality standards in 2005 (Grant and Bloxam, 2009). Although this represented significant progress, standards for many key toxicants were still not developed or updated including benzene, 1,3-butadiene, chromium compounds, manganese and manganese compounds, benzo(a)pyrene, nickel and nickel compounds, dioxin and dioxin-like furans and PCBs, uranium and uranium compounds and sulphur dioxide. New standards for these chemicals, with the exception of sulphur dioxide were implemented on July $1^{\text {st }} 2016$.

\footnotetext{
2 The Hazard Quotient (HQ) is the form of risk estimate for non-cancer effects, which is derived by dividing the estimated environmental exposure by a Reference Concentration (RfC) that represents an estimate of continuous inhalation exposure to the human population that is likely to be without an appreciable risk of health effects (Health Canada, 2010; U.S. Environmental Protection Agency, 1994).
} 


\subsection{Research Questions}

The summary of the environmental dispute concerning Chemical Valley shows that the conflict is multidimensional and concerned with pollution that has occurred in the past as well as emissions that are currently taking place under the MOECCs regulatory system. The Aamjiwnaang voluntary health survey represents belief, and evidence (although not necessarily meeting the standards of western science) on the part of local residents, that historical pollution, (as well as ongoing pollution in the case of asthma for example) has caused health effects in the population. The extensive literature review for the Lambton County Health Survey, however, determined that any such relationships between pollution and health effects were unlikely to be uncovered using empirical scientific methods due to lack of statistical power (Lambton Community Health Study Board, 2010). For concerned citizens, the requirement that their health concerns be quantitatively proven by science in order to be considered valid for policy-change has been both frustrating and recognized as a continuation of colonialism by placing western science as superior to Indigenous ways of knowing for decisions about first-nations land and peoples (Wiebe, 2016a).

Although not completely separate from these concerns, criticism of government's current regulatory system can be differentiated from historical concerns because of the MOECC's switch to a risk-based system of regulation in 2005. This system replaced what was considered a more lax standard-setting process that favoured industry input in the determination of air emission standards (Grant, C., R. Bloxam, 2009). The new system is a health-risk based system, in which standards of protection were based on the health risk levels discussed above. 
Nonetheless, the fact that facilities are regulated based on emissions modeling of single facilities under normal operating conditions, has led to concerns that the result of cumulative emissions from Chemical Valley facilities is causing unacceptable health risk for residents living near Chemical Valley. This leads to the following research questions:

\title{
Research Question \# 1: Have cumulative emissions from Chemical Valley resulted in increased quantitative health risk to the population living nearby?
}

To answer this question, this thesis carried out a quantitative health risk assessment of air monitoring data collected at the Aamjiwnaang Air monitor over the period from 20082014. The monitor, operated in partnership by the MOECC, Environment Canada and Aamjiwnaang First Nation is located in central location relative to many of the facilities and has taken hourly measurements of criteria air contaminants and VOCs as well as discrete 24-hour samples for VOCs, metals and PAHs over this monitoring period.

\author{
Research Question \# 2: Based on quantitative risk estimates generated by this thesis, \\ is Ontario's regulatory system sufficient to protect residents from health effects as \\ result of emissions? \\ This question was answered by comparing the risk estimates generated from this \\ monitoring data to Ontario's policy of acceptable risk, as well as by considering risk \\ estimates in the context of the literature regarding risk perception, environmental disputes \\ and Canadian colonialism.
}


Research Question \# 3: How does the practice of science in the regulation of Chemical Valley emissions conform to its expected role based on theories of environmental dispute resolution?

As the introduction has discussed, in addition to disputed scientific knowledge claims in Chemical Valley, conflicting interests and long-standing issues such as discrimination and colonialism are at stake in the conflict over Chemical Valley. The results of this thesis will be discussed in reference to the literature that theorizes environmental disputes as being conflicts in which issues of science and conflicting values are intertwined, and simplified science-only, or values-only analysis can only provide limited understanding of the dynamics of the conflict. 


\section{Chapter 2: Literature Review}

\subsection{Introduction}

Although later sections of this thesis will explore the ways in which scientific issues are tied to issues of policy and values in environmental conflict, the literature review begins by focussing on the scientific aspects of this conflict. These studies characterize the air emissions from petroleum refining and petrochemical facilities, and quantify the impacts of these emissions on the local environment. Many of these studies estimate health risk due to inhalation of ambient air in areas affected by industrial air emissions, and these will be compared against the risk estimates generated by this thesis.

The second component of the literature review introduces the fundamentals of quantitative health risk assessment, and connects this method to its broader use as a tool for informing environmental regulation. This includes review of the literature discussing what this thesis refers to as the risk-assessment - risk management paradigm - a method for environmental decision-making based on risk assessment, which can be used to describe Ontario's system for environmental regulation. The literature reviewed in this section points to problems with the straightforward separation of science and policy in environmental disputes. Further it suggests that improved scientific information, such as risk estimates derived as part of this thesis, is only part of the information needed to resolve environmental disputes, and that when scientific information is prioritized to the exclusion of other important concerns, it can even worsen the conflicts involved in environmental disputes. 


\subsection{VOC Emissions from Petrochemical Facilities}

Volatile organic compounds (VOCs) are the primary pollutants emitted at petroleum refineries and petrochemical plants and originate from a large number of sources including: processing units, combustion sources (including flaring), storage facilities and materials transfer, auxiliary processes such as cooling, and wastewater treatment, and fugitive emissions from leaks (U.S. Environmental Protection Agency, 2009a). Industry reported information has shown that fugitive emissions can account for $50-60 \%$ of all VOC emissions at a facility (Chen, Fang, \& Shu, 2005). Short-term sampling campaigns from either inside or within 500m of facilities have confirmed that VOC emissions come from numerous sources within facilities (Chen et al., 2005; Lin et al., 2004; Mo et al., 2015; Simpson et al., 2013). Generally these studies find alkanes and alkenes make up the majority of total VOC concentrations, however, the composition of VOC concentrations in emission plumes vary depending on the source within the facility. While aromatics and dienes make up less of the total VOC concentrations found in these studies, high concentrations of toxic and carcinogenic VOCs inside and beyond facility fence lines were found in several studies. Table 2 summarizes maximum concentrations of selected VOCs observed in these studies. 
Table 2: Maximum concentrations of toxic and carcinogenic VOCs observed in short-term studies inside or near petroleum industry facilities

\begin{tabular}{|c|c|c|c|c|}
\hline Study & $\begin{array}{l}\text { Type of } \\
\text { Facilities }\end{array}$ & $\begin{array}{l}\text { Sampling } \\
\text { Locations }\end{array}$ & VOC & $\begin{array}{l}\text { Max } \\
\text { Concentrations }\end{array}$ \\
\hline \multirow{3}{*}{$\begin{array}{l}\text { (Simpson et } \\
\text { al., 2013) - } \\
\text { Alberta's } \\
\text { Industrial } \\
\text { Heartland }\end{array}$} & \multirow{3}{*}{$\begin{array}{l}\text { Refinery and } \\
\text { Petrochemical }\end{array}$} & \multirow{3}{*}{$\begin{array}{l}\text { Outside } \\
\text { facilities } \\
500 \mathrm{~m} \\
\text { downwind }\end{array}$} & 1,3-butadiene & $27 \mathrm{ppb}$ \\
\hline & & & benzene & $6.6 \mathrm{ppb}$ \\
\hline & & & acetaldehyde & $74 \mathrm{ppb}$ \\
\hline \multirow{3}{*}{$\begin{array}{l}\text { (Chen et al., } \\
\text { 2005) } \\
\text { Taiwan }\end{array}$} & \multirow[t]{3}{*}{ Petrochemical } & \multirow[t]{3}{*}{ Within facility } & 1,3-butadiene & $157 \mathrm{ppb}$ \\
\hline & & & benzene & 650ppb (major leak) \\
\hline & & & M \& p xylene & $512 \mathrm{ppb}$ \\
\hline \multirow[t]{2}{*}{$\begin{array}{l}\text { (Lin et al., } \\
\text { 2004) } \\
\text { Taiwan }\end{array}$} & \multirow[t]{2}{*}{ Refinery } & \multirow[t]{2}{*}{$\begin{array}{l}\text { Within and } \\
\text { outside } \\
\text { facility }\end{array}$} & Benzene & $\begin{array}{l}618 \text { ppb within } \\
\text { facility } \\
31.4 \text { ppb offsite } \\
\text { downwind }\end{array}$ \\
\hline & & & Toluene & $\begin{array}{l}719 \text { ppb within } \\
\text { facility } \\
98.2 \text { ppb offsite } \\
\text { downwind }\end{array}$ \\
\hline $\begin{array}{l}\text { (Mo et al., } \\
\text { 2015) } \\
\text { China }\end{array}$ & $\begin{array}{l}\text { Petrochemical, } \\
\text { Basic } \\
\text { Chemical, } \\
\text { Chlorinated } \\
\text { Chemical } \\
\end{array}$ & $\begin{array}{l}\text { Within } \\
\text { facilities }\end{array}$ & $\begin{array}{l}\text { 1,3-butadiene } \\
\text { (reported as } \\
\text { health risk } \\
\text { only) }\end{array}$ & ILCR: $10 \times 10^{-6}$ \\
\hline
\end{tabular}

Longer-term Studies of VOCs in ambient environments have shown that petroleum refineries and petrochemical manufacturing can increase average and maximum concentrations of VOCs at distances up to 5km from sources (Jia \& Foran, 2013; Jobson et al., 2004; Kalabokas, Hatzianestis, Bartzis, \& Papagiannakopoulos, 2001; Ras, Marcé, \& Borrull, 2009; Thepanondh, Varoonphan, Sarutichart, \& Makkasap, 2011; Tiwari, Hanai, \& Masunaga, 2010). Some of these studies incorporated multiple sampling locations and found localized VOC hotspots beyond facility fence lines, which varied depending on location. These included separate locations with high concentrations of benzene, 1,3butadiene, 1,2-dicholormethane, naphthalene, isoprene and 1,2-dichloroethane 
respectively, that appeared to be caused by specific units within nearby facilities (Ras et al., 2009; Thepanondh et al., 2011).

\subsubsection{VOCs in the Local Environment near Petrochemical Industry}

The composition of total VOC concentrations found at monitoring sites in the local environment beyond facility boundaries tends to reflect the compositions found in the studies from within facilities, with alkanes and alkenes linked to petroleum industry sources. In areas influenced by both the petroleum industry and vehicular traffic, BTEX and 1,3 butadiene concentrations are thought to be influenced by both industry and vehicle exhaust (Jobson et al., 2004; Kalabokas et al., 2001; Thepanondh et al., 2011; Tiwari et al., 2010). A number of techniques have been used to try and differentiate these sources including VOC concentration ratios and correlations (Baltrènas, Baltrẻnaitė, Šerevičienė, \& Pereira, 2011; Jobson et al., 2004; Kalabokas et al., 2001; Miller et al., 2011; Miller, Xu, \& Luginaah, 2009; Tiwari et al., 2010), positive matrix factorization analysis (Jobson et al., 2004) and inspection of wind direction and concentration spikes (Jobson et al., 2004; Kalabokas et al., 2001). Two of these studies investigated VOC concentrations in the Sarnia area over a two-week period using passive samplers at 39 locations and found a large variation in VOC concentrations depending on location. Using VOC correlation (Miller et al., 2009) and BTEX ratios (Miller et al., 2011) they concluded that VOCs in areas close to industry were strongly influenced by petrochemical facility emissions while other areas of the city are more influenced by traffic. Although these studies only had data from one monitor on the Aamjiwnaang reserve, it was found to show strong industry influence. 


\subsubsection{Health Risks in VOC hotspots}

A number of studies have estimated health risk in air pollution hotspots. Some of these studies are in areas strongly influenced by petroleum industry sources such as the Tarragona region in Spain (Ramírez, Cuadras, Rovira, Borrull, \& Marcé, 2012) and Houston Texas (Sexton, Linder, Marko, Bethel, \& Lupo, 2007), while others are in areas influenced by other industrial and traffic sources of VOCs such as Memphis, Texas (Jia \& Foran, 2013), Camden, New Jersey (Wu et al., 2012; Zhu et al., 2008) and Dearborn, Michigan (Jia, Batterman, \& Godwin, 2008).

Ramírez et al., (2012) studied health risks due to VOC concentrations in three semirural to suburban locations, each within $1 \mathrm{~km}$ of the Tarragona petrochemical industrial complex and found that while hazard quotients for non-carcinogenic VOCs were $<1$ at all three sites, cumulative cancer risks were greater than $1 \times 10^{-4}$ for all three sites, with chloroform, benzene, carbon tetrachloride, ethylbenzene and tetrachloroethylene all found to have ILCRs greater than $1 \times 10^{-6}$. Important to note is that the study did not sample for 1,3-butadiene.

Houston Texas represents a unique region with air pollution hotspots because the area is home to more than 400 chemical manufacturing facilities including two of the largest refineries in the United States (Sexton et al., 2007). In addition there is heavy vehicular traffic, and marine shipping traffic representing the second most tonnage of any port in the United States. As a result, different areas of Houston are subject to elevated VOC concentrations resulting from all of these sources (Buzcu \& Fraser, 2006; Jobson et al., 2004). Sexton et al., (2007) investigated cancer risk and non-cancer hazards at monitoring locations across the city and found that 1,3-butadiene and benzene concentrations resulted 
in ILCR greater than $1 \times 10^{-4}$ at seven and two monitoring locations respectively, while nine other VOCs were reported by at least one monitor at concentrations representing ILCR between $1 \times 10^{-6}$ and $1 \times 10^{-4}$. Although Sexton et al., (2007) did not estimate the cumulative cancer risk at any given monitor, with such high ILCR values for individual chemicals, it can be assumed that cumulative cancer risks are likely high in areas within close proximity to industry and vehicular emissions.

An important set of issues related to health risk assessment in air pollution hot spots is the spatial variability of VOCs and the extent to which these emissions influence either indoor concentrations or personal exposure. Jia, Batterman, \& Godwin, (2008) found stronger and statistically significant correlations between outdoor and indoor VOC concentrations, including benzene, napthalene, and carbon tetrachloride in Dearborn Michigan, compared to suburban and urban areas without industry. Regression analysis of personal and ambient VOC monitoring in two Camden New Jersey neighbourhoods showed that ambient concentrations explained from 18 to $77 \%$ of personal exposure in the neighbourhood characterized by numerous industrial VOC sources compared to a neighbourhood only affected by traffic (Wu et al., 2012). Indoor exposure led to a cumulative ILCR of $1 \times 10^{-4}$ in Dearborn when the cumulative ILCR associated with outdoor air was $1 \times 10^{-6}$ range while personal exposures led to an ILCR in Camden in the $1 \times 10^{-6}$ range.

Studies investigating spatial variation of VOCs found that as distance from industrial and traffic sources of VOCs increases concentrations decrease. Source strength, wind speed and mixing height, and photochemical reactions all affect the influence of industrial sources on VOC concentrations at a given location (Buzcu \& Fraser, 2006; Zhu et al., 2008). Highly 
localized hotspots have been observed that are often specific to a single source and VOC. Those found in Camden New Jersey were less than 500m in diameter, small enough that central monitoring is not adequate to capture potential human exposure in areas with multiple point sources of VOCs (Zhu et al., 2008). 


\subsection{PAHs}

PAHs are considered to be ubiquitous in the environment and are released from the incomplete combustion of organic matter and fossil fuels. PAHs vary in their carcinogenic potential and potency, and individual PAHs as well as mixtures have been classified as possible or probable human carcinogens (Jarvis, Dreij, Mattsson, Jernström, \& Stenius, 2014). Oil refineries and petrochemical manufacturing facilities emit PAHs, and in particular, when refineries burn a variety of refuse gasses during cleaning, shutdown and emergency events, it is difficult to achieve complete combustion and emissions of black smokes are common (Yassaa \& Cecinato, 2005). There are a small number of studies examining the local effects of PAH emissions from refineries and petrochemical plants. Rehwagen, Müller, Massolo, Herbarth, \& Ronco, (2005) studied PAH concentrations in particulate matter from various locations and found that PAH concentrations near a large petroleum refinery were similar to urban traffic influenced locations but higher than a rural control area. PAH concentrations in soils sampled near a petroleum refining and petrochemical manufacturing complex in Spain were found to be higher than both a rural control area and an urban residential area, however the differences for the urban residential area were not statistically significant (Nadal, Schuhmacher, \& Domingo, 2007). A later study conducted at one rural and two suburban sites in the same region found that both gas and particle phase PAHs sampled in the air near the petrochemical complexes resulted in cancer risk at all locations above 1 x 10-6 (Ramírez, Cuadras, Rovira, Marcé, \& Borrull, 2011), and that the petrochemical facility emissions were likely a primary source of PAHs at the rural sampling site. Tsai, Being-Hwa, Ding-Zang, \& Lee, (1995) found that PAH concentrations were higher at sampling locations within and downwind from a 
petrochemical industry complex in Taiwan compared to a sampling location upwind- but these concentrations were still in the range of those found in urban Taipei-city. Yassaa \& Cecinato, (2005) measured PAHs in particulates near petroleum flares in Ouargla, Algeria and found that concentrations of PAHs were low, and did not have a significant influence on the carcinogenicity of organic aerosols in the city. PAHs studied in particulate matter near the Alberta Oil sands found that concentrations were generally lower than concentrations found in urban environments, but were influenced by oil sands emissions (Hsu, Harner, Li, \& Fellin, 2015). Although there is not a large number of studies examining PAH emissions from petroleum facilities, generally PAH emissions appear to influence background concentrations in environments near facilities, however, in several of these studies they were similar to urban PAH concentrations.

\subsection{Metals}

Nickel, vanadium, chromium, cadmium, zinc and lanthanum were identified in the literature as being present either in stack emissions from petroleum refineries or found in the local environment and linked to facility emissions (Bosco, Varrica, \& Dongarrà, 2005; Nadal et al., 2007; Sánchez de la Campa, Moreno, de la Rosa, Alastuey, \& Querol, 2011; U.S. Environmental Protection Agency, 2002b). There were, however, no studies assessing whether these emissions have led to potential health risks in the local environment, making it difficult to understand whether these emissions are likely to cause concern in Chemical Valley. 


\subsection{Criteria Air Contaminants}

Petroleum industry facilities typically emit carbon monoxide, sulphur oxides, nitrogen oxides and particulate matter (Cheremisinoff, 2002). Using 39 sampling locations over a two week period in Sarnia, Atari (2008) found that nitrogen dioxide and sulphur dioxide concentrations were highest near Chemical Valley and generally decreased with distance from the industrial corridor. Using pollution roses, and comparing operational and non-operational periods, Shie, Yuan, \& Chan, (2013) observed that peak hourly sulphur dioxide concentrations were significantly higher at monitors located 8-10km downwind of a petroleum refining complex when it was in operation. Almanza, Molina, \& Sosa, (2012) used a mix of modelling and monitoring to show that sour gas flaring at petroleum industrial facilities increased particulate matter and sulphur dioxide concentrations in downwind locations. Emissions of many reactive gases from petroleum facilities has led to an interest in whether ground level ozone is affected by petroleum facility emissions. In Houston Texas, studies have found that nitrogen oxides and VOC emissions from petroleum facilities vary greatly and that when there are large leaks of highly reactive VOCs during times when atmospheric conditions were conductive to ozone formation, leaks could affect ground level ozone concentrations significantly (Murphy \& Allen, 2005; Webster et al., 2007). Similar research was conducted in Beijing China finding similar results (Wei, Cheng, Li, Wang, \& Wang, 2014). 


\subsection{Regulating Emissions from Facilities}

Predicting emissions from petroleum refineries and petrochemical facilities is important for regulatory decision-making. In Ontario, facilities are regulated based on emissions predictions and air dispersion modeling (Ontario Ministry of the Environment and Climate Change, 2017a). One common way of predicting emissions at industrial facilities is by using emissions factors, a method which assumes emissions rates for various units and components at facilities. The widespread use of emissions factors produced by the EPA has led to a number of studies, many of which are in the grey literature, investigating the accuracy of VOC, as well as other gaseous emissions predictions. This literature has found emissions factors underestimate VOC emissions significantly (Cuclis, 2012; Hoyt \& Raun, 2015), principally because emissions factors are based on the assumption of equipment operating normally, and therefore do not capture the effects of unanticipated leaks (Cuclis, 2012). Studies in Houston Texas (Murphy \& Allen, 2005; Nam et al., 2008) have confirmed that very large non-routine VOC emissions can occur. McCoy, Fischbeck, \& Gerard, (2010) showed that emissions rates during upset conditions can be more than 50 times greater than routine emissions rates for carbon monoxide (CO), sulphur dioxide $\left(\mathrm{SO}_{2}\right)$ and VOCs at Houston facilities. Despite these findings, because many studies examining VOC emissions are short term, industry has frequently raised concerns that these short-term studies aren't reflective of long term differences between estimates and environmental concentrations (Cuclis, 2012). Johansson et al., (2014), however, show that long-term studies of facilities in Texas demonstrate emissions factor approaches systemically underestimate VOC emissions. Similarly, reporting to voluntary emissions 
inventories such as Canada's National Pollutant Release Inventory (NPRI) using emissions factors have been shown to be very inaccurate, both in Canada (Mclaren et al., 2017; Simpson et al., 2013) and in the United States (Ozymy \& Jarrell, 2011).

Since emissions factors can be used in dispersion modelling submitted to the MOECC for regulatory decision-making in Ontario, potential underestimation of emissions, particularly in an area such as Chemical Valley where there are multiple facilities operating in close proximity further highlights the need for monitoring studies to assess facility emissions and their impact on the local environment such as this thesis.

\subsection{Connecting Empirical Studies to the Dispute at Chemical Valley}

The studies noted above generally show that emissions from petroleum refineries and petrochemical facilities can influence the local environment and increase health risk due to inhalation of ambient air; even in regulated areas such as Houston, Texas. That many of these environments are also influenced by large amounts of traffic highlights a difference between the environments in these studies and the environment near the Aamjiwnaang Air monitor, which does not have heavy traffic. So it is possible that industrial emissions in Chemical Valley will influence and increase health risk due to ambient air in the area, but that health risks may be lower than some of the studies in the literature due to the absence of significant vehicular traffic. In reference to the research question \# 1 then, this literature leads to the hypothesis that the ambient air in Chemical Valley could well be affected by emissions and that this could lead to increased health risks. Therefore, empirical studies of air emissions from petroleum refineries and petrochemical facilities generally support

doubts stakeholders have expressed about the MOECC's regulation of Chemical Valley, and 
it seems at least possible that ambient air concentrations of contaminants are higher than allowed for individual facilities.

In order to connect this hypothesis to the research question \#2 and \#3, the quantitative literature above must be linked to the literature discussing how health risk is connected to policy about acceptable risk, as well as other value-based concerns in environmental disputes.

\subsection{Scientific Background on Risk Assessment}

Before describing risk assessment, framing the scientific knowledge about the relationship between chemicals and adverse health impacts is necessary. First, it is recognized that many chemicals have the potential to cause harm to human and biological systems. The potential to cause harm is described as hazard, which is considered to produce risk only if an exposure pathway to humans exists, and if exposure creates the possibility of harm (Covello \& Merkhofer, 1993). In quantitative risk assessment, risk is the numerical probability that this harm will occur (Health Canada, 2010).

Because the adverse outcomes caused by human exposure to chemicals are rare, the relationship between exposure and effect can only be reliably observed at rates well above those that would be considered acceptable by regulators or the general public (McClellan, 1999). For example, an increase in the rate of any health effect by $10 \%$ due to chemical exposure would cause outrage, and for important chemicals such as benzene, has only occurred in occupational settings before the effects of exposure were fully understood (Infante, 2013; McClellan, 1999). Risk assessment often extrapolates from studies of higher exposure to generate risk estimates at very low probabilities of effects (see figure 2). Even 
when considering the higher end of exposures to chemicals encountered in the outdoor ambient environment, quantitative estimates of risk, and not direct measuring of health effects, is often the most reliable scientific information that can be produced about the harm caused by emissions.

Figure 2. Representation of Observable Risks and High to Low dose Extrapolation Source: (McClellan, 1999)

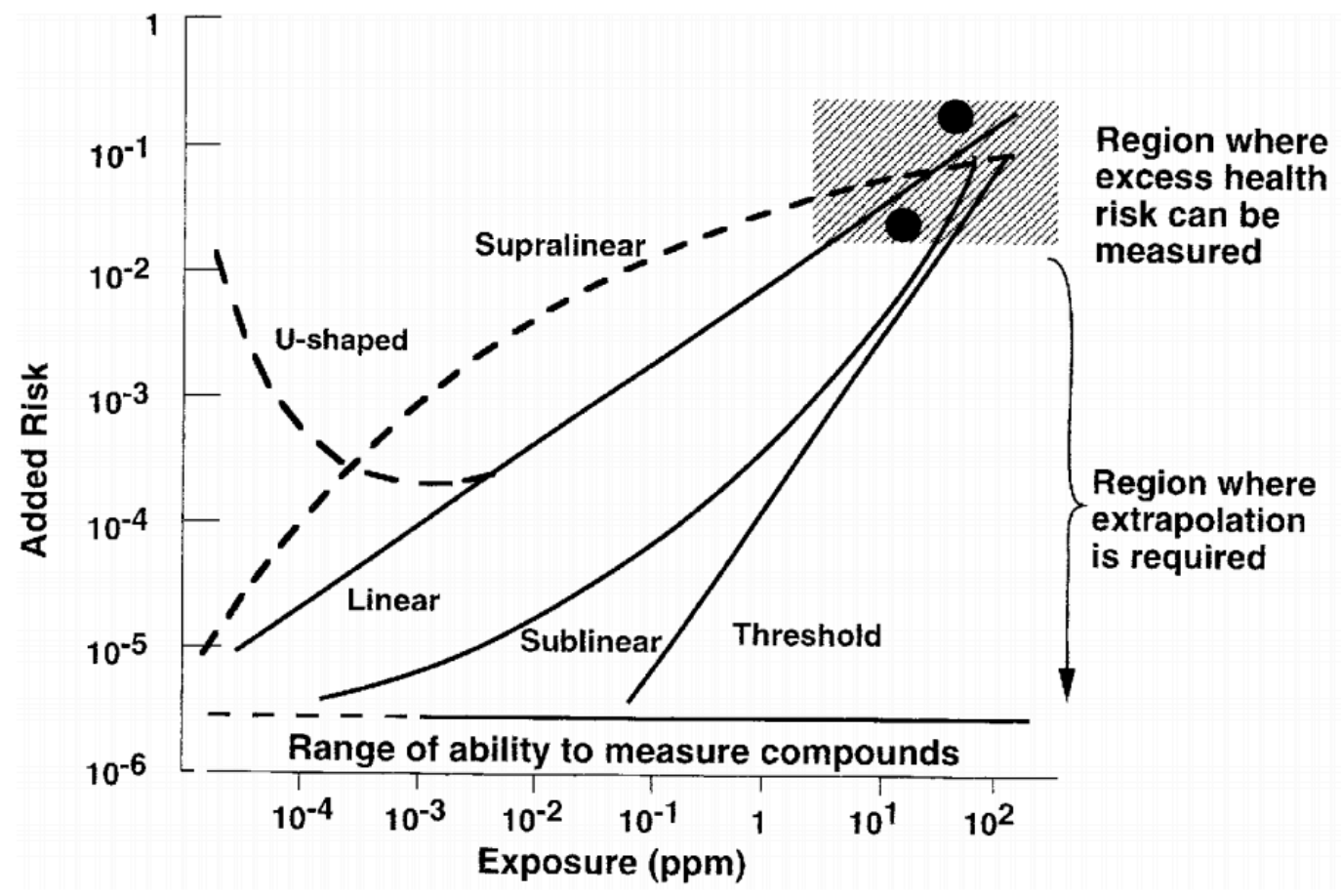

FIGURE 8. Schematic representation of exposure-added risk relationship, indicating cross-hatched region where added risks can be observed and alternative models for extrapolating to lower levels of risk.

The extrapolation shown above, of effects from high doses in either human occupational or animal studies, to risks associated with low levels of exposure, is the backbone of the quantitative risk assessment modeling because it quantifies the relationship between exposure and health effects at environmental concentrations such as those found near Chemical Valley. The modelling of this relationship, called dose-response 
assessment, is one part of the quantitative health risk assessment process. When applied to specific scenarios such as in this thesis, health risk assessment often follows four steps to numerically quantify the risk of exposure of a specific population to environmental hazards. These steps are:

- hazard assessment: involves qualitatively identifying the hazardous effects of chemicals identified for assessment.

- dose-response assessment: involves quantifying the relationship between exposure and effect.

- exposure assessment: involves quantitatively assessing the magnitude, frequency and length of exposure for the affected population or individuals

- Risk characterization: integrates the dose-response relationship with estimates of exposure in a population to characterize the likelihood of health effects. Risk characterizations should include both quantitative estimates and qualitative descriptors of risk, and discussion of model assumptions and data uncertainties (Health Canada, 2010; National Research Council, 1983; Williams \& Paustenbach, 2002)

Through these steps, a site-specific risk assessment conducts a qualitative hazard assessment, and then quantifies this potential to cause harm as a function of the human exposure measured in the environment. By combining the assessment of a population's environmental exposure (exposure assessment), and quantitative descriptors of the exposer-response relationship (dose-response assessment), risk assessment provides estimates of risk for the specific population of interest. 


\subsection{Transforming Risk Estimates into Policy}

Health risk assessments are not conducted in isolation - they are used to evaluate the outcome of human decision-making and this ties risk assessment into larger social conflicts over how the physical-human environment is altered. A key insight from the literature examining the use of science in environmental policy is that science provides an analytic framework for defining and resolving environmental problems that excludes important human value conflicts from explicit consideration. The literature shows that in environmental disputes, scientific knowledge claims made by government are consistently attacked from all sides of the political spectrum, and that policy decisions using these claims have rarely been considered sufficient by all stakeholders involved. This literature suggests that differing values around how to define health, how to define risk, how to interpret uncertainty, and who should have the power to define and decide, are all important components in what makes policies around risk sufficient for stakeholders. Further, this literature speculates that when these considerations are not given space in the policy process, arguments over science may intensify. This literature therefore paints a picture of environmental disputes in which science is politicized, and does not offer clear resolution to value differences involved in the conflict. It is against this picture that Chemical Valley will be compared to answer research question \# 3: How does the practice of science in the regulation of Chemical Valley conform to its expected role based on theories of environmental disputes? 


\subsubsection{Environmental Disputes at the Science-Policy Interface}

Environmental disputes inevitably occur at the science-policy interface as science is seen as a source of authority for knowledge about phenomena in the physical world, and environmental disputes involve competing beliefs amongst social groups about what the physical world should look like (Ozawa, 1996; Sarewitz, 2004). There is a large and diverse literature-base examining the various problems that arise when science is used in policy decision-making, and almost universally this research links problems occurring at sciencepolicy interface to the fact that in an environmental dispute, a statement about scientific issues is inherently also a statement which privileges some interests and not others (Salter, 1988). This literature describes how in these contexts, science is linked to political action, and why, for many reasons, asking empirical science to resolve policy conflicts has left scientists, regulators and stakeholders disappointed with both the process of decisionmaking, and decision-making outcomes (National Research Council, 1983; van den Hove, 2007). Many characteristics of the awkward relationship between science and policy have been suggested, and there are some common themes that emerge across the literature:

- Science conducted for policy decisions is different by nature than science conducted within academia because it is tied to taking a political action. Names such as "transscience" "mandated science" or "regulatory science" have been applied to these (Greenwood, 1984; Jasanoff, 1990; Salter, 1988; Weinberg, 1972).

- Regulatory Science involves a close and relationship between science and valuesespecially about which facts should be emphasized when there is uncertainty, and 
how much evidence is required to justify a decision (Elliott \& Resnik, 2014; Jasanoff, 1990; Salter, 1988)

- Regulatory science often involves areas where conventional scientific methods cannot reduce certain sources of uncertainty (Cumming, 1981; Kentel \& Aral, 2004; Salter, 1988; van den Hove, 2007; Whipple, 1986) — and uncertainty itself may also result from social value-differences expressed via scientific debate (Koppenjan \& Klijn, 2004; Sarewitz, 2004).

- Value differences drive environmental disputes but science excludes direct means of resolving value differences (Koppenjan \& Klijn, 2004; Sarewitz, 2004).

To a certain extent, these insights imply that scientific arguments about the effectiveness of the MOECC's regulatory system can be evaluated empirically, but also as mechanisms for exerting influence in the broader social conflict in Chemical Valley. The use of riskassessment to investigate the effectiveness of MOECC regulatory policy must therefore be discussed within the context of the science-policy interface.

\subsubsection{The Risk-Assessment - Risk Management Paradigm}

In conflicts involving exposure to industrial chemicals, risk assessment has been the primary method for bringing scientific knowledge into policy decision-making for environmental disputes. Risk assessment's centrality in this process was firmly established with the publication of the widely influential Red Book (officially titled Risk Assessment in the Federal Government: Managing the Process) by the U.S. National Academies press in 1983, which set out guidelines for conducting risk assessment and discussed key issues in its implementation for policy-making (Burke, 2003; McClellan, 1999). 
One of the core principles established by the Red Book was the separation of risk assessment and risk management, with risk assessment representing the scientific, factgathering aspect of environmental regulation, and risk management encompassing the process of weighing policy alternatives using information generated by risk assessment (National Research Council, 1983). The separation of the science and policy elements of environmental management proposed by The Red Book is an example of the classic twostage model of policy making: "Get the facts right, then act" (Haller \& Gerrie, 2007). In practice, this has resulted in risk-based environmental regulation policies, which have two key features:

- A risk assessment component that produces quantitative risk-estimates

- A risk-management component, that establishes acceptable risk levels for the general population (and sometimes also for population sub-groups). Acceptable risk levels are sometimes contingent upon economic or technical considerations (Kelly, 1991; Travis, Richter, Crouch, Wilson, \& Klema, 1987).

Years of research observing the practice of risk assessment and policy-making have shown that this model, in which science is supposed to be separated from the influence of policy decisions has not succeeded in reducing conflict in environmental disputes - and that this is partially because the science simply can't be separated from the decision it will influence (Haller \& Gerrie, 2007; Michaels, 2008; Salter, 1988; Sarewitz, 2004).

\subsubsection{Risk Assessment, Uncertainty and the Penetration of Politics in Science}

Although the Red Book sought to separate risk assessment from risk-management, it also recognized that when there was uncertainty within the science database, judgments, 
whether implicit or explicit had to be made, and these required some sort of value-basis (National Research Council, 1983). Therefore, the Red Book established a second category of policy, called risk assessment policy, that concerned itself with how to proceed when science offered competing judgements, or theories that could not be resolved by using the existing database itself.

"In each step [of risk assessment] a number of decision points occur where risk to human health can only be inferred from the available evidence. Both scientific judgements and policy choices may be involved in selecting from among possible inferential bridges and we have used the term risk assessment policy to differentiate between those judgements and choices made from broader social and economic issues that are inherent in risk management."

The Red Book acknowledged that some form of policy judgement is necessary in choosing amongst assumptions in risk assessment, but asserted that these policies should be separate from, and different in kind, than the explicit balancing of social values, which occurs in risk management.

Although useful as a concept, scholars have pointed out that the distinction between policies about how to analyze data, and policies that use the outcome of those analyses to pick winners and losers in the realm of social conflict, has led actors in environmental disputes to channel their value claims into upstream conflicts over the scientific interpretation of data (Elliott \& Resnik, 2014; Michaels, 2008; Salter, 1988; Sarewitz, 2004). That actors in an environmental dispute will be invested in, and attempt to influence the scientific judgements which occur within the scientific component of two-stage sciencebased policy is only natural because errors in scientific judgment will have an impact on the distributive justice of the policy decision (Hammond, 2000). Even if not explicit or 
intentional, values around how much weight should be given to different kinds of scientific evidence have been shown to have a strong influence on debates over the scientific merit of policy decisions (Elliott \& Resnik, 2014). Various studies have described the ways this phenomenon is sometimes the result of values implicitly influencing scientific judgement (Hammond, 2000; Koehler, 1993; Kraus, Malmfors, \& Slovic, 1992; Slovic et al., 1995; Slovic, Malmfors, Mertz, Neil, \& Purchase, 1997), or at other times, the result of an outright strategy by actors to advance their interests (Michaels, 2008). Regardless of intention, when policies are determined on a scientific basis, the most effective strategy for stakeholders to advance their interest is through scientific argument. As Greenwood, (1984) discusses, undermining the scientific competence of government decisions has become a tactic for actors from all sides of the political spectrum:

"To mobilize political strength to effect change, interest groups of whatever stripe cannot merely complain in public that the agency acted contrary to their preferences. Such complaints would be discounted readily as advocacy by all except those who share the critic's interests or policy preferences. To argue that an agency is incompetent, however, is to raise an issue that both commands attention and erodes the agency's authority and legitimacy. No one disagrees with the assertion that agencies should be competent."

Given these phenomena, there are scholars that argue strict adherence to sciencebased approaches to policy has harmed not only stakeholders unable to argue effectively for their interests, but also trust in government, and trust in science itself (Sarewitz, 2004).

The image that emerges from the environmental dispute literature is therefore of a duality, in which environmental disputes at first appear to be about science, but are also deeply tied to dissatisfaction with the distributive justice of risk-management policies. 


\subsubsection{Risk Management and Acceptability of Risk}

As presented in the Red Book, risk management is supposed provide room for the balancing of risk estimates and social values in decision-making. The practice of risk management by the U.S. Environmental Protection agency as well as the MOECC, however, has mostly excluded differing social values from explicit consideration in risk management - except for economic values. This has occurred because the basis for riskmanagement has been setting acceptable quantitative risk levels based on notions of safety or negligible risk originating from standards-of-practice within the risk-assessment community (Kelly, 1991; Travis et al., 1987). If these standards are met, development is generally approved without explicit consideration of other social factors except for when there are economic/technical barriers to industry meeting the standards, in which case regulations are not always enforced (Ontario Ministry of the Environment and Climate Change, 2017b; Travis et al., 1987). Within this framework, the risk of death from cancer has traditionally been considered negligible when incremental risk is below $1 \times 10^{-6}$ from a lifetime of continuous exposure- And regulators have often allowed for smaller subsets of the population to face a risk of $1 \times 10^{-4}$, particularly when the cost of additional regulation on industry appears to be higher (Travis et al., 1987). For chronic hazards, the safe level is based on a proxy for risk called a hazard quotient (exposures resulting in a hazard quotient $<1$ are considered safe). As practiced therefore, current risk-management policies in the US 
and Ontario have included economic values, but not the values of those opposed to particular industrial projects. ${ }^{3}$

Although in the abstract, the notions of acceptable quantitative risk above seem reasonable, a broad range of risk research has demonstrated that particularly for those involuntarily exposed to risk, detachment of this quantitative acceptable risk level from other qualitative values (such as trust and fairness), is simply not possible within the human brain (Roeser \& Pesch, 2015; Slovic, Finucane, Peters, \& MacGregor, 2004). These findings are supported by earlier research that also suggested this splitting of quantitative acceptable risk from cognitive, social and cultural values is not reflective of how the public interprets risk (Bradbury, 1989; Otway \& Von Winterfeldt, 1982; Rayner \& Cantor, 1987; Slovic, 1999; Starr, 1969). This literature is complex, and itself leads to varying hypotheses of how government reliance on universal and quantitative policies of acceptable risk contribute to environmental disputes, however, two key findings are relevant for this thesis:

- Conceptualizing risk as a quantitative probability of a specific health outcome only, is too narrow to capture the kinds of concerns, which determine the public's conception of risk.

- That consent is a very important determinant of whether risk is acceptable.

\footnotetext{
3 There are high profile scholars within toxicology who often advocate on behalf of industry, such as Dennis Paustenbach and others (see Finkel, 1989) that have argued the practice of risk assessment itself is biased towards overprotection of health, and they would likely also argue that health-protection oriented values are already well-represented within risk-assessment-risk-management because they are embedded within risk assessment (as practiced). This line of argument, however, is framed as an argument over the scientific quality of risk assessment, and is not explicitly concerned with whether competing social values should be incorporated in risk-management.
} 
Although it appears from the literature that there is no way to universally define risk, for the practice of this thesis, two notions of risk are acknowledged:

1. Risk as a numerical probability that can be separated from the value-oriented question "is it acceptable?" (quantitative), and

2. That when stakeholders are affected by decisions in an environmental dispute, the numerical risk they bear is not experienced as separate from the value-laden question of "is it acceptable?" which involves intuitive notions of consent, trust and justice (qualitative).

Accepting that both these definitions of risk can exist at the same time is important for understanding the role of science and values in environmental disputes. Doing so allows for simultaneous analysis of the problem using scientific methods, as well as analysis of how this science fits into the larger dispute. For this thesis, the first definition of risk (quantitative) will be used to estimate health risk due to inhalation of ambient air, and compare these results to Ontario's risk management policy of acceptable risk (answering research questions \#1 and \#2). The second definition of risk (qualitative) will be used as an alternative framework to answer question \#2, and this will demonstrate that evaluating the sufficiency of regulatory policy will always incorporate subjective elements, and that problem resolution will require consideration of values such as justice and fairness. Together, this analysis will demonstrate that the dispute over Chemical Valley fits well with existing environmental conflict literature, in which conflicting science and conflicting values act in dynamic ways and perpetuate conflict, even as the general stringency of environmental regulations increase across society. 


\subsubsection{Risk Assessment, Risk Management and Defining Health}

An additional consideration, which is not always addressed in risk analysis

literature, is that under the traditional risk assessment - risk management paradigm health is defined by default as the absence of physical illness. This definition is significantly more narrow that the WHO's definition of health, as well as Indigenous definitions of health (Durie, 2004; Richmond \& Ross, 2009; Wilson, 2003; World Health Organization, 2018). In particular, Richmond \& Ross, (2009) highlight the impact of environmental dispossession as a fundamental way in which colonialism has negatively affected First Nations and Inuit health by severing the connection of aboriginal people to their traditional lands. In that study, community health representatives from a number of Indigenous communities across Canada identified six determinants of health: "balance, life control, education, material resources, social resources, and environmental/cultural connections." In relation to the definitions of risk above, these determinants of health demonstrate that even the definition of health is subject to differing values which are also left out of explicit consideration in the traditional risk assessment - risk management paradigm. Applying the traditional risk assessment - risk management paradigm as the only decision-tool to an environmental dispute involving an Indigenous population, therefore involves excluding important values around defining health from decision-making. 


\section{Chapter 3: Quantitative Health Risk Assessment Methods}

\subsection{Study Area and Monitoring Location and Equipment}

The data for the quantitative component of this thesis was publically available government data collected at the Aamjiwnaang Air Monitor, which was established by the MOECC in September 2008, in partnership with the Aamjiwnaang First Nation and Environment and Climate Change Canada (ECCC). The station is located in a secured and fenced building located at the intersection of Tashmoo Ave. and Lasalle Rd. (see figure 3 below). The figure shows the location of the air monitor as well as a number of the facilities located nearby. Figure 4 is a wind rose based on 2014 hourly wind-direction measurements, and shows that the most frequent wind directions were from the West North West, South-South West and South West. The largest residential neighbourhoods near the facilities are in Corunna (located South of the Shell facility), South Western Sarnia (located to the North East of the facilities at the top of the map), and Aamjiwnaang First Nation (located in the centre of the map). Much of the First Nation is forested, although infrastructure such as roads, pipelines, railway and power lines cut through the reserve. The population on the reserve are located along a north-south strip on Tashmoo Ave. (directly north of the monitor), as well as in the Southwest corner of the reserve and along highway 33 by the St. Claire River (North of the Shell Facility and South of the Suncor facility). While Corunna and Southwest Sarnia represent larger populations than the Aamjiwnaang reserve, they may be less affected by Chemical Valley emissions because they are only down wind from facilities during a single wind direction, whereas the residents of 
Aamjiwnaang are almost surrounded by facilities in all directions except from the East, which is the least frequent wind direction.

The monitor uses the following equipment to take hourly (called continuous) and non-continuous samples of a wide variety of air contaminants. Table 3 lists the parameters sampled and equipment used at the Aamjiwnaang monitor. The monitor has two methods for sampling VOC concentrations and these are listed in table 3. Important to note is that this list in table 3 represents upgrades made in July 2017, where the MOECC replaced an experimental-grade Gas Chromatograph/Mass Spectrometer, which had been used to take hourly VOC measurements with commercial grade equipment. Up until July 2017, the experimental-grade continuous VOC monitor had an unknown method detection limit that appeared to be above background concentrations for VOCs of interest such as benzene and 1,3-butadiene. The continuous VOC dataset over the study period (2008-2014), could therefore not be used to reliably estimate long term VOC concentrations, so the assessment used the dataset generated by the non-continuous sampling using summa canister and described in Galarneau et al., (2016). The continuous dataset for VOCs was, however, useful for observing spikes in VOC concentrations, which are useful for distinguishing between industrial leaks and traffic as sources of pollution. This is discussed in Appendix 1. 
Table 3. Monitoring Equipment at the Aamjiwnaang Monitor

(Source: Ontario Ministry of the Environment and Climate Change, 2017f)

\begin{tabular}{|c|c|c|}
\hline & Parameters & Instruments \\
\hline \multirow{8}{*}{ 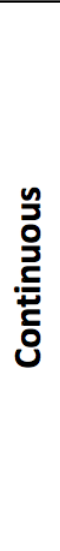 } & Sulphur dioxide $\left(\mathrm{SO}_{2}\right)$ & Teldyne Model T100 \\
\hline & Nitrogen oxides $\left(\mathrm{NO} / \mathrm{NO}_{2} / \mathrm{NO}_{\mathrm{x}}\right)$ & Thermo Scientific Model 42i \\
\hline & Total reduced sulphur (TRS) compounds & $\begin{array}{l}\text { Thermo Scientific Model 43c with } \\
\text { Teldyne model } 200 \text { oxidizer }\end{array}$ \\
\hline & Fine particulate matter $\left(\mathrm{PM}_{2.5}\right)$ & Grimm Dust Monitor EDM180 \\
\hline & Volatile organic compounds (VOC) & $\begin{array}{l}\text { Shimadzu Model QP2010s with } \\
\text { ACEM } 905 \text { Thermal Desorber }\end{array}$ \\
\hline & Carbon monoxide (CO) & Thermo Scientific Model 48c \\
\hline & Ground-level ozone $\left(\mathrm{O}_{3}\right)$ & Thermo Scientific Model 49c \\
\hline & Wind speed and direction & RM Young model 5103 Anemometer \\
\hline \multirow{3}{*}{ 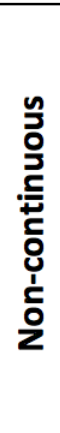 } & $\begin{array}{l}\text { Volatile organic compounds (VOC), 24- } \\
\text { hour sampling, } 12 \text { day cycle }\end{array}$ & $\begin{array}{l}\text { Summa canister (analyzed by } \\
\text { Environment and Climate Change Canada } \\
\text { Laboratory) }\end{array}$ \\
\hline & $\begin{array}{l}\text { Polycyclic aromatic hydrocarbons (PAH), } \\
\text { 24-hour sampling, } 12 \text { day cycle }\end{array}$ & $\begin{array}{l}\text { High volume air sampler (analyzed by } \\
\text { MOECC Laboratory) }\end{array}$ \\
\hline & $\begin{array}{l}\text { Suspended particulate (SP) and } \\
\text { constituent metals, 24-hour sampling, } 6 \\
\text { day cycle }\end{array}$ & $\begin{array}{l}\text { High volume air sampler (analyzed by } \\
\text { MOECC Laboratory) }\end{array}$ \\
\hline
\end{tabular}


Figure 3. Map of Chemical Valley Facilities

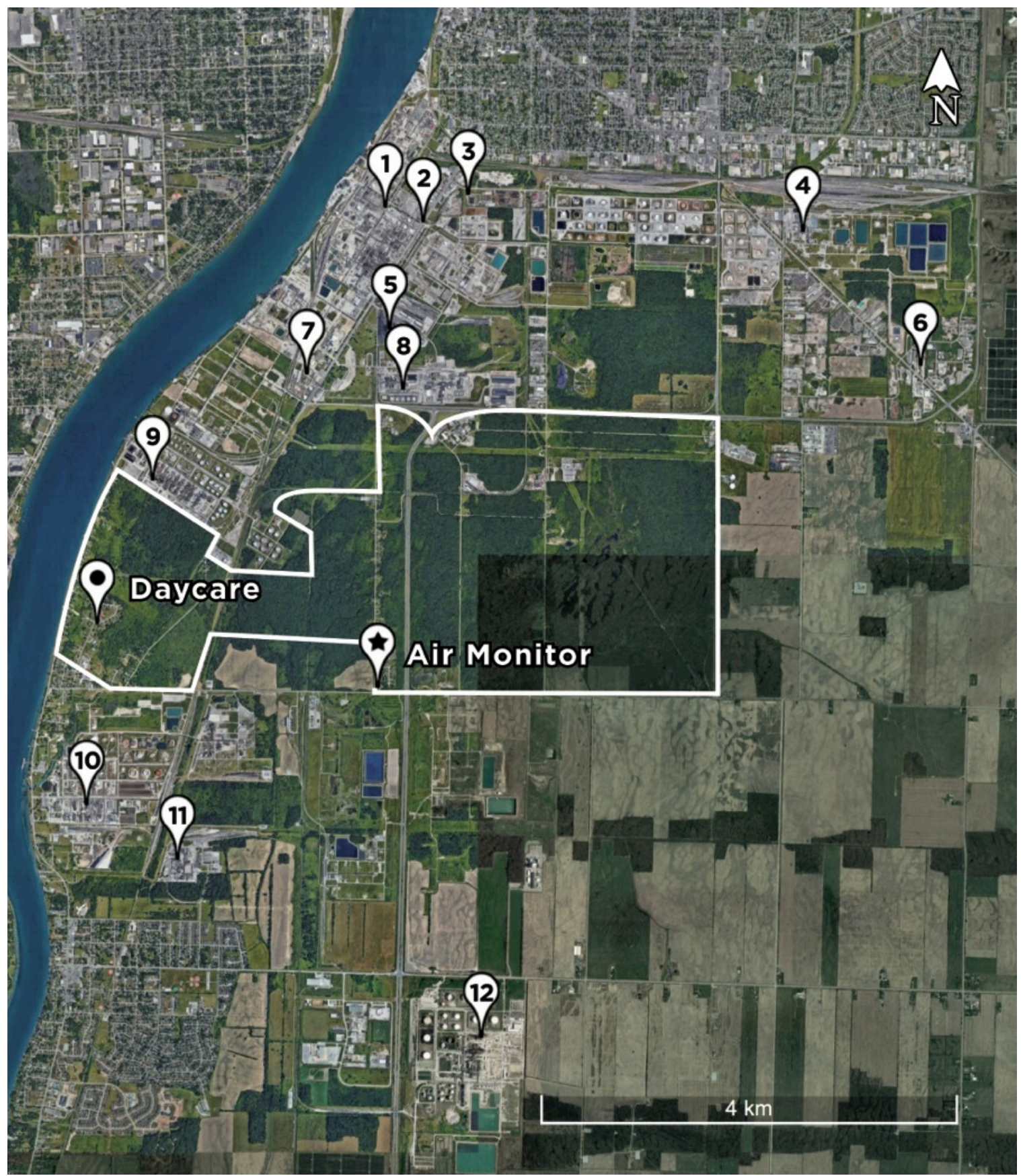

\section{Legend:}
1. Imperial Oil
2. HC Stark / Toda Kogyo
3. Sarnia Water Pollution Control
4. Plains Midstream
8. Styrolution
9. Suncor Refinery
10. Shell Refinery

11. NOVA Chemicals St. Claire/ Dupont

12. NOVA Chemicals Corunna 
Figure 4. Wind Rose 2014 Aamjiwnaang Air Monitor 2014 Wind Direction (percent)

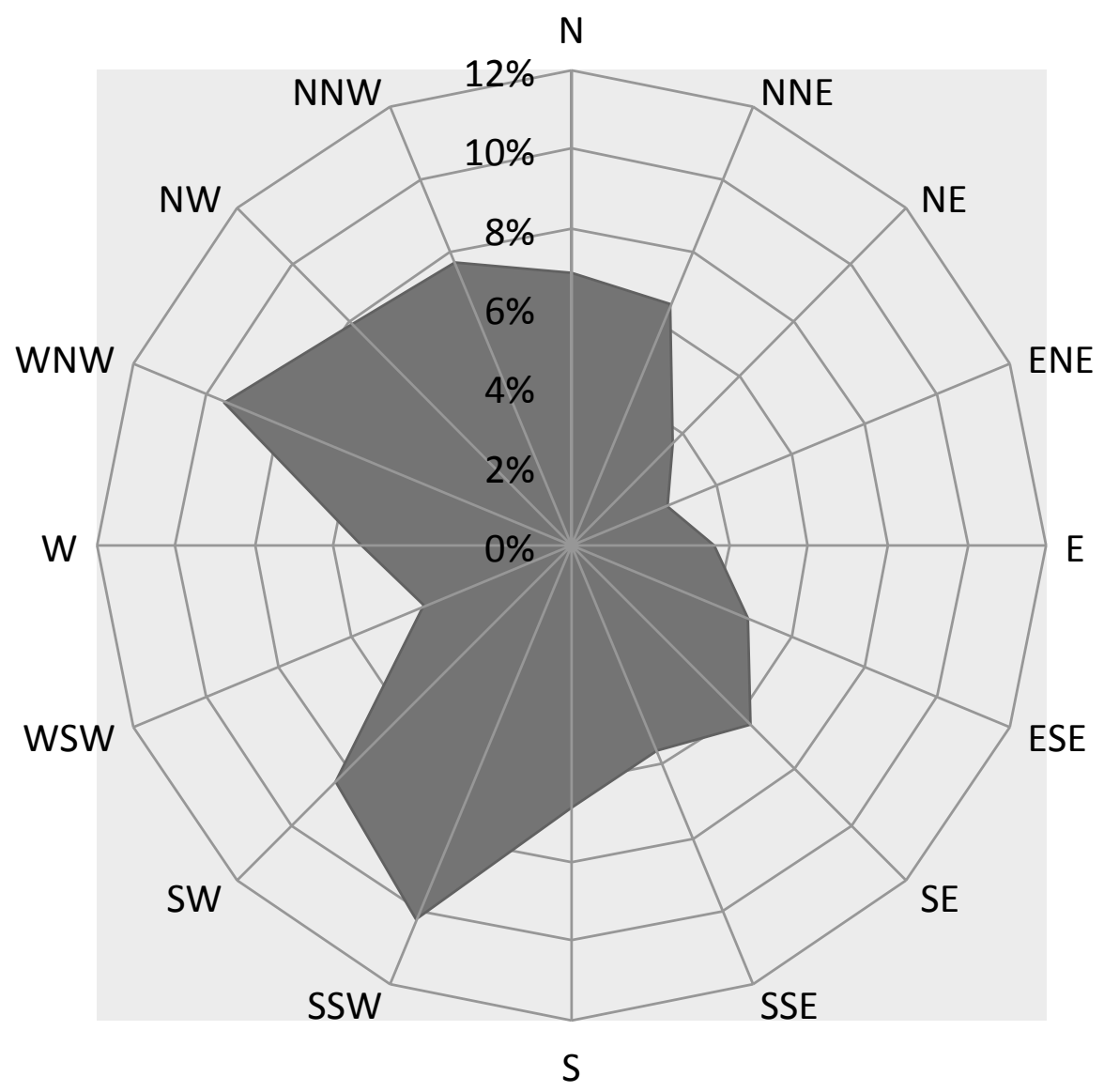

\subsection{Overview of Methods}

For site-specific risk assessments, several steps are recommended by regulatory agencies including:

- Problem formulation: describes the physical environment and identifies the sources of chemicals of concern and the pathways through which humans may be exposed.

- Hazard Assessment: involves qualitatively identifying the hazardous effects of chemicals the chemicals identified in problem formulation. 
- Exposure Assessment: involves quantitatively assessing the magnitude, frequency and length of exposure for the affected population or individuals.

- Dose-Response Assessment: involves quantifying the relationship between exposure and effect.

- Risk Characterization: integrates the dose-response relationship with estimates of exposure in a population to characterize the likelihood of health effects. Risk characterizations should include both quantitative estimates and qualitative descriptors of risk, and discussion of model assumptions and data uncertainties. The Results chapter of this thesis carries out the quantitative aspect of risk characterization, while the risk characterization chapter discusses the results in the context of uncertainties and assumptions.

(Health Canada, 2010; National Research Council, 1983; Williams \& Paustenbach, 2002)

This study follows these five steps, and for clarity they will be described for four categories contaminants:

3.2 VOCS

3.3 Metals

3.4 PAHs

3.5 Criteria Air Contaminants \& $\mathrm{H}_{2} \mathrm{~S}$

Since these groups of chemicals are monitored using different technologies and also involve different dose-response assumptions, most of the information in the methods section is specific to each group. The following is a brief description of methods that apply to all chemicals assessed. 


\subsubsection{Identification of Chemicals of Concern}

Chemicals of concern were identified using a mixture of literature review of peer reviewed scientific studies of petroleum refining and petrochemical plant emissions, as well as the EPA's emissions factor handbook for petroleum refineries (U.S. Environmental Protection Agency, 2009a) and Canada's National Pollutant Release Inventory (NPRI), which is a voluntary emissions inventory maintained by Environment Canada. As was discussed in the literature review, the NPRI is not sufficient by itself for identifying emissions due to well-documented problems with accuracy. For this reason, the literature review and emissions factor handbook were the primary basis for identification of chemicals of concern.

\subsubsection{Pathways of Exposure}

Because this thesis focuses specifically on air emissions, the only pathway examined is the inhalation pathway. This limits the scientific accuracy of the health risk assessment as human exposure to contaminants in the environment occurs through multiple pathways including inhalation, ingestion and dermal absorption. Unfortunately it is beyond the scope to cover monitoring and assessment of all of these pathways in this thesis.

\subsubsection{Hazard Assessment}

Site-specific risk assessments do not generally perform hazard assessments, but use previously completed hazard assessments carried out by the regulatory agencies to inform the identification of hazards. 


\subsubsection{Exposure and Dose-Response Assumptions}

For VOCs, metals and PAHs, exposure is assumed to be lifetime continuous exposure to the average concentration measured at the Aamjiwnaang monitor over the monitoring period (2008/09-2013/14). This represents a significant assumption, which may not be completely accurate for much of the population living near Chemical Valley because individual exposure varies through space and time (Batterman, Su, Li, Mukherjee, \& Jia, 2014). Unfortunately, individual exposures to ambient air pollutants are difficult and costly to measure, and therefore modelling exposure based on fixed-location monitoring, along with assumptions such as lifetime continuous exposure offer the best information available at the time of assessment (W. E. Wilson, Mage, \& Grant, 2000). The extent to which these assumptions, and resultant uncertainty affect the assessment will be discussed in the Risk Characterization section of this thesis (Chapter 6).

For criteria air contaminants, acute effects to the respiratory system are often of central concern, and so the exposure assumptions are influenced by dose-response relationships established for these contaminants as well as by practical considerations, which will be explained in more detail in the criteria air contaminants section below.

\subsubsection{Dose-Response Assessment}

Like hazard assessment, site-specific risk assessments use previously established dose-response relationships in order to estimate risk. For this study, EPA dose-response relationships were used for VOCs and metals (see VOC methods). For PAHs, the WHO's dose-response relationship for $\mathrm{BaP}$ as surrogate for $\mathrm{PAH}$ mixtures was used (see $\mathrm{PAH}$ methods). For Criteria Air Contaminants, Canadian Council of Ministers of the Environment 
(CCME) standards were used, and these combine exposure assessment and dose-response assessment (see Criteria Air Contaminant methods).

\subsection{VOC Methods}

\subsubsection{Identification of Contaminants of Concern}

Potential chemical hazards were identified in studies of VOC plumes from petroleum refineries and petrochemical manufacturing facilities (Cheng, Fu, Angle, \& Sandhu, 1997;

Jobson et al., 2004; Mo et al., 2015; Ramírez et al., 2012; Simpson et al., 2013) and studies of air pollution hot spots influenced by petroleum refining and petrochemical manufacture (Jia \& Foran, 2013; Sexton et al., 2007). Additionally Cheremisinoff, (2002) was consulted for a list of typical emissions expected from petroleum refining and petrochemical manufacturing facilities.

From these sources, a list of potential chemical hazards was generated and evaluated to see if they had effects from chronic exposure, and if they are monitored as a part of the Aamjiwnaang monitoring program. If chemicals did not have estimated doseresponse relationships under the EPAs IRIS program, they were not carried forward for assessment. Chemicals identified in the literature having chronic or carcinogenic effects but not monitored at Aamjiwnaang could not be quantitatively assessed as part of this study and are listed below.

Additionally, using Environment Canada's National Pollutant Release Inventory (NPRI), industrial facilities located within 5km of the Aamjiwnaang reserve were identified and examined for additional chemical emissions not identified in the literature review. There were very few VOCs identified through the NPRI list that were not found in the 
literature. There was only one VOC with an estimated dose-response relationship under the IRIS program (Cumene) that was monitored at Aamjiwnaang and was carried forward for assessment. Six others either did not have an estimated dose-response relationship or were not monitored at Aamjiwnaang.

Table 4. VOCs identified in literature review or NPRI database not monitored at Aamjiwnaang Monitor

\begin{tabular}{|l|l|l|l|}
\hline $\begin{array}{l}\text { Chemical Identified } \\
\text { in Lit Review/NPRI }\end{array}$ & IRIS Assessment & Monitored & $\begin{array}{l}\text { Reported in } \\
\text { NPRI }\end{array}$ \\
\hline Acetaldehyde & Yes & No & Yes \\
\hline Acrylonitrile & Yes & No & No \\
\hline Formaldehyde & Yes & No & Yes \\
\hline Ammonia & Yes & No & Yes \\
\hline Methanol & Yes & No & Yes \\
\hline Acetonitrile & Yes & No & Yes \\
\hline Biphenyl & Yes & No & Yes \\
\hline 2-Butoxyethanol & Yes & No & Yes \\
\hline Tert butyl alcohol & No & No & Yes \\
\hline Carbon disulphide & Yes & No & Yes \\
\hline Cresol & $\begin{array}{l}\text { Yes (oral route } \\
\text { only) }\end{array}$ & No & Yes \\
\hline
\end{tabular}




\subsubsection{VOCs Assessed}

Tables 1 and 2 list the VOCs identified as potential hazards in Chemical Valley. For systemic toxicants, the table lists the toxic end point in the human body. For carcinogenic effects, the cancer type is listed as well as the EPA weight of evidence conclusion regarding the chemical's carcinogenicity. For most of the chemicals assessed as carcinogens, the EPA has classified them based on its 2005 guidelines. The classification "carcinogenic to humans" indicates strong evidence of human carcinogenicity including convincing epidemiological evidence of a causal association between human exposure and cancer (National Research Council, 2011). "Likely to be carcinogenic to humans" indicates evidence adequate to demonstrate carcinogenic potential to humans but less definitive evidence than required for classification as "carcinogenic to humans". The EPA's classification for 1,2-dichloroethane and bromoform have not been updated as per the 2005 guidelines and are classified based on the EPA's 1986 guidelines. They are both classified "B2-probable human carcinogens", which indicates sufficient evidence of carcinogenicity from animal studies but inadequate data from human studies (U.S. Environmental Protection Agency, 2004). 
Table 5 VOCs assessed with chronic effects

\begin{tabular}{|l|l|c|}
\hline Chemical & Chronic Hazard & RfC $(\boldsymbol{\mu g} / \mathbf{m} 3)$ \\
\hline 1,3-Butadiene & Reproductive & 2 \\
\hline Benzene & Immune & 30 \\
\hline $\begin{array}{l}\text { Carbon } \\
\text { Tetrachloride }\end{array}$ & Hepatic & 100 \\
\hline chloromethane & Nervous & 90 \\
\hline Cumene & $\begin{array}{l}\text { Endocrine and } \\
\text { urinary }\end{array}$ & 400 \\
\hline cyclohexane & Developmental & 6000 \\
\hline Dichloromethane & Hepatic & 600 \\
\hline Ethylbenzene & Developmental & 1000 \\
\hline N-Hexane & Nervous & 700 \\
\hline naphthalene & $\begin{array}{l}\text { Nervous and } \\
\text { Respiratory }\end{array}$ & 3 \\
\hline P-dichlorobenzene & Hepatic & 800 \\
\hline Styrene & Nervous & 1000 \\
\hline tetrachloroethylene & neurotoxicity & 40 \\
\hline Toluene & Nervous & 5000 \\
\hline Trichloroethylene & $\begin{array}{l}\text { Multiple* } \\
\text { developmental } \\
\& \text { decreased } \\
\text { female thymus } \\
\text { weight }\end{array}$ & \\
\hline Vinyl Chloride & Hepatic & 100 \\
\hline Xylenes & Nervous & 100 \\
\hline
\end{tabular}


Table 6 VOCs assessed with USEPA carcinogenic classification and type

\begin{tabular}{|c|c|c|c|}
\hline Chemical & Cancer Classification & Cancer Type & $\begin{array}{l}\text { IUR } \\
(1 / \mu \mathrm{g} / \mathrm{m} 3)\end{array}$ \\
\hline 1,2-Dichloroethane & $\begin{array}{l}\text { B2 (Probable human } \\
\text { carcinogen - based on } \\
\text { sufficient evidence of } \\
\text { carcinogenicity in } \\
\text { animals) }\end{array}$ & Hemangiosarcomas & $2.60 \times 10^{-5}$ \\
\hline 1,3-butadiene & Carcinogenic to humans & Leukemia & $3.00 \times 10^{-5}$ \\
\hline Benzene & Carcinogenic to humans & AML & $7.80 \times 10^{-6}$ \\
\hline Bromoform & $\begin{array}{l}\text { B2 (Probable human } \\
\text { carcinogen - based on } \\
\text { sufficient evidence of } \\
\text { carcinogenicity in } \\
\text { animals) }\end{array}$ & $\begin{array}{l}\text { Neoplastic lesions in } \\
\text { the large intestine } \\
\text { (NTP, 1988) }\end{array}$ & $1.10 \times 10^{-6}$ \\
\hline $\begin{array}{l}\text { Carbon } \\
\text { tetrachloride }\end{array}$ & $\begin{array}{l}\text { Likely to be } \\
\text { carcinogenic to humans }\end{array}$ & $\begin{array}{l}\text { Pheochromocytoma } \\
\text { (Nagano et al. 2007b, } \\
\text { JBRC 1998) }\end{array}$ & $6.00 \times 10^{-6}$ \\
\hline Dichloromethane & $\begin{array}{l}\text { Likely to be } \\
\text { carcinogenic to humans }\end{array}$ & $\begin{array}{l}\text { Hepatocellular } \\
\text { carcinomas or } \\
\text { adenomas, } \\
\text { bronchoalveolar } \\
\text { carcinomas or } \\
\text { adenomas (Mennear } \\
\text { et al. (1988), NTP } \\
(1986))\end{array}$ & $1.00 \times 10^{-8}$ \\
\hline Tetrachloroethylene & $\begin{array}{l}\text { Likely to be } \\
\text { carcinogenic to humans }\end{array}$ & $\begin{array}{l}\text { Hepatocellular } \\
\text { adenomas or } \\
\text { carcinomas (JISA, } \\
\text { 1993) }\end{array}$ & $2.60 \times 10^{-7}$ \\
\hline Trichloroethylene & Carcinogenic to humans & $\begin{array}{l}\text { Renal cell carcinoma, } \\
\text { non-Hodgkin's } \\
\text { lymphoma, and liver } \\
\text { tumors }\end{array}$ & $4.10 \times 10^{-6}$ \\
\hline Vinyl chloride & Carcinogenic to humans & $\begin{array}{l}\text { Liver angiosarcomas, } \\
\text { angiomas, } \\
\text { hepatomas,neoplastic } \\
\text { nodules }\end{array}$ & $4.40 \times 10^{-6}$ \\
\hline
\end{tabular}




\subsubsection{Exposure Assessment}

The exposure assessment followed EPA guidance for estimating inhalation risk and estimated ambient concentrations of VOCs using monitoring data retrieved from Environment Canada's National Air Pollution Surveillance (NAPS) program from the Aamjiwnaang air monitor. The program's sampling methods are described in (Galarneau et al., 2016). The monitor collects air in evacuated electro-polished 6L stainless steel canisters every 12 days over 24 hours (midnight to midnight). The canisters are collected and sent to Ottawa for analysis (see Galarneau et al., 2016). Samples were collected over a five year period from August 16, 2008 to December 24, 2013 with n=162.

The risk of chronic effects and cancer generally depends on mean exposure relative to other statistical measures of air concentrations (Kenny S Crump, 1998; Stephen M Rappaport, 1991). This has been demonstrated for VOCs even when there is significant variability in concentration over time (S M Rappaport, Kupper, \& Lin, 2005). The EPA recommends using the arithmetic mean to estimate the concentration term for cancer and chronic health risk regardless of distribution (U.S. Environmental Protection Agency, 1992). Exposure assessment was therefore carried out calculating the arithmetic mean for each VOC assessed.

Exposure Frequency and duration were assumed to be continuous and lifetime respectively for two different hypothetical scenarios:

1. An adult exposed over their lifetime

2. A child with exposure starting from birth and continuing over their adult life These scenarios allow for reasonably conservative assessment about the risk posed to individuals living on the reserve located close to the monitor. For those living much closer 
to facilities than the monitor, exposure to VOCs could be potentially higher than observed at the monitor but this depends on whether emissions are significant from that specific facility. This uncertainty is discussed in the Risk Characterization section.

Based on the EPA's guidance documents, no adjustment for potential higher inhaled doses from children was made, as these potential differences are accounted for by the uncertainty factor applied to RfCs and the inherent conservatism in linear extrapolation used to derive IURs (U.S. Environmental Protection Agency, 2009b, 2012). Age specific adjustment factors (ADAFs) of 10 for exposures prior to 2 years of age and 3 from ages 2 through 16 were applied to mutagenic carcinogens when recommended by the EPA to account for potential increased susceptibility in childhood (U.S. Environmental Protection Agency, 2005b, 2014). For vinyl chloride, the child-specific IUR was also used for assessment of the scenario of lifetime exposure including childhood as recommended by the EPA (U.S. Environmental Protection Agency, 2014).

\subsubsection{Dose-Response Assessment}

This thesis utilized dose-response relationships estimated by the EPA's IRIS program. For risk assessment purposes, the relationship between dose and response is modelled to follow one of two patterns: threshold for non-carcinogens and linear nonthreshold response for carcinogens. A threshold dose-response relationship is based on the observation that for many toxicants, there is some minimum dose that must be exceeded in order for toxic effects to occur (Rhomberg, Goodman, \& Lewandowski, 2010). For dose response assessment of threshold contaminants, the EPA IRIS program derives an RfC, which is an estimate of continuous inhalation exposure that is likely without appreciable 
risk of chronic, non-cancer health effects during a lifetime (U.S. Environmental Protection Agency, 1994). As is discussed below, the RfC is estimated with expected uncertainty spanning perhaps an order of magnitude and is meant to be protective for sensitive subgroups of the population.

Although not all carcinogens have been demonstrated to damage DNA, the EPA's default assumption in the absence of definitive mode of action evidence supporting a threshold dose-response relationship is that probability of carcinogenesis increases linearly with dose (U.S. Environmental Protection Agency, 2005a). Under the IRIS program the EPA estimates inhalation unit risks (IUR), which describe the increased probability of cancer expected from exposure to a concentration of $1 \mu \mathrm{g} / \mathrm{m}^{3}$ for a lifetime. The IUR is the slope of the line estimated in dose-response analysis of either animal studies (in which case IUR is adjusted for inter-species differences in inhaled dose) or human occupational studies (U.S. Environmental Protection Agency, 2005a). The EPA's inhalation dosimetry methods implicitly convert the external air concentration into an inhaled dose, and so external air concentration, exposure duration, exposure frequency and averaging time are the only variables that must either be estimated or assumed in order to carry out the risk assessment.

\subsubsection{VOC Risk Assessment Model}

For threshold toxicants, the arithmetic mean at the monitor was compared against the RfC to estimate a hazard quotient (equation 2). No adjustments were made due to exposure time, frequency, duration and averaging time as the RfCs are derived assuming

lifetime continuous exposure. Equation 1 demonstrates how exposure frequency, duration, 
and averaging time variables cancel each other out when exposure is assumed to be lifetime continuous.

\section{Equation 1:}

$\mathrm{HQ}=\mathrm{C}^{*} \mathrm{ET}^{*} \mathrm{EF}^{*} \mathrm{ED} /\left(\mathrm{RfC}^{*} \mathrm{AT}\right)$

$\mathrm{HQ}=\mathrm{C}^{*}\left[(24 \mathrm{hrs} / \text { day })^{*}(365\right.$ days $\left./ \mathrm{yr}) *(70 \mathrm{yrs})\right] /[(70 \mathrm{yrs} * 365$ days*24hrs/day)*RfC $]$

$\mathrm{HQ}=\mathrm{C} / \mathrm{RfC}$ (Equation 2)

Where:

$\mathrm{C}=$ Arithmetic Sample Mean

ET= Exposure Time (hrs/day)

$\mathrm{EF}=$ Exposure Frequency (days/year)

$\mathrm{ED}=$ Exposure duration (years)

AT $=$ Averaging time $=$ (lifetime in years $\times 365$ days/year $\times 24$ hours $/$ day $)$

Source: (U.S. Environmental Protection Agency, 2009b)

\section{Equation 2}

Where:

$$
\mathrm{HQ}=\mathrm{C} / \mathrm{RfC}
$$

C=Arithmetic Sample Mean

The EPA considers its RfCs to be sufficient for children exposed as well as adults (U.S.

Environmental Protection Agency, 2009b). For carcinogens, the arithmetic mean measured at the monitor was multiplied by the inhalation unit risk to estimate the incremental lifetime cancer risk (ILCR) for each chemical. Since lifetime continuous exposure is assumed, the same cancelling out of exposure time, frequency, duration and averaging time results in the simplified equation 3 for adults. 


\section{Equation 3}

$$
\text { ILCR }=\mathrm{C}^{*} \mathrm{IUR}
$$

Where:

C=Arithmetic Sample Mean

For children, Vinyl Chloride was assessed using the child specific inhalation unit risk estimated by the EPA using the same formula as above because the EPA's IUR for vinyl chloride is estimated so as to include childhood exposure. For some other mutagenic carcinogens, the EPA recommends using a default age-dependant adjustment factor (U.S. Environmental Protection Agency, 2009b). For these, the ILCR was calculated as follows:

\section{Equation 4: Incremental Lifetime Cancer Risk using Age Dependent Adjustment}

\section{Factor}

$\operatorname{ILCR}=\left(\mathrm{C}^{*} \mathrm{ADAF}_{(0-2 \mathrm{yrs})} * \mathrm{IUR}^{*} \mathrm{ED}_{(0-2)} / \mathrm{AT}\right)+\left(\mathrm{C}^{*} \mathrm{ADAF}_{(2-16 \mathrm{yrs})} * \mathrm{IUR}^{*} \mathrm{ED}_{(2-16)} / \mathrm{AT}\right)+\left(\mathrm{C}^{*} \mathrm{IUR}^{*} \mathrm{ED}_{(16-}\right.$ 70)/AT)

Where:

C= Arithmetic Sample Mean, $\mathrm{ADAF}=$ Age Dependent Adjustment Factor, $\mathrm{ED}=$ Exposure Duration for the life-stage (in years), $\mathrm{AT}=$ averaging time $=70 \mathrm{yrs}$

\subsection{Metals}

\subsubsection{Identification of Metals of Concern}

Unlike VOCs, the literature concerning metals emissions from petroleum refining and petrochemical manufacturing was not sufficient to generate a comprehensive list of metals of concern. Nickel, vanadium, chromium, cadmium, zinc and lanthanum were identified in the literature as being present either in stack emissions from petroleum 
refineries or found in the local environment and linked to facility emissions (Bosco et al., 2005; Nadal et al., 2007; Sánchez de la Campa et al., 2011; U.S. Environmental Protection Agency, 2002b). There were, however, no studies assessing whether these emissions have led to potential health risks in the local environment, making it difficult to understand whether these emissions are likely to cause concern in Chemical Valley.

The NPRI emissions inventory for the facilities in Chemical Valley reported air emissions of aluminum, cobalt, lead, mercury, nickel, selenium, vanadium and zinc. The Aamjiwnaang monitoring program monitors 11 metals and covers all of the metals identified in the literature except for lanthanum. It does not cover all of the metals reported in the NPRI, however, it does monitor some metals not found in the literature nor NPRI. Table 1 lists the metals identified in the literature, NPRI database and Aamjiwnaang monitor 
Table 7: Metals found in literature, NPRI and monitored at Aamjiwnaang monitor

\begin{tabular}{|l|l|l|}
\hline Literature & NPRI & Monitored \\
\hline Nickel & Nickel & Nickel \\
\hline Vanadium & Vanadium & Vanadium \\
\hline Zinc & Zinc & Zinc \\
\hline Chromium & Mercury & Chromium \\
\hline Cadmium & Cobalt & Cadmium \\
\hline Lanthanum & Lead & Lead \\
\hline & Aluminum & Silicon \\
\hline & Lanthanum & Copper \\
\hline & & Selenium \\
\hline & & Iron \\
\hline & & Calcium \\
\hline
\end{tabular}

\subsubsection{Hazard Identification}

Of the metals monitored, only nickel, chromium, cadmium and manganese have estimated dose-response relationships under the EPA's IRIS program, and these were carried through for assessment.

\subsubsection{Sampling Method}

The samples were collected using a filter-based PQ-100 particulate sampler, which takes a sample over a 24-hour period once every six days using a filter analyzed by the 
MOECCs laboratory. The sampling period was from January 2009 - December 2014 with $\mathrm{n}=331$. The metals concentrations are reported in elemental form and estimated based on the total suspended particulate that includes all particulate that is $\leq 44$ microns in diameter (Aamjiwnaang First Nation, 2017).

\subsubsection{Exposure and Dose-Response Assessment}

An important consideration for exposure assessment of inhaled metals is the particle size fraction (Paustenbach, 2014). The Aamjiwnaang monitoring program reports results as a concentration based on the total suspended particulate. Generally, the majority of particles greater than 10um in diameter are expected to be captured in the upper respiratory tract and then either removed by sneezing or mucus wiping or ingested; whereas the fine particles will penetrate the lower respiratory tract where they are readily absorbed (Brain, Kreyling, \& Godleski, 2014; Brown, Gordon, Price, \& Asgharian, 2013; Paustenbach, 2000). As the concentrations are reported for all particles $\leq 44 \mathrm{um}$, it is unclear as to whether all of the metals recorded as mass/per volume of air would be from the respirable fraction and therefore readily available for absorption in the lung. Since atmospheric metals emissions from refining and petrochemical facilities result from combustion, metals released from stacks are likely to be found in the fine particle fractions and this has been demonstrated empirically (Sánchez de la Campa et al., 2011). Still, because of the large size range collected by the particle sampler, some portion of metals reported in the concentration data could be from the larger size fraction and therefore not be respirable and may also originate from geological dusts as opposed to local combustion sources (Chow \& Watson, 1998). For this thesis, the metals concentration is assumed to be 
$100 \%$ available for absorption, and this assumption introduces uncertainty, which will be discussed in Risk Characterization chapter.

In addition to the size fraction assumption, human dose-response for metals can be dependent on speciation, in particular for chromium where the chromium (VI) ion has been found to be the principle cause of toxic responses- whereas it is typically found as both chromium III and chromium VI ions in the atmosphere(Caussy, Gochfeld, Gurzau, Neagu, \& Ruedel, 2003; Dayan \& Paine, 2001; Kotaś \& Stasicka, 2000). ${ }^{4}$ Since only the elemental form of chromium is reported under the Aamjiwnaang monitoring program, this thesis assumes that $100 \%$ of the chromium measured is chromium (VI) - an assumption likely to overestimate exposure. Additionally, for nickel, the EPA's dose-response relationship is estimated based on studies of workers exposed to nickel refining dust, which is a mixture of many nickel compounds (U.S. Environmental Protection Agency, 2016). It is unclear whether the nickel compounds measured at the Aamjiwnaang monitor are similar to those found in nickel refinery dust. This thesis assumes that the nickel concentration reported is similar in concentration to nickel refinery dust, and this assumption introduces uncertainty into the assessment.

\subsubsection{Data Processing}

Unlike the VOC sampling methods, which had almost no observations below the method detection limit, between $44 \%$ and $67 \%$ of the observations were below the method detection limit for the metals assessed. Due to this high proportion of non-detects, two

\footnotetext{
${ }^{4}$ One study found the ratio of $\operatorname{Cr}(\mathrm{III}) / \mathrm{Cr}$ (VI) of 0.3 in welding fumes, however computer simulations show that atmospheric conditions favor thee reduction of $\mathrm{Cr}(\mathrm{VI})$ to $\mathrm{Cr}$ (III) (Kotaś \& Stasicka, 2000).
} 
assessments were carried out. One in which a value of half the detection limit was used, and one in which non-detect values were replaced with zeros. The high proportion of values below detection likely introduces significant uncertainty into the assessment.

\subsubsection{Risk Assessment}

The risk assessment models for metals risk assessment used the same equations as were used for the VOC risk assessment. For metals with chronic effects with established dose-response relationships under the IRIS program, equation 2 was used to estimate a hazard quotient. For metals with carcinogenic effects, equation 3 was used.

\subsection{PAHs Methods}

\subsubsection{Hazard Identification}

PAHs are formed during incomplete combustion and are ubiquitous the environment and found in complex mixtures (Boström et al., 2002). The toxic endpoint of PAHs is cancer, and the causal relationship is well established (Boström et al., 2002). As PAHs are released from combustion sources, it can be assumed that a number of PAHs are emitted by the facilities operating in Chemical Valley. Several PAHs were reported in the NPRI, and the Aamjiwnaang monitoring program samples for eight PAHs listed in table 8, along with their EPA Weight of Evidence cancer classification. 
Table 8. List of PAHs monitored and their cancer classification

\begin{tabular}{|l|l|}
\hline PAH Monitored & EPA Cancer Classification \\
\hline Chrysene/Triphenylene & $\begin{array}{l}\text { B2 (Probable human carcinogen - based } \\
\text { on sufficient evidence of carcinogenicity } \\
\text { in animals) }\end{array}$ \\
\hline Benzo[b]fluoranthene & $\begin{array}{l}\text { B2 (Probable human carcinogen - based } \\
\text { on sufficient evidence of carcinogenicity } \\
\text { in animals) }\end{array}$ \\
\hline Benzo[k]fluoranthene & $\begin{array}{l}\text { B2 (Probable human carcinogen - based } \\
\text { on sufficient evidence of carcinogenicity } \\
\text { in animals) }\end{array}$ \\
\hline Benzo[a]pyrene & Carcinogenic to humans \\
\hline Dibenz[a,h]Anthracene/Dibenz[a,b]Anthracene & $\begin{array}{l}\text { B2 (Probable human carcinogen - based } \\
\text { on sufficient evidence of carcinogenicity } \\
\text { in animals) }\end{array}$ \\
\hline Benzo[g,h,i]perylene & $\begin{array}{l}\text { D (Not classifiable as to human } \\
\text { carcinogenicity) }\end{array}$ \\
\hline Benz[a]anthracene & $\begin{array}{l}\text { B2 (Probable human carcinogen - based } \\
\text { on sufficient evidence of carcinogenicity } \\
\text { in animals) }\end{array}$ \\
\hline Indeno[1,2,3-cd]Pyrene & $\begin{array}{l}\text { B2 (Probable human carcinogen - based } \\
\text { on sufficient evidence of carcinogenicity } \\
\text { in animals) }\end{array}$ \\
\hline & \\
\hline
\end{tabular}

For the majority of individual PAHs, the source of toxicological information is animal studies (Boström et al., 2002) and this is reflected in the cancer classifications in the table above. While there are likely more PAHs present in the air near Chemical Valley than those which are monitored, or reported in the NPRI, it is not practical to monitor and assess the toxicity for every PAH present in the air. In addition, the toxicity of the mixture may not be a simple sum of the individual toxicity of PAHs due to interactions that could cause both more and less-than additive effects (Jarvis et al., 2014). In general, three approaches have been recommended: Benzo[a]Pyrene as a whole-mixture surrogate, a comparative potency 
approach comparing similar mixtures, and a relative potency factor approach (Flowers et al., 2002). All three methods result in considerable uncertainty in the risk estimate, however, when assessing mixtures, a whole-mixture approach is considered preferable because it implicitly accounts for interactions among PAHs and the toxicity of unidentified PAHs within the mixture (U.S. Environmental Protection Agency, 2010). For this thesis, the World Health Organization's (WHO) PAH dose-response estimate, which uses the air concentration of $\mathrm{BaP}$ as a surrogate to assess the cancer risk of the PAH mixture, was used to estimate the cancer risk of PAHs. This method is based on an epidemiological study of exposure to coke oven workers (World Health Organization, 2000).

\subsubsection{Sampling Method}

Like metals, PAHs are collected using a filter-based particulate sampler, which takes a sample over a 24-hour period once every twelve days. The sampling period was from January 2009 - December 2014 with n=167. Reporting PAH concentrations without breaking down the distribution of the PAH across particle size fractions introduces the same uncertainties as was discussed for metals due to particle size distribution.

Additionally, because only eight PAHs are monitored, the full mixture is not characterized.

\subsubsection{Exposure Assessment and Dose-Response}

Using the WHO's PAH as surrogate for whole-mixture dose-response relationship essentially means assuming that the mixture of PAHs to which residents living near Chemical Valley are exposed is similar to the mixture in the coke-oven worker study used to estimate the dose-response relationship. 


\subsubsection{Data Processing}

For BaP, roughly $9 \%$ of the samples were below the method detection limit. For observations below detection limits, a value of half the detection limit was used.

\subsubsection{Risk Assessment}

The risk assessment model for the PAH risk assessment used the same equations used for the VOC risk assessment, except using the sample mean of BaP as a surrogate for exposure to the entire mixture of PAHs present in the environment near Chemical Valley. The ILCR was estimated using equation 3 above.

\subsection{Criteria Air Contaminants Methods and $\mathrm{H}_{2} \mathrm{~S}$}

\subsubsection{Identification of Contaminants of Concern}

Since criteria air contaminants are considered ubiquitous in urban or industryinfluenced environments (Suh, Bahadori, Vallarino, \& Spengler, 2000), the four criteria air contaminants (ozone, sulphur dioxide, PM2.5 and nitrogen dioxide) identified in by the Canadian Council of Ministers of the Environment (CCME) were assessed in this study. While carbon monoxide (CO) is considered a criteria air contaminant in the United States, CO concentrations measured at the Aamjiwnaang monitor are very low, and therefore did not need to be assessed (not a single $1 \mathrm{hr}$ measurement exceeded 1ppm during monitoring period compared to the NAAQS $1 \mathrm{hr}$ limit of 35ppm).

Hydrogen sulphide $\left(\mathrm{H}_{2} \mathrm{~S}\right)$ is a gas sometimes released by petroleum refineries (Cheremisinoff, 2002) and is often associated with odour complaints and symptoms such as nausea, eye irritation, headaches etc. despite these symptoms not being observed in 
acute toxicity studies (Ontario Ministry of the Environment and Climate Change, 2007). Hydrogen sulphide's chronic effects occur at levels higher than measured odour thresholds (Ontario Ministry of the Environment and Climate Change, 2007), however odour assessment is complex and beyond the scope of this thesis (see Dann, 2016 for example).

\subsubsection{Exposure and Dose-Response Assessment}

Dose-response and exposure assessment are combined in the CAAQC standards developed by the CCME and therefore, risk assessment for these substances involves comparing the air concentrations to the standards directly. Although science-informed, the statistical form of the standards for these chemicals is based on dose-response as well as practical considerations in implementation in both the United States and Canada (McClellan, 2012; Ontario Ministry of the Environment and Climate Change, 2017e). For the CAAQC, the CCME uses four different standards for each contaminant, which establish ranges of values representing various air quality management scenarios.

Figure 5: CCME CAAQS management levels

\begin{tabular}{|c|c|}
\hline Management Level & Objective \\
\hline Red & $\begin{array}{l}\text { Achieve air zone CAAQS through advanced air zone } \\
\text { management actions }\end{array}$ \\
\hline Orange & $\begin{array}{l}\text { Improve air quality through active air management } \\
\text { and prevent a CAAQS exceedance }\end{array}$ \\
\hline Yellow & $\begin{array}{l}\text { Improve air quality using early and ongoing actions } \\
\text { for continuous improvement }\end{array}$ \\
\hline Green & $\begin{array}{c}\text { Maintain good air quality through proactive air } \\
\text { management measures }\end{array}$ \\
\hline
\end{tabular}

(Canadian Council of Ministers of the Environment, 2012)

As, the table indicates, the zones are not directly characterized by the health-risk associated with each level. Despite this, they are a useful point of reference because they 
consider both scientific information about dose-response, as well as background levels at pristine sites in Canada. Since criteria air contaminants are thought to have a linear doseresponse function with no threshold when considering sensitive individuals (World Health Organization, 2005), using background concentrations as a starting point for assessment is logical because any increase in concentrations above background theoretically represents a small increase in the number of health effects experienced by the exposed population. There is also scientific uncertainty about effects at concentrations below levels for which statistically significant effects in the general population have been found (World Health Organization, 2005). The green management level is therefore representative of background concentrations in pristine environments while the area below the red management zone can be thought of as concentrations for which the majority, but not all members of the population will be protected from adverse effects. This system of assessment and management is likely designed to reflect the ubiquitous nature of criteria air contaminants and the reality that governments need to assess and manage criteria contaminants at a larger geographic scale than this thesis. To apply them to Chemical Valley however, a discussion of their science-basis and how they can be interpreted for health-risk assessment purposes is necessary.

\subsubsection{Ozone}

The green and yellow zones of the CAAQC for Ozone $\left(50 \mathrm{ppb}\right.$ and 53ppb $4^{\text {th }}$ highest annual 8hr avg.) were established based on studies of ozone concentrations in pristine environments in Canada, and can therefore be used to compare the ozone concentrations near Chemical Valley to background concentrations without the influence of human 
activities. Without an estimated dose-response relationship, which is beyond the scope of this study to estimate, the risk-level at any of the CAAQC management levels is imprecise, however, information in (McGarity, 2015) discusses the relative protection offered by various similar standards that were considered by the EPA in the development of the ozone standard in the United States. It appears that while it is reasonable to assume that there may be no effects threshold for ozone, statistically significant results in the general population have only been demonstrated above $60 \mathrm{ppb}$, although these results have been challenged and are subject to uncertainty and error (Brown, 2009). Additionally, sensitive individuals, such as those with asthma can be expected to suffer effects below this threshold. For the purposes of this assessment, it will be assumed that sensitive individuals may experience effects above the green CAACQ management level (03>50ppb) and members of the general public will be protected within the orange management level $(56 \mathrm{ppb}<03<63 \mathrm{ppb})$

\subsubsection{Particulate Matter}

The CAACQ management levels and their associated standards are also based on estimations of background levels based on rural monitoring stations and PM2.5 is similarly thought to have no threshold for effects (Fann, Gilmore, \& Walker, 2016). Therefore any increase above background can be thought of as representing an increase of the risk of some members of the population suffering effects relative to background levels. Quantifying the extent of this is beyond the scope of this thesis and would be subject to significant uncertainty. For long term effects, the WHO concluded in its review of PM2.5 concentration-response studies that an annual mean concentration of $10 \mu \mathrm{g} / \mathrm{m} 3$ was an 
adequate standard for annual mean PM2.5 concentration because it was slightly below the concentration at which the health effects of reductions in PM2.5 can't be quantified with certainty — and because it is considered achievable (World Health Organization, 2005). For short-term effects, the CCME also developed its management levels based on establishing concentrations near background. Established concentration-response data are not readily available to further inform the discussion of $24 \mathrm{hr}$ CAACQ metric.

\subsubsection{Sulphur Dioxide}

There are no public CCME documents that present the rationale for the CAACQ management level standards for sulphur dioxide, as they are not set to be implemented until 2020. Nonetheless they are useful as a point of comparison, and it appears the scientific basis of the standards is from Health Canada's establishment of a 10 minute Rfc of 67ppb, which was converted to a one hour metric of 40ppb (Ontario Ministry of the Environment and Climate Change, 2017e). This 1-hour exposure concentration falls within the yellow management level. There is no further information currently available on the derivation of the CCME annual sulphur dioxide standards.

\subsubsection{Nitrogen Dioxide}

Similar to sulphur dioxide, the CCME has not provided public documentation of the rationale for the proposed nitrogen dioxide standard, however, Health Canada has published its risk assessment carried out to inform the standard setting. The risk assessment concluded that there is no evidence of a threshold and that if there was a population threshold (excluding sensitive populations), it would likely be at the lower end of monitored ambient $\mathrm{NO}_{2}$ exposures in Canada (Health Canada, 2016). This suggests that 
the management levels are likely derived on a similar basis for all four criteria air contaminants.

\subsubsection{Hydrogen Sulphide}

The Aamjiwnaang monitor takes hourly measurements of total reduced sulphur, which is a mixture composed of hydrogen sulphide $\left(\mathrm{H}_{2} \mathrm{~S}\right)$, mercaptans, dimethyl sulphide, and dimethyl disulphide. Ontario has a 10-minute standard (9.1ppb assuming 100\% $\mathrm{H}_{2} \mathrm{~S}$ ) for total reduced sulphur based on odour and a 24hour average standard of $4 \mathrm{ppb}$ (assuming 100\% $\mathrm{H}_{2} \mathrm{~S}$ ) for chronic health effects. Using the hourly monitoring data to compare against a 10 minute standard could lead to an underestimation of effects, as shortterm spikes might be smoothed out over the course of the hour. As is discussed in Dann, (2016) odour assessment is difficult as individual sensitivity to odours can vary 100-fold. In the Wood Buffalo region near the Alberta Oil Sands, odour complaints frequently occur when concentrations of TRS are below 10ppb (Dann, 2016). Given this, an odour assessment was beyond the scope of this thesis, and TRS was compared to the 24-hour standard based on chronic effects.

\subsubsection{Sampling methods and Data Processing}

Criteria air contaminants are monitored hourly at the Aamjiwnaang monitor. Since the CAAQs use various statistical measures of concentrations involving calculation of daily maximum one hour concentrations as well as 8-hour running averages over multiple years, data processing was carried out using Microsoft Excel following CCME Guidance (Canadian Council of Ministers of the Environment, 2012). 


\subsubsection{Risk Assessment}

After processing the hourly concentration data for the criteria air contaminants into the statistical measures required for assessment against the CAACQ, these measures were compared against the following CAACQ.

\section{Sulphur Dioxide}

\begin{tabular}{|l|l|l|}
\hline \multirow{2}{*}{ Statistical Form } & \multicolumn{2}{|c|}{ CCME Standard (ppb) } \\
\cline { 2 - 3 } & 2020 & 2025 \\
\hline 99th percentile of 1-hour & $>70$ (red) & $>65$ (red) \\
daily maximum & $>50$ (orange) & $>50$ (orange) \\
concentrations, averaged over & $>30$ (yellow) & $>30$ (yellow) \\
3 years & $<30$ (green) & $<30$ (green) \\
\hline
\end{tabular}

\begin{tabular}{|l|l|l|}
\hline \multirow{2}{*}{ Statistical } & \multicolumn{2}{|l|}{ CCME Standard (ppb) } \\
\cline { 2 - 3 } Form & 2020 & 2025 \\
\hline Annual & $>5$ (red) & $>4$ (red) \\
Mean & $>3$ (orange) & $>3$ (orange) \\
& $>2$ (yellow) & $>2$ (yellow) \\
& $<2$ (green) & $<2$ (green) \\
\hline
\end{tabular}

\section{Nitrogen Dioxide}

\begin{tabular}{|l|l|l|}
\hline \multirow{2}{*}{ Statistical Form } & \multicolumn{2}{|c|}{ CCME Standard (ppb) } \\
\cline { 2 - 3 } & 2020 & 2025 \\
\hline 98th percentile of 1-hour & $>60$ (red) & $>42$ (red) \\
daily maximum & $>31$ (orange) & $>31$ (orange) \\
concentrations, averaged over & $>20$ (yellow) & $>20$ (yellow) \\
3 years & $<20$ (green) & $<20$ (green) \\
& & \\
\hline
\end{tabular}

\begin{tabular}{|l|l|l|}
\hline \multirow{2}{*}{$\begin{array}{l}\text { Statistical } \\
\text { Form }\end{array}$} & \multicolumn{2}{|l|}{ CCME Standard (ppb) } \\
\cline { 2 - 3 } & 2020 & 2025 \\
\hline
\end{tabular}




\begin{tabular}{|l|l|l|}
\hline Annual & $>17$ (red) & $>12$ (red) \\
Mean & $>7$ (orange) & $>7$ (orange) \\
& $>2$ (yellow) & $>2$ (yellow) \\
& $<2$ (green) & $<2$ green) \\
\hline
\end{tabular}

\section{Ozone}

\begin{tabular}{|l|l|l|}
\hline \multirow{2}{*}{ Statistical Form } & \multicolumn{2}{|c|}{ CCME Standard (ppb) } \\
\cline { 2 - 3 } & 2015 & 2020 \\
\hline 3-year average of the & $>63$ (red) & $>62$ (red) \\
annual 4th- & $>56$ (orange) & $>56$ (orange) \\
highest daily maximum 8- & $>50$ (yellow) & $>50$ (yellow) \\
hour average concentrations & $<50$ (green) & $<50$ (green) \\
& & \\
\hline
\end{tabular}

\section{Particulate Matter}

\begin{tabular}{|l|l|l|}
\hline \multirow{2}{*}{ Statistical Form } & \multicolumn{2}{|c|}{ CCME Standard $\left(\mu \mathrm{g} / \mathrm{m}^{3}\right)$} \\
\cline { 2 - 3 } & 2015 & 2020 \\
\hline The 3-year average of the & $>28$ (red) & $>27$ (red) \\
annual 98th percentile of the & $>19$ (orange) & $>19$ (orange) \\
daily 24-hour average & $>10$ (yellow) & $>10$ (yellow) \\
concentrations & $<10$ (green) & $<10$ (green) \\
\hline
\end{tabular}

\begin{tabular}{|l|l|l|}
\hline \multirow{2}{*}{ Statistical Form } & \multicolumn{2}{|l|}{ CCME Standard $\left(\mu \mathrm{g} / \mathrm{m}^{3}\right)$} \\
\cline { 2 - 3 } & 2015 & 2020 \\
\hline The 3-year average of the annual & $>10$ (red) & $>8.8$ (red) \\
average concentrations. & $>6.4$ (orange) & $>6.4$ (orange) \\
& $>4$ (yellow) & $>4$ (yellow) \\
& $<4$ (green) & $<4$ (green) \\
\hline
\end{tabular}

\section{Total Reduced Sulphur}

\begin{tabular}{|l|}
\hline Ontario 24-hour standard \\
\hline $4 \mathrm{ppb}$ \\
\hline
\end{tabular}




\section{Chapter 4: Results}

\subsection{VOC Results}

The results from the risk assessment of VOCs, Metals, PAHs and criteria air contaminants are presented below. For VOCs, Metals and PAHs, the results are presented for each group, and then combined to estimate cumulative cancer risk and a cumulative hazard index for contaminants affecting the same organ or target biological system. As the criteria air contaminants assessment is carried out using different methods, it is presented separately in section 4.5 .

\subsubsection{VOC Descriptive Statistics}

Table 9 presents descriptive statistics for the VOCs assessed as part of this thesis. Environmental concentration data are often skewed (Gilbert, 1987) and comparison of the sample mean and median shows that for the majority of the VOCs this is the case.

Chloromethane, $\mathrm{n}$-hexane and cyclohexane all had high maximum values compared to their median values; and toluene, benzene and xylenes also showed high maximum values relative to their medians. These results are not surprising given the factors that typically influence environmental concentrations of VOCs, including potential strong but varying local sources (Jia, D'Souza, \& Batterman, 2008). Compared to these six compounds, the mean, median and maximum concentrations for most of other VOCs were relatively low. Important to note are styrene and 1,3-butadiene- which both had maximum values significantly higher than mean and median. These high values were not removed as outliers when estimating the sample means because it is possible they represent spill events during which air concentrations reach higher levels than background. 
Table 9 VOC Descriptive Statistics

\begin{tabular}{|c|c|c|c|c|c|}
\hline VOC & \multirow{2}{*}{$\begin{array}{l}\text { Mean } \\
\left(\mu \mathrm{g} / \mathrm{m}^{3}\right)\end{array}$} & \multirow{2}{*}{$\begin{array}{l}\text { Median } \\
\left(\mu \mathrm{g} / \mathrm{m}^{3}\right)\end{array}$} & \multirow{2}{*}{$\begin{array}{l}\text { Standard } \\
\text { Deviation }\end{array}$} & \multirow{2}{*}{$\begin{array}{l}\operatorname{Min} \\
\left(\mu \mathrm{g} / \mathrm{m}^{3}\right)\end{array}$} & \multirow{2}{*}{$\begin{array}{l}\operatorname{Max} \\
\left(\mu \mathrm{g} / \mathrm{m}^{3}\right)\end{array}$} \\
\hline & & & & & \\
\hline chloromethane & 2.78 & 1.25 & 4.12 & 0.91 & 32.01 \\
\hline n-hexane & 2.35 & 0.69 & 4.81 & 0.12 & 28.79 \\
\hline cyclohexane & 1.70 & 0.49 & 2.86 & 0.04 & 15.68 \\
\hline toluene & 1.40 & 1.11 & 0.98 & 0.19 & 5.50 \\
\hline benzene & 1.17 & 0.90 & 0.83 & 0.17 & 5.85 \\
\hline xylenes & 0.58 & 0.47 & 0.41 & 0.06 & 2.10 \\
\hline carbon tetrachloride & 0.54 & 0.54 & 0.07 & 0.34 & 0.72 \\
\hline dichloromethane & 0.25 & 0.23 & 0.07 & 0.15 & 0.78 \\
\hline ethylbenzene & 0.24 & 0.16 & 0.21 & 0.03 & 1.36 \\
\hline styrene & 0.18 & 0.06 & 0.59 & 0.00 & 6.30 \\
\hline 1,3-butadiene & 0.13 & 0.052 & 0.332 & 0.01 & 3.63 \\
\hline naphthalene & 0.087 & 0.068 & 0.067 & 0.004 & 0.394 \\
\hline tetrachloroethylene & 0.072 & 0.051 & 0.079 & 0.014 & 0.755 \\
\hline 1,2-dichloroethane & 0.070 & 0.066 & 0.026 & 0.034 & 0.234 \\
\hline trichloroethylene & 0.023 & 0.018 & 0.019 & 0.004 & 0.116 \\
\hline cumene & 0.020 & 0.013 & 0.047 & 0.003 & 0.581 \\
\hline p-dichlorobenzene & 0.018 & 0.014 & 0.023 & 0.005 & 0.286 \\
\hline bromoform & 0.017 & 0.014 & 0.012 & 0.005 & 0.094 \\
\hline vinyl chloride & 0.008 & 0.003 & 0.036 & 0.000 & 0.419 \\
\hline
\end{tabular}

For comparison, the $95 \%$ upper confidence level of the mean was computed for VOCs using the EPA's PRO UCL software. The software uses a built-in algorithm that tests for distributional fit (normal, lognormal, gamma) and estimates upper confidence limits of the mean using various statistical techniques depending on the distribution and goodness of fit. For data that did not fit a distribution, non-parametric methods were used to calculate the upper 95\% confidence limit (U.S. Environmental Protection Agency, 2015). 
Table 10: VOC 95\% Upper Confidence Level of Mean

\begin{tabular}{lrr}
\hline VOC & $\begin{array}{r}\text { Mean } \\
\left(\mu \mathrm{g} / \mathrm{m}^{3}\right)\end{array}$ & $\begin{array}{r}95 \% \mathrm{UCL} \text { of } \\
\text { Mean } \\
\left(\mu \mathrm{g} / \mathrm{m}^{3}\right)\end{array}$ \\
\hline chloromethane & 2.78 & 4.17 \\
n-hexane & 2.35 & 3.99 \\
cyclohexane & 1.70 & 2.68 \\
toluene & 1.40 & 1.52 \\
benzene & 1.17 & 1.28 \\
xylenes & 0.58 & 0.65 \\
carbon tetrachloride & 0.54 & 0.55 \\
dichloromethane & 0.25 & 0.26 \\
ethylbenzene & 0.24 & 0.27 \\
styrene & 0.18 & 0.26 \\
1,3-butadiene & 0.13 & 0.25 \\
naphthalene & 0.087 & 0.110 \\
tetrachloroethylene & 0.072 & 0.099 \\
1,2-dichloroethane & 0.070 & 0.073 \\
trichloroethylene & 0.023 & 0.025 \\
cumene & 0.020 & 0.037 \\
p-dichlorobenzene & 0.018 & 0.026 \\
bromoform & 0.017 & 0.018 \\
vinyl chloride & 0.008 & 0.020
\end{tabular}

Table 11 reports the risk assessment results for chronic effects using both the mean and the $95 \%$ percent upper confidence limit of the mean. Using the $95 \%$ upper confidence limit of the mean is a more conservative exposure estimate and implies a 95\% probability that the mean lies below that value. The hazard quotients (HQs) estimated for each VOC were all less than 0.10 , with the exception of 1,3-butadiene when using the $95 \%$ upper confidence limit, which had an $\mathrm{HQ}=0.12$. 
Table 11 VOCs Chronic Risk Assessment using mean and 95\% UCL of mean

\begin{tabular}{|c|c|c|c|c|}
\hline VOC & System & $\begin{array}{r}\mathrm{RfC} \\
\mu \mathrm{g} / \mathrm{m}^{3}\end{array}$ & $\begin{array}{r}\mathrm{HQ} \\
\text { (mean/RfC) }\end{array}$ & $\begin{array}{l}\text { HQ (UCL } \\
95 / \mathrm{RfC})\end{array}$ \\
\hline 1,3-Butadiene & Reproductive & 2 & 0.07 & 0.12 \\
\hline Benzene & Immune & 30 & 0.04 & 0.04 \\
\hline chloromethane & Nervous & 90 & 0.03 & 0.05 \\
\hline naphthalene & $\begin{array}{l}\text { Nervous and } \\
\text { Respiratory }\end{array}$ & 3 & 0.03 & 0.04 \\
\hline Xylenes & Nervous & 100 & 0.01 & 0.01 \\
\hline $\begin{array}{l}\text { Carbon } \\
\text { Tetrachloride }\end{array}$ & Hepatic & 100 & 0.01 & 0.01 \\
\hline N-Hexane & Nervous & 700 & 0.00 & 0.01 \\
\hline tetrachloroethylene & neurotoxicity & 40 & 0.00 & 0.00 \\
\hline Trichloroethylene & $\begin{array}{l}\text { developmental \& } \\
\text { decreased female } \\
\text { thymus weight }\end{array}$ & 2 & 0.00 & 0.01 \\
\hline Dichloromethane & Hepatic & 600 & 0.00 & 0.00 \\
\hline cyclohexane & Developmental & 6000 & 0.00 & 0.00 \\
\hline Toluene & Nervous & 5000 & 0.00 & 0.00 \\
\hline Ethylbenzene & Developmental & 1000 & 0.00 & 0.00 \\
\hline Styrene & Nervous & 1000 & 0.00 & 0.00 \\
\hline Vinyl Chloride & Hepatic & 100 & 0.00 & 0.00 \\
\hline Cumene & Endocrine and urinary & 400 & 0.00 & 0.00 \\
\hline P-dichlorobenzene & Hepatic & 800 & 0.00 & 0.00 \\
\hline
\end{tabular}

Table 12 presents the result of cancer risk assessment. Four chemicals: benzene, 1,3-

butadiene, carbon tetrachloride and 1,2-dichlorethane were estimated to cause an

increased lifetime cancer risk of between $1.81 \times 10^{-6}$ and $9.09 \times 10^{-6}$ using the estimated sample mean. Using the $95 \%$ upper confidence limit of the sample mean caused a less than

1 in a million difference in estimated risk for all three of these chemicals with the exception

of 1,3-butadiene, where the risk estimate increased by roughly 3 in a million. The rest of

the VOCs assessed resulted in risk estimates below $1 \times 10^{-7}$. Table 13 presents the results of the cancer risk assessment for the exposure scenario of lifetime exposure beginning from 
childbirth. Only vinyl chloride, trichloroethylene, and dichloromethane were adjusted for early childhood susceptibility as per EPA guidance, and the adjustments did not significantly change the risk estimates.

Table 12: VOCs Cancer Risk Assessment

\begin{tabular}{|c|c|c|c|c|}
\hline Cancer & Tumour type(s): & $\begin{array}{l}\text { IUR (per } \\
\left.\mu \mathrm{g} / \mathrm{m}^{3}\right):\end{array}$ & $\begin{array}{l}\text { ILCR } \\
\text { (mean) }\end{array}$ & $\begin{array}{l}\text { ILCR } \\
\text { (95\% UCL) }\end{array}$ \\
\hline $\begin{array}{l}\text { Benzene* upper } \\
\text { estimate }\end{array}$ & $\begin{array}{l}\text { Acute Myelogenous } \\
\text { Leukemia }\end{array}$ & $7.80 \times 10^{-6}$ & $9.09 \times 10^{-6}$ & $9.95 \times 10^{-6}$ \\
\hline 1,3-butadiene & Leukemia (all leukemia) & $3.00 \times 10^{-5}$ & $3.98 \times 10^{-6}$ & $7.38 \times 10^{-6}$ \\
\hline carbon tetrachloride & Pheochromocytoma & $6.00 \times 10^{-6}$ & $3.26 \times 10^{-6}$ & $3.31 \times 10^{-6}$ \\
\hline 1,2-Dichloroethane & Hemangiosarcomas & $2.60 \mathrm{E}-05$ & $1.81 \times 10^{-6}$ & $1.90 \times 10^{-6}$ \\
\hline trichloroethylene & $\begin{array}{l}\text { Renal cell carcinoma, non- } \\
\text { Hodgkin's lymphoma, and } \\
\text { liver tumors }\end{array}$ & $4.10 \times 10^{-6}$ & $9.57 \times 10^{-8}$ & $1.03 \times 10^{-7}$ \\
\hline vinyl chloride & & $4.40 \times 10^{-6}$ & $3.42 \times 10^{-8}$ & $8.76 \times 10^{-8}$ \\
\hline tetrachloroethylene & $\begin{array}{l}\text { Hepatocellular adenomas or } \\
\text { carcinomas }\end{array}$ & $2.60 \times 10^{-7}$ & $1.88 \times 10^{-8}$ & $2.58 \times 10^{-8}$ \\
\hline Bromoform & $\begin{array}{l}\text { Neoplastic lesions in the } \\
\text { large intestine }\end{array}$ & $1.10 \times 10^{-6}$ & $1.85 \times 10^{-8}$ & $2.02 \times 10^{-8}$ \\
\hline Dichloromethane & $\begin{array}{l}\text { Hepatocellular carcinomas or } \\
\text { adenomas, bronchoalveolar } \\
\text { carcinomas or adenomas }\end{array}$ & $1.00 \times 10^{-8}$ & $2.49 \times 10^{-9}$ & $2.58 \times 10^{-9}$ \\
\hline $\begin{array}{l}\text { Cumulative Cancer } \\
\text { Risk }\end{array}$ & & & $1.83 \times 10^{-5}$ & $2.28 \times 10^{-5}$ \\
\hline
\end{tabular}

Table 13: VOCs Cancer Risk Assessment Exposure from birth

\begin{tabular}{|l|l|l|l|l|}
\hline Cancer & Tumour type(s): & $\begin{array}{l}\text { IUR (per } \\
\left.\mu \mathrm{g} / \mathrm{m}^{3}\right):\end{array}$ & $\begin{array}{l}\text { ILCR } \\
(\text { mean) }\end{array}$ & $\begin{array}{l}\text { ILCR } \\
(95 \%) \mathrm{UCL}\end{array}$ \\
\hline $\begin{array}{l}\text { Benzene* upper } \\
\text { estimate }\end{array}$ & AML & $7.80 \times 10^{-6}$ & $9.09 \times 10^{-6}$ & $9.95 \times 10^{-6}$ \\
\hline 1,3-butadiene & Leukemia & $3.00 \times 10^{-5}$ & $3.98 \times 10^{-6}$ & $7.38 \times 10^{-6}$ \\
\hline & $\begin{array}{l}\text { Pheochromocytoma } \\
\text { (Nagano et al. 2007b, JBRC } \\
\text { 1998) }\end{array}$ & $6.00 \times 10^{-6}$ & $3.26 \times 10^{-6}$ & $3.31 \times 10^{-6}$ \\
\hline carbon tetrachloride & Hemangiosarcomas & $2.60 \times 10^{-5}$ & $1.81 \times 10^{-6}$ & $1.90 \times 10^{-6}$ \\
\hline trichloroethane & $\begin{array}{l}\text { Renal cell carcinoma, non- } \\
\text { Hodgkin's lymphoma, and } \\
\text { liver tumors }\end{array}$ & $4.10 \times 10^{-6}$ & $1.59 \times 10^{-7}$ & $1.71 \times 10^{-7}$ \\
\hline
\end{tabular}




\begin{tabular}{|l|l|l|l|l|}
\hline \multicolumn{2}{|l|}{ vinyl chloride* child } & $8.80 \times 10^{-6}$ & $6.84 \times 10^{-8}$ & $1.75 \times 10^{-7}$ \\
\hline tetrachloroethylene & $\begin{array}{l}\text { Hepatocellular adenomas or } \\
\text { carcinomas (JISA, 1993) }\end{array}$ & $2.60 \times 10^{-7}$ & $1.88 \times 10^{-8}$ & $2.58 \times 10^{-8}$ \\
\hline Bromoform & $\begin{array}{l}\text { Neoplastic lesions in the } \\
\text { large intestine (NTP, 1988) }\end{array}$ & $1.10 \times 10^{-6}$ & $1.85 \times 10^{-8}$ & $2.02 \times 10^{-8}$ \\
\hline & $\begin{array}{l}\text { Hepatocellular carcinomas or } \\
\text { adenomas, bronchoalveolar } \\
\text { carcinomas or adenomas } \\
(\text { Mennear et al. (1988), NTP } \\
(1986))\end{array}$ & $1.00 \times 10^{-8}$ & $4.12 \times 10^{-9}$ & $4.28 \times 10^{-9}$ \\
\hline Dichloromethane & & $1.84 \times 10^{-5}$ & $2.29 \times 10^{-5}$ \\
\hline
\end{tabular}

\subsection{Metals}

\subsubsection{Metals Descriptive Statistics}

The metals samples $(n=331)$ had a high percentage of observations below the method detection level for all of the metals assessed (between only $37 \%-65 \%$ of observations above method detection limit). For observations below the method detection limit, a value of half the detection limit was used in order to estimate the sample mean. For comparison, sample means calculated by substituting zeros for observations below the method detection limit are also presented. For chromium, the estimated mean is below the method detection limit, and for nickel, cadmium, and manganese the means are all within $0.001 \mu \mathrm{g} / \mathrm{m}^{3}$ of the detection limit. The cadmium data set had two different method detection limits, representing a change in precision of the sampling technique beginning after the first 50 samples. 
Table 14: Metals descriptive statistics

\begin{tabular}{|l|r|r|r|r|r|r|}
\hline Metal & $\begin{array}{l}\text { Mean }(1 / 2 \\
\mathrm{MDL}) \\
\left(\mu \mathrm{g} / \mathrm{m}^{3}\right)\end{array}$ & $\begin{array}{l}\text { Mean } \\
(\text { zeros }) \\
\left(\mu \mathrm{g} / \mathrm{m}^{3}\right)\end{array}$ & $\begin{array}{l}\text { MDL } \\
\left(\mu \mathrm{g} / \mathrm{m}^{3}\right)\end{array}$ & $\begin{array}{l}\text { Max } \\
\left(\mu \mathrm{g} / \mathrm{m}^{3}\right)\end{array}$ & $\begin{array}{l}\text { Observations } \\
<\mathrm{MDL}\end{array}$ & $\begin{array}{l}\text { Percent } \\
\text { detected }\end{array}$ \\
\hline Manganese & 0.0038 & 0.0032 & 0.0030 & 0.027 & 117 & $65 \%$ \\
\hline & & & 0.005 & & & \\
Cadmium & 0.0015 & 0.0010 & 0.001 & 0.01 & 203 & $39 \%$ \\
\hline Nickel & 0.0012 & 0.0009 & 0.0010 & 0.019 & 164 & $50 \%$ \\
\hline Chromium & 0.0008 & 0.0004 & 0.0010 & 0.005 & 207 & $37 \%$ \\
\hline
\end{tabular}

Table 15 presents the chronic risk assessment for metals using both substitution values (1/2 MDL and using zeros) to estimate hazard quotients. For both chromium and manganese the $\mathrm{HQ} / \mathrm{s}$ are an order of magnitude below 1.

Table 15: Metals Chronic Risk Assessment

\begin{tabular}{|l|l|r|r|r|}
\hline Metal & System & $\begin{array}{l}\text { RfC } \\
\left(\boldsymbol{\mu g} / \mathbf{m}^{\mathbf{3}}\right)\end{array}$ & $\begin{array}{l}\text { HQ (1/2 } \\
\mathbf{M D L})\end{array}$ & $\begin{array}{l}\text { HQ (0s for } \\
\mathbf{M D L})\end{array}$ \\
\hline Chromium & Respiratory & 0.1 & 0.0076 & 0.0044 \\
\hline Manganese & Nervous & 0.05 & 0.076 & 0.065 \\
\hline
\end{tabular}

For the cancer risk assessment, the estimated incremental lifetime cancer risk associated with chromium exposure was $9.1 \times 10^{-6}$, however, this is likely a large over-estimation because the chromium results are un-speciated, and because so many values are below the method detection limit. For nickel and cadmium, risk levels are below 1 x 10-6.

Table 16: Metals Cancer Risk Assessment

\begin{tabular}{|l|l|r|r|l|}
\hline Metal & Tumour Type & $\begin{array}{l}\text { Inhalatio } \\
\mathbf{n} \text { Risk } \\
\left(\mu \mathrm{g} / \mathbf{m}^{3}\right)\end{array}$ & $\begin{array}{l}\text { ILCR using } \\
\mathbf{1 / 2} \mathbf{~ M D L}\end{array}$ & $\begin{array}{l}\text { ILCR using } \\
\text { zeros }\end{array}$ \\
\hline Chromium & Lung cancer & 0.012 & $9.10 \times 10^{-6}$ & $5.33 \times 10^{-6}$ \\
\hline Cadmium & Lung, trachea, bronchus cancer & 0.00046 & $7.09 \times 10^{-7}$ & $4.36 \times 10^{-7}$ \\
\hline Nickel & Lung cancer & 0.00024 & $2.93 \times 10^{-7}$ & $1.07 \times 10^{-7}$ \\
\hline
\end{tabular}




\subsection{PAHs}

Table 17 shows summary statistics for the eight PAHs monitored in particulate matter at the Aamjiwnaang Air monitor. All PAHs had some samples below method detection limit but most were detected in $90 \%$ or more of the samples.

Table 17: Summary Statistics for Benzo[a]Pyrene

\begin{tabular}{|c|c|c|c|c|c|c|}
\hline & $\begin{array}{l}\text { Mean }(1 / 2 \\
\mathrm{MDL}) \\
\left(\mathrm{ng} / \mathrm{m}^{3}\right)\end{array}$ & $\begin{array}{l}\text { Median } \\
\left(\mathrm{ng} / \mathrm{m}^{3}\right)\end{array}$ & $\begin{array}{l}\mathrm{MDL} \\
\left(\mathrm{ng} / \mathrm{m}^{3}\right)\end{array}$ & $\begin{array}{l}\text { Observations } \\
<\mathrm{MDL}\end{array}$ & $\begin{array}{l}\text { Percent } \\
\text { detected }\end{array}$ & $\begin{array}{l}\max \\
\left(\mathrm{ng} / \mathrm{m}^{3}\right)\end{array}$ \\
\hline $\mathrm{B}[\mathrm{b}] \mathrm{F}$ & 0.153 & 0.110 & $\begin{array}{l}0.01 \\
0.025\end{array}$ & 4 & $98 \%$ & 2.75 \\
\hline$B[g, h, i] P$ & 0.100 & 0.074 & $\begin{array}{l}0.01 \\
0.025\end{array}$ & 5 & $97 \%$ & 1.23 \\
\hline Chrysene & 0.095 & 0.054 & $\begin{array}{l}0.01, \\
0.025\end{array}$ & 14 & $92 \%$ & 1.90 \\
\hline $\mid[1,2,3] \mathrm{P}$ & 0.091 & 0.070 & $\begin{array}{l}0.01 \\
0.025\end{array}$ & 9 & $95 \%$ & 1.25 \\
\hline $\mathrm{B}[\mathrm{a}] \mathrm{P}$ & 0.056 & 0.041 & $\begin{array}{l}0.01 \\
0.025\end{array}$ & 16 & $91 \%$ & 0.63 \\
\hline $\mathrm{B}[\mathrm{k}] \mathrm{F}$ & 0.055 & 0.040 & $\begin{array}{l}0.01 \\
0.025\end{array}$ & 17 & $90 \%$ & 0.70 \\
\hline$B[a] A$ & 0.039 & 0.020 & $\begin{array}{l}0.01 \\
0.025\end{array}$ & 53 & $69 \%$ & 0.60 \\
\hline $\mathrm{D}[\mathrm{a}, \mathrm{h}] \mathrm{A}$ & 0.018 & 0.013 & $\begin{array}{l}0.01 \\
0.025\end{array}$ & 74 & $57 \%$ & 0.31 \\
\hline
\end{tabular}

The health risk endpoint for exposure to mixtures of PAHs is respiratory cancer, and table 18 presents the cancer risk estimated using the WHO's inhalation unit risk method which uses $\mathrm{B}[\mathrm{a}] \mathrm{P}$ as a surrogate for the whole mixture as well as risk estimated using the toxic equivalency factor (TEF) approach. The incremental lifetime cancer risk estimate using the WHO's dose-response method was estimated at $4.91 \times 10^{-6}-$ more than 10 times higher than the TEF approach. This is not surprising given that only eight PAHs are monitored and that there is debate as to whether TEF approach underestimates whole-mixture cancer risk 
(Boström et al., 2002; Pufulete, Battershill, Boobis, \& Fielder, 2004). As PAHs are mutagenic in their mode of action, the US EPA recommends applying an Age-Dependent Adjustment Factor to the risk estimate curve to estimate the risk of exposure starting from birth, as shown in equation 4 (chapter 3). Applying this factor to the WHO's whole-mixture doseresponse estimate, the ILCR increases form $4.91 \times 10^{-6}$ to $8.13 \times 10^{-6}$.

Table 18: Cancer Risk Assessment for PAH mixture

\begin{tabular}{|c|c|c|c|c|}
\hline & $\begin{array}{l}\text { Tumour } \\
\text { Type }\end{array}$ & $\begin{array}{l}\text { Inhalation } \\
\text { Risk }\end{array}$ & ILCR & $\begin{array}{l}\text { ILCR } \\
\text { (95\% UCL) }\end{array}$ \\
\hline $\begin{array}{l}\mathrm{PAH} \text { mixture using } \mathrm{B}[\mathrm{a}] \mathrm{P} \text { as } \\
\text { surrogate } \\
\mathrm{PAH} \text { mixture using TEFs }\end{array}$ & $\begin{array}{l}\text { Respiratory } \\
\text { cancer }\end{array}$ & $\begin{array}{r}8.70 \times 10^{-5} \\
(\mathrm{ng} / \mathrm{m} 3) \\
6.00 \times 10^{-4} \\
(\mu \mathrm{g} / \mathrm{m} 3)\end{array}$ & $\begin{array}{l}4.91 \times 10^{-6} \\
1.61 \times 10^{-7}\end{array}$ & $5.60 \times 10^{-6}$ \\
\hline
\end{tabular}

Table 19: Cancer Risk Assessment for PAH mixture exposure from childbirth scenario

\begin{tabular}{|l|l|l|l|l|}
\hline & $\begin{array}{l}\text { Tumour } \\
\text { Type }\end{array}$ & $\begin{array}{l}\text { Inhalation } \\
\text { Risk }\end{array}$ & ILCR Child & $\begin{array}{l}\text { ILCR Child } \\
\text { (95\% UCL) }\end{array}$ \\
\hline $\begin{array}{l}\text { PAH mixture using B[a]P as } \\
\text { surrogate }\end{array}$ & $\begin{array}{l}\text { Respiratory } \\
\text { cancer }\end{array}$ & $\begin{array}{r}8.70 \times 10^{-5} \\
(\mathrm{ng} / \mathrm{m} 3)\end{array}$ & $8.13 \times 10^{-6}$ & $9.28 \times 10^{-6}$ \\
PAH mixture using TEFs & $\begin{array}{r}6.00 \times 10^{-4} \\
(\mu \mathrm{gg} / \mathrm{m} 3)\end{array}$ & $2.67 \times 10^{-7}$ & \\
& & & & \\
\hline
\end{tabular}

\subsection{Cumulative Chronic and Cancer Risk from VOCs, Metals and PAHs}

Tables 20 and 21 present cumulative hazard indexes and cancer risk estimates following EPA guidance. It's important to note that these estimates may over or under estimate cumulative health risk and there is little scientific basis upon which to assess this (Callahan \& Sexton, 2007). Therefore they are not particularly useful as quantitative estimates of risk 
but may help understand the risks from an overall perspective and identify chemicals affecting either similar health endpoints. These estimates used the mean exposure concentration. For chronic effects there is no health endpoint with a cumulative hazard index greater than 0.2 . For cancer, the cumulative cancer risk estimated was $3.33 \times 10^{-5}$ and this includes contaminants (1,3-butadiene and chromium) for which risk estimates likely represent an overestimation and this will be discussed in the discussion section. Applied to the exposure from childbirth scenario, the cumulative cancer risk was estimated to be 3.66 $\times 10^{-5}$.

Table 20: Cumulative Hazard Index for Chronic Effects

\begin{tabular}{|l|l|r|}
\cline { 2 - 3 } \multicolumn{1}{l|}{} & System & HI (mean/RfC) \\
\hline Ethylbenzene & Developmental & 0.0002404 \\
\hline cyclohexane & Developmental & 0.0002825 \\
\hline Trichloroethylene & $\begin{array}{l}\text { Multiple* developmental \& decreased female } \\
\text { thymus weight }\end{array}$ & 0.00058325 \\
\hline $\begin{array}{l}\text { Cumulative } \\
\text { Developmental }\end{array}$ & & 0.00110615 \\
\hline Dichloromethane & Hepatic & 0.000414833 \\
\hline Carbon Tetrachloride & Hepatic & 0.005435 \\
\hline P-dichlorobenzene & Hepatic & 0.000022875 \\
\hline Vinyl Chloride & Hepatic & 0.00007769 \\
\hline Cumulative Hepatic & & 0.005950398 \\
\hline N-Hexane & Nervous & 0.003355714 \\
\hline Toluene & Nervous & 0.000279 \\
\hline Xylenes & Nervous & 0.005839 \\
\hline Styrene & Nervous & 0.0001849 \\
\hline chloromethane & Nervous & 0.030688889 \\
\hline naphthalene & Nervous and Respiratory & 0.029026667 \\
\hline Manganese & Nervous & 0.0755 \\
\hline Cumulative Nervous & & 0.14487417 \\
\hline naphthalene & Nervous and Respiratory & 0.029026667 \\
\hline Chromium & Respiratory & 0.007583 \\
\hline $\begin{array}{l}\text { Cumulative } \\
\text { Respiratory }\end{array}$ & & 0.036609667 \\
\hline
\end{tabular}


Table 21: Cumulative Cancer Risk

\begin{tabular}{|c|c|c|c|c|}
\hline VOCs & & $\begin{array}{l}\text { Individual } \\
\text { ILCR }\end{array}$ & $\begin{array}{l}\text { Cumulative } \\
\text { ILCR }\end{array}$ & $\begin{array}{l}\text { Exposure } \\
\text { from } \\
\text { Childbirth }\end{array}$ \\
\hline $\begin{array}{l}\text { Benzene* upper } \\
\text { estimate }\end{array}$ & AML & $9.09 \times 10^{-6}$ & & $9.09 \times 10^{-6}$ \\
\hline 1,3-butadiene & Leukemia & $3.98 \times 10^{-6}$ & & $3.98 \times 10^{-6}$ \\
\hline carbon tetrachloride & $\begin{array}{l}\text { Pheochromocytoma } \\
\text { (Nagano et al. 2007b, } \\
\text { JBRC 1998) }\end{array}$ & $3.26 \times 10^{-6}$ & & $3.26 \times 10^{-6}$ \\
\hline 1,2-Dichloroethane & Hemangiosarcomas & $1.81 \times 10^{-6}$ & & $1.81 \times 10^{-6}$ \\
\hline trichloroethylene & $\begin{array}{l}\text { Renal cell carcinoma, } \\
\text { non-Hodgkin's } \\
\text { lymphoma, and liver } \\
\text { tumors }\end{array}$ & $9.57 \times 10^{-8}$ & & $1.59 \times 10^{-7}$ \\
\hline \multicolumn{2}{|l|}{ vinyl chloride } & $3.42 \times 10^{-8}$ & & $6.84 \times 10^{-8}$ \\
\hline tetrachloroethylene & $\begin{array}{l}\text { Hepatocellular } \\
\text { adenomas or } \\
\text { carcinomas (JISA, 1993) }\end{array}$ & $1.88 \times 10^{-8}$ & & $1.88 \times 10^{-8}$ \\
\hline Bromoform & $\begin{array}{l}\text { Neoplastic lesions in } \\
\text { the large intestine } \\
\text { (NTP, 1988) }\end{array}$ & $1.85 \times 10^{-8}$ & & $1.85 \times 10^{-8}$ \\
\hline Dichloromethane & $\begin{array}{l}\text { Hepatocellular } \\
\text { carcinomas or } \\
\text { adenomas, } \\
\text { bronchoalveolar } \\
\text { carcinomas or } \\
\text { adenomas (Mennear et } \\
\text { al. (1988), NTP (1986)) }\end{array}$ & $2.49 \times 10^{-9}$ & & $4.12 \times 10^{-9}$ \\
\hline \multicolumn{2}{|l|}{ Cumulative VOCs } & & $1.83 \times 10^{-5}$ & $1.84 \times 10^{-5}$ \\
\hline \multicolumn{5}{|l|}{ Metals } \\
\hline Chromium & Lung cancer & $9.10 \times 10^{-6}$ & & $9.10 \times 10^{-6}$ \\
\hline Cadmium & $\begin{array}{l}\text { Lung, trachea, } \\
\text { bronchus cancer deaths }\end{array}$ & $7.09 \times 10^{-7}$ & & $7.09 \times 10^{-7}$ \\
\hline Nickel & Lung cancer & $2.93 \times 10^{-7}$ & & $2.93 \times 10^{-7}$ \\
\hline \multicolumn{2}{|l|}{ Cumulative Metals } & & $1.01 \times 10^{-5}$ & $1.01 \times 10^{-5}$ \\
\hline \multicolumn{5}{|l|}{$\mathrm{PAHs}$} \\
\hline $\mathrm{B}[\mathrm{a}] \mathrm{P}$ as surrogate & Respiratory cancer & $4.91 \times 10^{-6}$ & $4.91 \times 10^{-6}$ & $8.13 \times 10^{-6}$ \\
\hline \multicolumn{2}{|c|}{ Total Cumulative ILCR } & & $3.33 \times 10^{-5}$ & $3.66 \times 10^{-5}$ \\
\hline
\end{tabular}




\subsection{Criteria Air Contaminants}

The results from the assessment of the criteria air contaminants are presented below. For acute effects, the CCME guidelines use statistical measures that smooth the highest ( $99^{\text {th }}$ or $98^{\text {th }}$ percentile) daily, or hourly maximum or average concentrations over three years depending on the contaminant. The statistic for each year presented in the graphs below, therefore, represents an assessment of the extent to which short term episodes of high concentrations occurred over the preceding three years. Ozone exceeded the CCME limit and was in the red management level for all years of assessment. All three other contaminants $\left(\mathrm{PM}_{2.5}, \mathrm{NO}_{2}, \mathrm{SO}_{2}\right)$ exceeded the yellow CCME limit and were in the orange management level for all years assessed. For long-term effects, $\mathrm{NO}_{2}$ and $\mathrm{PM}_{2.5}$ exceeded the yellow CMME limit and were in the orange management level, while $\mathrm{SO}_{2}$ was slightly below the orange management threshold.

\subsubsection{Nitrogen Dioxide}

Table 22 Nitrogen Dioxide Assessment using CCME guidelines- Acute

\begin{tabular}{|l|l|l|l|l|l|l|}
\hline \multirow{2}{*}{ Statistical Form } & \multicolumn{3}{|c|}{$\begin{array}{c}\text { CCME Standard } \\
\text { (ppb) }\end{array}$} & \multicolumn{3}{|c|}{ Aamjiwnaang Monitor (ppb) } \\
\cline { 2 - 7 } & 2020 & 2025 & 2011 & 2012 & 2013 & 2014 \\
\hline 98th percentile of 1-hour & $>60$ & $>42$ & 27.92 & 25.79 & 23.76 & 22.22 \\
daily maximum & $>31$ & $>31$ & & & & \\
concentrations, averaged over & $>20$ & $>20$ & & & & \\
3 years & $<20$ & $<20$ & & & & \\
\hline
\end{tabular}

Table 23 Nitrogen Dioxide Assessment using CCME guidelines- long-term

\begin{tabular}{|l|l|l|l|l|l|l|l|l|}
\hline \multirow{2}{*}{$\begin{array}{l}\text { Statistical } \\
\text { Form }\end{array}$} & \multicolumn{2}{l}{$\begin{array}{l}\text { CCME Standard } \\
(\mathrm{ppb})\end{array}$} & \multicolumn{6}{l|}{ Aamjiwnaang Monitor (ppb) } \\
\cline { 2 - 9 } & 2020 & 2025 & 2009 & 2010 & 2011 & 2012 & 2013 & 2014 \\
\hline Annual & $>17$ & $>12$ & 12.74 & 14.44 & 11.05 & 11.46 & 11.51 & 10.20 \\
Mean & $>7$ & $>7$ & & & & & & \\
& $>2$ & $>2$ & & & & & & \\
& $<2$ & $<2$ & & & & & & \\
\hline
\end{tabular}


Figure 6: Nitrogen Dioxide Assessment using CCME guidelines- Acute

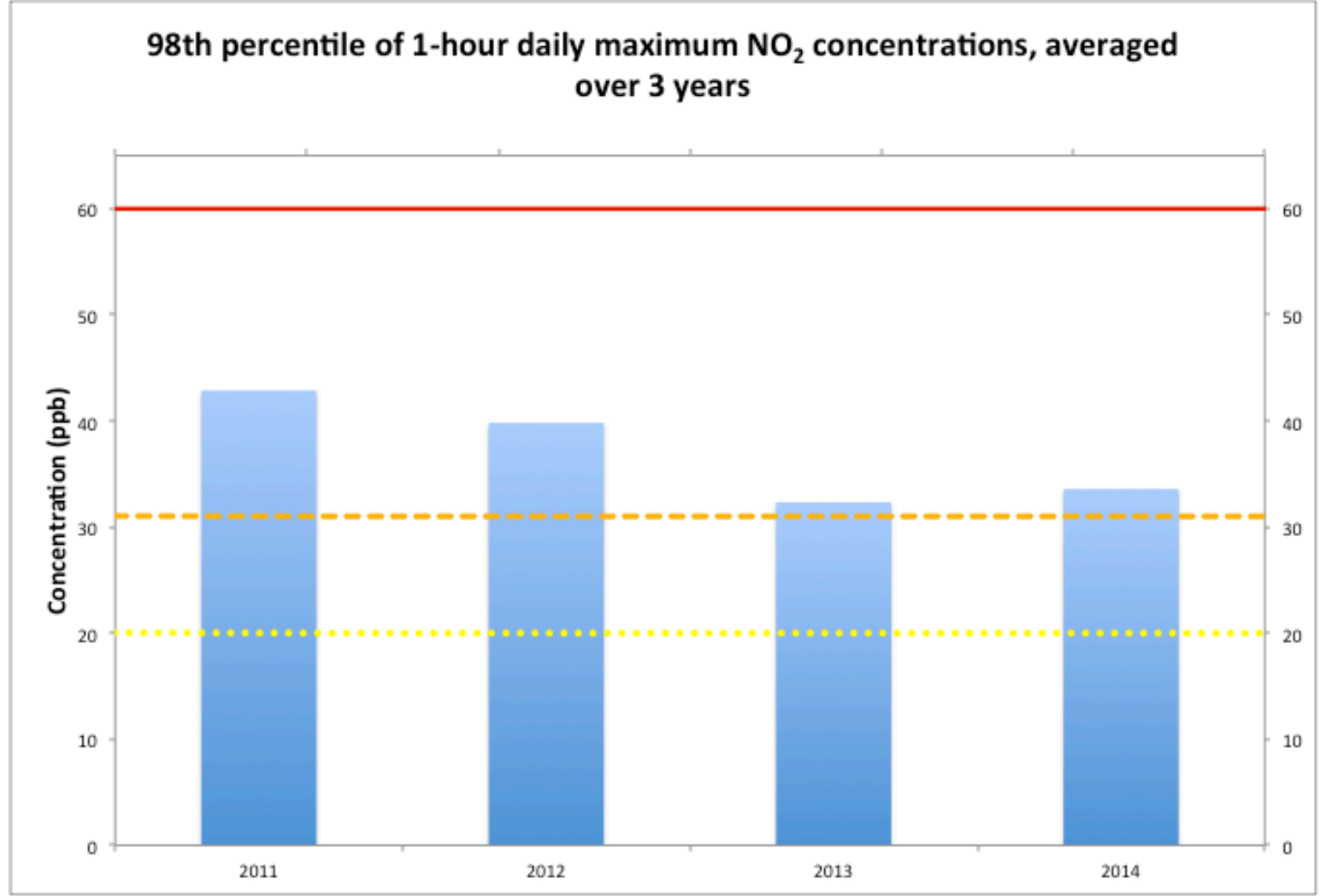

Figure 6: Blue bars represent the $98^{\text {th }}$ percentile 1-hour daily maximum $\mathrm{NO}_{2}$ concentrations averaged over 3 years for 2011-2014. The red solid line represents the threshold for the CCME red management area, the orange dashed line represents the threshold for the orange management area, the yellow dotted line represents the threshold for yellow management area- below this line is the green management area.

Both measures of short-term maximum concentrations and long-term average $\mathrm{NO}_{2}$ concentrations show a slight decline over the sampling period for although both were in the orange management level over the entire sampling period. 


\subsubsection{Sulphur Dioxide}

Table 24: Sulphur Dioxide Assessment using CCME guidelines- Acute

\begin{tabular}{|l|l|l|l|l|l|l|}
\hline Statistical Form & \multicolumn{2}{|c|}{$\begin{array}{c}\text { CCME Standard } \\
\text { (ppb) }\end{array}$} & \multicolumn{3}{c|}{ Aamjiwnaang Monitor (ppb) } \\
\cline { 2 - 7 } & 2020 & 2025 & 2011 & 2012 & 2013 & 2014 \\
\hline 99th percentile of 1-hour & $>70$ & $>65$ & 70 & 59 & 55 & 59 \\
daily maximum & $>50$ & $>50$ & & & & \\
concentrations, averaged over & $>30$ & $>30$ & & & & \\
3 years & $<30$ & $<30$ & & & & \\
\hline
\end{tabular}

Table 25: Sulphur Dioxide Assessment using CCME guidelines - Long-term

\begin{tabular}{|l|l|l|l|l|l|l|l|l|}
\hline \multirow{2}{*}{$\begin{array}{l}\text { Statistical } \\
\text { Form }\end{array}$} & \multicolumn{2}{l|}{$\begin{array}{l}\text { CCME Standard } \\
(\mathrm{ppb})\end{array}$} & \multicolumn{2}{l|}{ Aamjiwnaang Monitor (ppb) } \\
\cline { 2 - 8 } & 2020 & 2025 & 2009 & 2010 & 2011 & 2012 & 2013 & 2014 \\
\hline Annual & $>5$ & $>4$ & 2.99 & 2.80 & 2.51 & 2.41 & 2.44 & 2.41 \\
Mean & $>3$ & $>3$ & & & & & & \\
& $>2$ & $>2$ & & & & & & \\
& $<2$ & $<2$ & & & & & & \\
\hline
\end{tabular}


Figure 7: Sulphur Dioxide Assessment using CCME guidelines- Acute

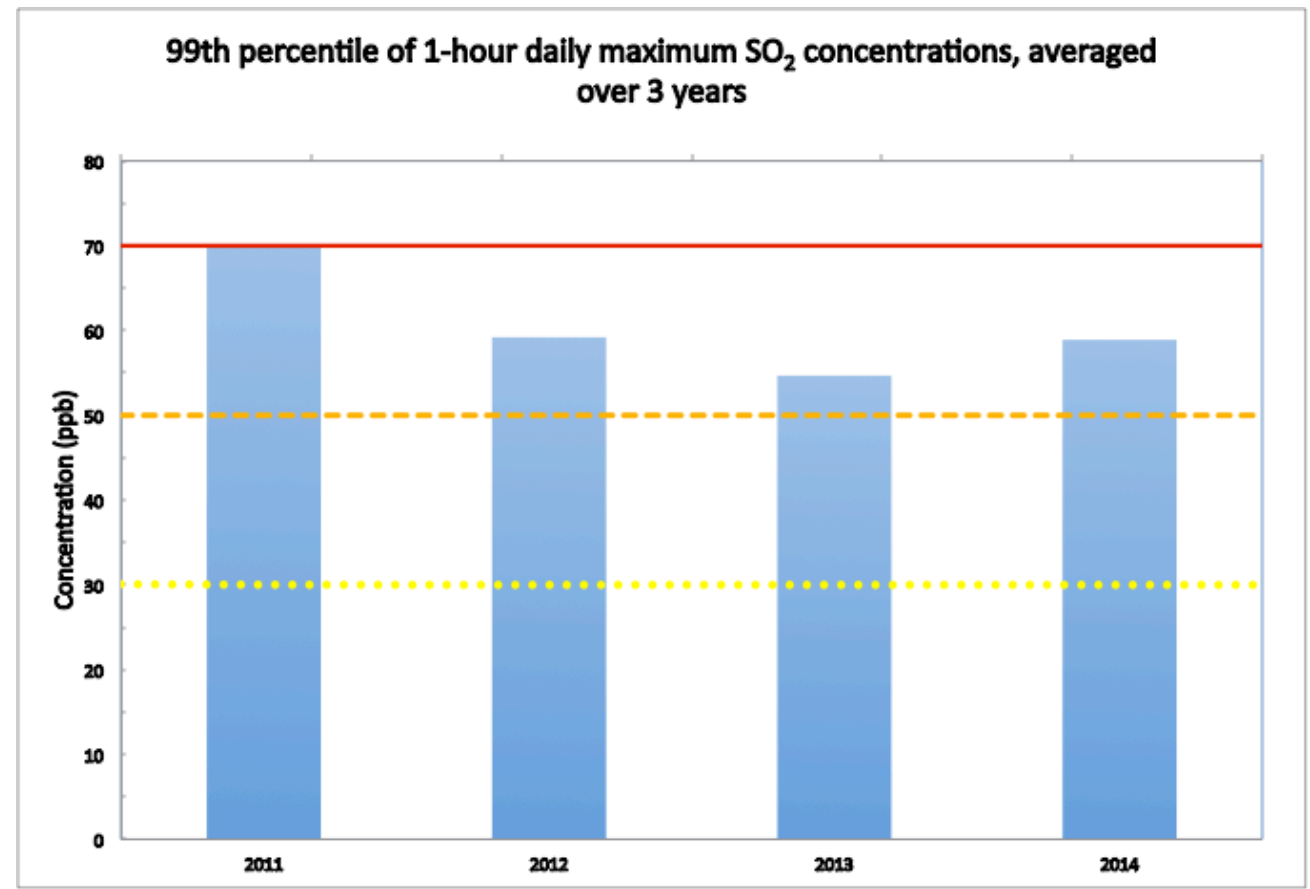

Figure 7: Blue bars represent the 99th percentile 1-hour daily maximum $\mathrm{SO}_{2}$ concentrations averaged over 3 years for 2011-2014. The red solid line represents the threshold for the CCME red management area, the orange dashed line represents the threshold for the orange management area, the yellow dotted line represents the threshold for yellow management area- below this line is the green management area.

For acute effects, the statistical measure for 2011, which represents the three-year average of 1hour high concentration episodes over 2009-2011 almost exceeded the red CCME threshold, while the following periods showed decline. These results, however, still indicate that high concentration events are a problem in the area, as they fall within the orange management zone. That the annual $\mathrm{SO}_{2}$ concentrations fall within the yellow management zone indicate that short-term, high concentration events are more of a problem than long-term average concentrations in the area. 


\subsubsection{Ozone}

Table 26 Ozone assessment using CCME guidelines- Acute

\begin{tabular}{|l|l|l|l|l|l|l|}
\hline \multirow{2}{*}{ Statistical Form } & \multicolumn{2}{|c|}{$\begin{array}{c}\text { CCME Standard } \\
\text { (pp) }\end{array}$} & \multicolumn{3}{|c|}{ Aamjiwnaang Monitor (ppb) } \\
\cline { 2 - 7 } & 2015 & 2020 & 2011 & 2012 & 2013 & 2014 \\
\hline 3-year average of the & $>63$ & $>62$ & 67.33 & 74.55 & 75.76 & 72.84 \\
annual 4th- & $>56$ & $>56$ & & & & \\
highest daily maximum 8- & $>50$ & $>50$ & & & & \\
hour average concentrations & $<50$ & $<50$ & & & & \\
& & & & & & \\
\hline
\end{tabular}

Figure 8: Ozone assessment using CCME guidelines- Acute

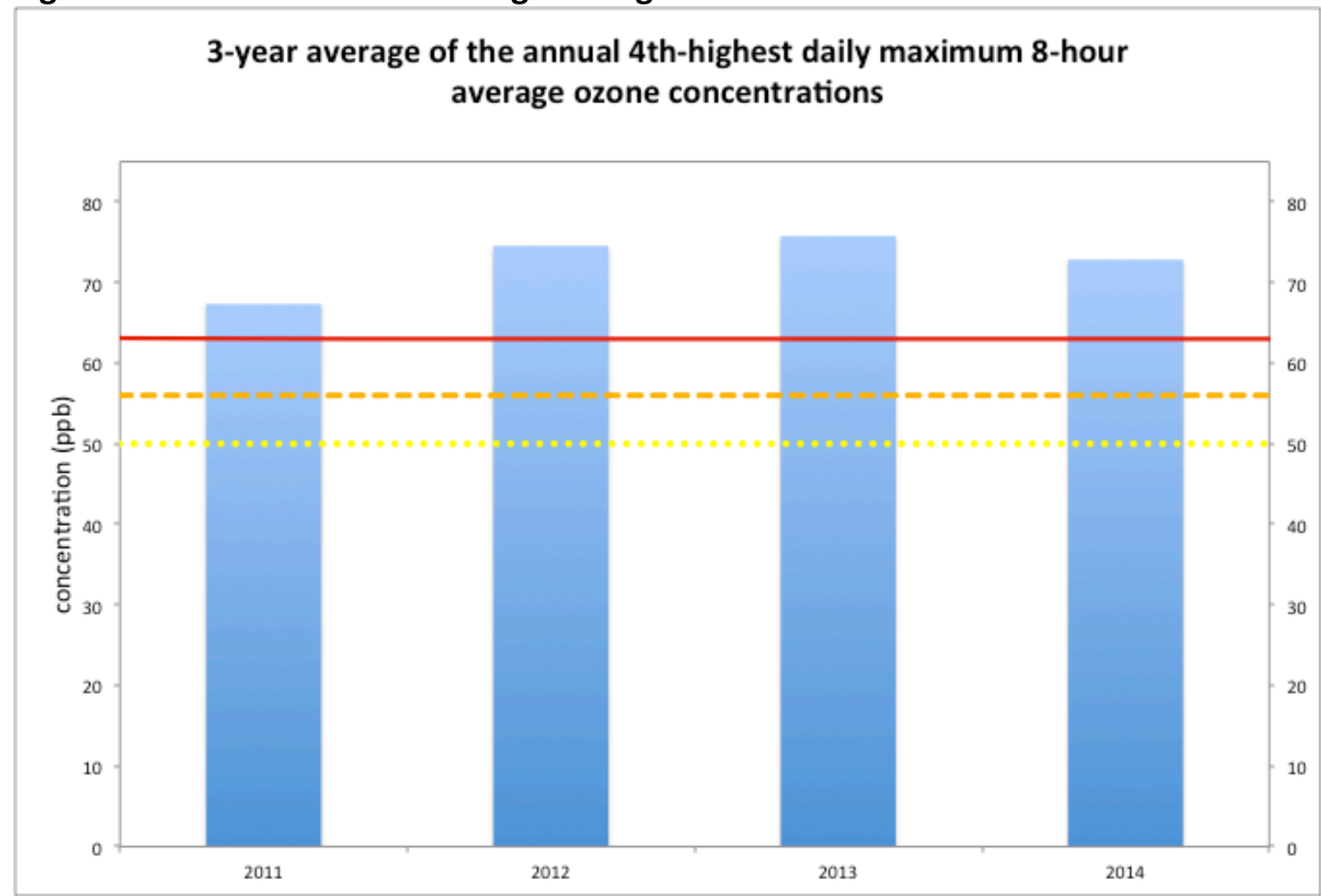

Figure 8: Blue bars represent the $4^{\text {th }}$ highest daily maximum 8-hour average concentrations averaged over 3 years for 2011-2014. The red solid line represents the threshold for the CCME red management area, the orange dashed line represents the threshold for the orange management area, the yellow dotted line represents the threshold for yellow management area- below this line is the green management area.

Ozone was consistently above the red threshold CCME limit and did not show a decline over the sampling period. 


\subsubsection{Fine Particulate Matter}

For acute effects, the statistical measure for fine particulate matter decreased over the sampling period and was in the orange management level. The 3-year average concentration of $\mathrm{PM}_{2.5}$ also declined over the sampling period; however, it was in the red management area for the years representing 2009-2011. For the statistical measure in years 2012 on, the three-year average $\mathrm{PM}_{2.5}$ was in the orange management area.

Table 27: Fine Particulate assessment using CCME guidelines- Acute

\begin{tabular}{|l|l|l|l|l|l|l|}
\hline \multirow{2}{*}{ Statistical Form } & \multicolumn{3}{|c|}{$\begin{array}{c}\text { CCME Standard } \\
\left(\mu \mathrm{g} / \mathrm{m}^{3}\right)\end{array}$} & \multicolumn{3}{|c|}{ Aamjiwnaang Monitor $\left(\mu \mathrm{g} / \mathrm{m}^{3}\right)$} \\
\cline { 2 - 7 } & 2015 & 2020 & 2011 & 2012 & 2013 & 2014 \\
\hline The 3-year average of the & $>28$ & $>27$ & 27.92 & 25.79 & 23.76 & 22.22 \\
annual 98th percentile of the & $>19$ & $>19$ & & & & \\
daily 24-hour average & $>10$ & $>10$ & & & & \\
concentrations & $<10$ & $<10$ & & & & \\
\hline
\end{tabular}

Table 28: Fine Particulate assessment using CCME guidelines - Long-term

\begin{tabular}{|l|l|l|l|l|l|l|}
\hline \multirow{2}{*}{ Statistical Form } & \multicolumn{3}{l|}{$\begin{array}{l}\text { CCME Standard } \\
\left(\mu \mathrm{g} / \mathrm{m}^{3}\right)\end{array}$} & \multicolumn{3}{l|}{ Aamjiwnaang Monitor $\left(\mu \mathrm{g} / \mathrm{m}^{3}\right)$} \\
\cline { 2 - 7 } & 2015 & 2020 & 2011 & 2012 & 2013 & 2014 \\
\hline 3 The 3-year average of the & $>10$ & $>8.8$ & 10.03 & 9.70 & 9.08 & 8.53 \\
annual average & $>6.4$ & $>6.4$ & & & & \\
concentrations. & $>4$ & $>4$ & & & & \\
& $<4$ & $<4$ & & & & \\
& $<4$ &
\end{tabular}


Figure 9: Fine Particulate assessment using CCME guidelines- Acute

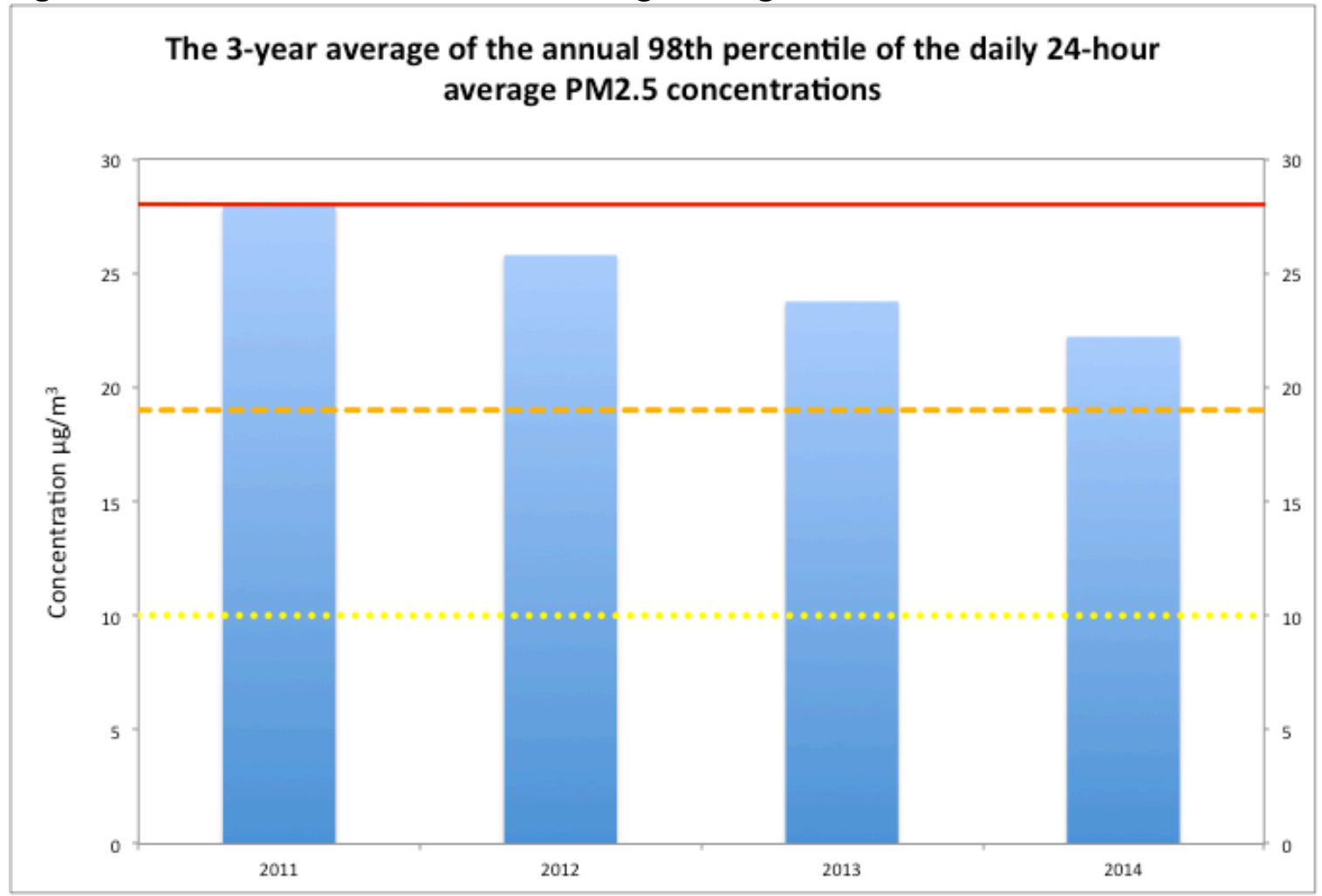

Figure 9: The blue bars represent the $98^{\text {th }}$ percentile 24-hour daily average $\mathrm{PM}_{2.5}$ concentrations averaged over 3 years for 2011-2014. The red solid line represents the threshold for the CCME red management area, the orange dashed line represents the threshold for the orange management area, the yellow dotted line represents the threshold for yellow management area- below this line is the green management area.

\subsubsection{Total Reduced Sulphur/Hydrogren Sulphide}

Table 28 shows the results of the assessment of total reduced sulphur. Total reduced sulphur equalled or exceeded Ontario's AAQC 24 hour health-based standard 5 times over the sampling period. As the table shows all of these occurred in 2009 or 2010. As was noted in the methods section, this assessment did not include odour effects. Given that complaints over odours have been documented in Chemical Valley (see introduction), and that exposure to odours can have harmful mental and physiological effects (Dann, 2016), odour effects of Chemical Valley emissions should be investigated in further studies. 
Table 29: Total Reduced Sulphur / Hydrogen Sulphide

\begin{tabular}{|l|l|l|l|l|l|l|}
\hline & 2009 & 2010 & 2011 & 2012 & 2013 & 2014 \\
\hline $\begin{array}{l}\text { Number of days equal } \\
\text { to or in exceedance of } \\
\text { 4ppb 24hr average }\end{array}$ & $\mathbf{4}$ & $\mathbf{1}$ & $\mathbf{0}$ & $\mathbf{0}$ & $\mathbf{0}$ & $\mathbf{0}$ \\
\hline
\end{tabular}




\section{Chapter 5 Risk Characterization}

Risk characterization integrates the dose-response relationship with estimates of exposure in a population to characterize the likelihood of health effects, and this component of risk characterization was presented in results section above. In addition, risk characterization should include a discussion of model assumptions and data uncertainties and the following chapter presents this discussion.

\subsection{Major Assumptions and Uncertainties and Variability}

The risk assessment generated numerical estimates of risk for cancer, and hazard quotients for chronic illness. To interpret these, however, it is important to discuss how well they represent the true risk to the population living near Chemical Valley, and this requires understanding the assumptions and uncertainties involved in how this thesis applied the risk assessment model.

\subsubsection{Exposure Assumptions, Uncertainty and Variability affecting all Chemicals}

The exposure assessment in this thesis made several assumptions that relate to both variability and uncertainty. First, the environmental exposure concentration for each contaminant was assumed to be the sample mean recorded at the Aamjiwnaang monitor. This assumption fails to capture spatial variability in the real world; where environmental concentrations vary through space. Particularly for VOCs, spatial variation has been shown to vary greatly over short distances (Miller et al., 2009; Wu et al., 2012; Zhu et al., 2008). The population living near Chemical Valley will therefore not be uniformly exposed to the exposure concentration at the Aamjiwnaang monitor, but have a distribution of varying exposure to VOCs, with peaks and valleys. While some individuals who live and spend most 
of their time near the Aamjiwnaang monitor may be exposed to environmental concentrations similar to those recorded at the monitor, those living closer to the facilities to the west and north of the monitor may be exposed to differing environmental concentrations. Unfortunately, this thesis cannot quantify this variability. Depending on the sources of contaminants measured at the Aamjiwnaang monitor, as well as atmospheric conditions, the sample mean at the monitor could underestimate the mean exposure concentration for some individuals and overestimate it for others. Given that there are more densely populated areas closer to Chemical Valley facilities than the monitor itself, it is possible that in these areas, the sample mean at the Aamjiwnaang monitor underestimates the true mean exposure to these residents, however this is dependent on the source location and strengths of VOC emissions over time and would need to be empirically validated. ${ }^{5}$

\section{Major Assumption \# 1 Aamjiwnaang monitor location}

\begin{tabular}{|l|l|l|l|}
\hline $\begin{array}{l}\text { Source of } \\
\text { Uncertainty }\end{array}$ & Assumption & $\begin{array}{l}\text { Implication for } \\
\text { population } \\
\text { average risk }\end{array}$ & $\begin{array}{l}\text { Implication for } \\
\text { most exposed } \\
\text { individuals }\end{array}$ \\
\hline $\begin{array}{l}\text { Spatial variability } \\
\text { in environmental } \\
\text { contaminant } \\
\text { concentrations }\end{array}$ & $\begin{array}{l}\text { Sample mean at } \\
\text { monitor represents } \\
\text { mean exposure for } \\
\text { all residents living } \\
\text { near facilities }\end{array}$ & $\begin{array}{l}\text { Mean may be } \\
\text { biased estimate of } \\
\text { average } \\
\text { environmental } \\
\text { exposure } \\
\text { concentration }\end{array}$ & $\begin{array}{l}\text { Sample mean } \\
\text { underestimates } \\
\text { true exposure for } \\
\text { certain individuals } \\
\text { and over estimates } \\
\text { it for others. }\end{array}$ \\
\hline
\end{tabular}

\footnotetext{
${ }^{5}$ In 2015 the MOECC conducted mobile monitoring (Ontario Ministry of the Environment and Climate Change, 2017g) discussed in appendix 1 that showed both high and non-detect concentrations of various VOCs at differing locations on the Aamjiwnaang reserve. In this document the MOECC states that fence-line VOC monitoring will eventually be required for facilities, and this indicates this empirical information may become available in the future.
} 
The second major assumption associated with the exposure assessment model is that the sample mean adequately represents the mean environmental concentration at the monitor through time. Since all samples with the exception of the criteria air contaminants are taken at discreet time intervals (one 24-hour sample every 12 days for VOCs and PAHs, one 24 -hour sample every 6 days for metals), it is possible that by random chance, the sampling days either overestimate or underestimate the mean due to over or under representing spikes or low concentration values. To a certain extent, the use of a 95 percent upper confidence level of the sample mean helps reduce this uncertainty, in particular because for this thesis, the use of appropriate non-parametric methods was used to estimate these values when necessary. As the assessment for VOCs demonstrated, use of the 95\% UCL mean did not significantly change the risk assessment results.

\section{Major Assumption \# 2 Samples Representative of Temporal Variation}

\begin{tabular}{|l|l|l|l|}
\hline $\begin{array}{l}\text { Source of } \\
\text { Uncertainty }\end{array}$ & Assumption & $\begin{array}{l}\text { Implication for } \\
\text { population average } \\
\text { risk }\end{array}$ & $\begin{array}{l}\text { Implication for } \\
\text { most exposed } \\
\text { individuals }\end{array}$ \\
\hline $\begin{array}{l}\text { Temporal } \\
\text { variability in } \\
\text { environmental } \\
\text { contaminant } \\
\text { concentrations }\end{array}$ & $\begin{array}{l}\text { Sample mean at } \\
\text { monitor represents } \\
\text { true mean } \\
\text { exposure over time }\end{array}$ & $\begin{array}{l}\text { Mean could } \\
\text { underestimate or } \\
\text { overestimate } \\
\text { average } \\
\text { environmental } \\
\text { exposure } \\
\text { concentration }\end{array}$ & $\begin{array}{l}\text { Mean could } \\
\text { underestimate or } \\
\text { overestimate } \\
\text { average } \\
\text { environmental } \\
\text { exposure } \\
\text { concentration }\end{array}$ \\
\hline
\end{tabular}

Although it appears uncertainty due to temporal variability in environmental contaminant concentrations may not be a significant source of uncertainty in risk estimates based on the upper 95 per cent confidence limits, data from the continuous VOC monitor do raise some uncertainty, in particular for benzene, which shows many short-term spikes (see appendix 1). Because the continuous monitor has an unknown method detection limit according to 
the MOECC, and that limit appears to be above background concentrations for these VOCs, it is impossible to use the continuous monitor to quantitatively assess the representativeness of the non-continuous samples. Qualitative evaluation of the data, however, shows that short term spikes, likely from spills or leaks at facilities, and these should be investigated further (see appendix 1).

The third major assumption of the exposure assessment is that the exposed population will spend their lifetime continuously exposed to the mean environmental exposure concentration measured at the monitor. This assumption is unrealistic for obvious reasons, and fails to capture variability about where humans spend their time. Despite this, there are several reasons to make this assumption. First, studies have shown that indoor air in polluted areas tends to be influenced more by ambient VOC pollution than in unpolluted areas (Jia, Batterman, et al., 2008; Wu et al., 2012). So time spent indoors near Chemical Valley would not necessarily reduce the cumulative exposure of residents living near facilities. Second, since much of the area near Chemical Valley is a First Nations reserve, regular patterns of population movement cannot be assumed, and the cultural ties to reserve lands increases the likelihood that some residents will spend the majority of their lives in the area.

Major Assumption \# 4 Continuous lifetime exposure

\begin{tabular}{|l|l|l|l|}
\hline $\begin{array}{l}\text { Source of } \\
\text { Uncertainty }\end{array}$ & Assumption & $\begin{array}{l}\text { Implication for } \\
\text { population average } \\
\text { risk }\end{array}$ & $\begin{array}{l}\text { Implication for } \\
\text { most exposed } \\
\text { individuals }\end{array}$ \\
\hline $\begin{array}{l}\text { Spatial variability } \\
\text { in where exposed } \\
\text { population spends } \\
\text { their time. }\end{array}$ & $\begin{array}{l}\text { Individuals spend } \\
\text { all of their time for } \\
\text { (70yrs) near the } \\
\text { monitor }\end{array}$ & $\begin{array}{l}\text { Mean could } \\
\text { overestimate } \\
\text { average duration } \\
\text { and frequency of } \\
\text { exposure }\end{array}$ & $\begin{array}{l}\text { Mean could } \\
\text { overestimate } \\
\text { average duration } \\
\text { and frequency of } \\
\text { exposure }\end{array}$ \\
\hline
\end{tabular}


Lastly, for the US EPA estimated concentration-response relationships derived from animal studies, this thesis' exposure assessment uses adult population averages for breathing rates and body weight, as well as other factors related to the kinetics of inhalation and absorption in the respiratory system. Since cross-species extrapolation of absorbed dose must be carried out in order apply the results of animal studies to human exposures, default population averages must be used. Since there is variability in these factors across the population, the use of averages will underestimate exposure for some individuals and overestimate it in others. The U.S. EPA has addressed this issue and states that uncertainty factors applied to RfCs, and linear extrapolation applied for carcinogens provides sufficient protection, even for individuals who might not be adequately represented by population averages (U.S. Environmental Protection Agency, 2002a). Some critics argue that for children this is not sufficient, however this is beyond the scope of this thesis to resolve (see Ginsberg, Foos, Dzubow, \& Firestone, 2010).

For dose-response relationships derived from occupational studies of exposed workers, some of the natural variability of these exposure factors will be captured in the concentration-response relationship because it is present in the population of workers in study population — but this will not capture all variability - in particular for children. As with dose-response relationships estimated from animal studies, the U.S. EPA states that uncertainty factors and linear extrapolation for carcinogens provides adequate protection despite this uncertainty. 
Major Assumption \# 5 Use of Adult and Average Exposure Kinetics

\begin{tabular}{|l|l|l|l|}
\hline $\begin{array}{l}\text { Source of } \\
\text { Uncertainty }\end{array}$ & Assumption & $\begin{array}{l}\text { Implication for } \\
\text { population average } \\
\text { risk }\end{array}$ & $\begin{array}{l}\text { Implication for } \\
\text { most exposed } \\
\text { /sensitive } \\
\text { individuals }\end{array}$ \\
\hline $\begin{array}{l}\text { Variability in } \\
\text { human exposure } \\
\text { kinetics (breathing } \\
\text { rate, body weight, } \\
\text { lung surface area } \\
\text { etc.) }\end{array}$ & $\begin{array}{l}\text { a) Population } \\
\text { average for D-Rs } \\
\text { derived from } \\
\text { animal studies } \\
\text { b) Healthy males } \\
\text { for DRs from } \\
\text { occupational } \\
\text { health studies }\end{array}$ & $\begin{array}{l}\text { Mean is likely an } \\
\text { accurate } \\
\text { representation of } \\
\text { population- } \\
\text { average absorbed } \\
\text { dose }\end{array}$ & $\begin{array}{l}\text { Mean could } \\
\text { underestimate } \\
\text { average absorbed } \\
\text { dose }\end{array}$ \\
\hline
\end{tabular}

\subsubsection{Dose Response Assumptions, Uncertainty and Variability affecting all Chemicals}

As discussed in the methods section, site-specific risk assessments use previously estimated dose-response relationships, and these involve assumptions that also contribute to uncertainty in the results of the risk assessment. There are several factors that lead to significant uncertainty in the estimated dose-response relationships used in this study.

\subsubsection{High to Low Dose Extrapolation:}

For all of the contaminants assessed, excluding criteria air contaminants, the doseresponse relationships were estimated by extrapolating from studies observing effects at doses much higher than are typical from exposure to ambient air. Due to insufficient statistical power, the low-dose region of dose-response functions cannot be characterized empirically and must be guided by theory and other sources of evidence (Rodricks, Gaylor, \& Turnbull, 2007). This extrapolation is therefore a source of uncertainty because assumptions about the shape the dose-response function over the low-dose range can result in significant differences in the risk estimates generated at low doses (Kenny S. Crump, 2011; Schneiderman, Decouflé, \& Brown, 1979; Slob, 1999). For non-carcinogens, 
this thesis used dose-response functions that assumed a linear relationship between dose and effect so that even a very small increase in exposure results in a proportional increase in the risk of cancer. This assumption is in concordance with theories of cancer in which genetic damage can occur from exposure to even one molecule of a chemical, and this damage causes a corresponding and additive increase in risk (K S Crump, Hoel, Langley, \& Peto, 1976). There is significant debate about whether this linear extrapolation overestimates risk at low doses, particularly for contaminants in which the mode-of-action is not sufficiently understood (Calebrese, 2014). Although less prominent in the literature, there is also debate as to whether processes such as enzyme saturation at high-doses causes a steeper dose-response curve at low doses; in which case linear extrapolation could underestimate the risk of exposure at low doses (McHale, Zhang, \& Smith, 2012; Swenberg et al., 1987).

\section{Major Assumption \# 6 Linear Extrapolation for carcinogens}

\begin{tabular}{|l|l|l|l|}
\hline $\begin{array}{l}\text { Source of } \\
\text { Uncertainty }\end{array}$ & Assumption & $\begin{array}{l}\text { Implication for } \\
\text { population average } \\
\text { risk }\end{array}$ & $\begin{array}{l}\text { Implication for } \\
\text { most exposed } \\
\text { individuals }\end{array}$ \\
\hline $\begin{array}{l}\text { Lack of } \\
\text { information to } \\
\text { characterize dose- } \\
\text { response curve at } \\
\text { low doses }\end{array}$ & $\begin{array}{l}\text { A linear dose- } \\
\text { response curve } \\
\text { extrapolated from } \\
\text { data points at high } \\
\text { doses }\end{array}$ & $\begin{array}{l}\text { Could overestimate } \\
\text { or underestimate } \\
\text { risk }\end{array}$ & $\begin{array}{l}\text { Could overestimate } \\
\text { or underestimate } \\
\text { risk }\end{array}$ \\
\hline
\end{tabular}

\subsubsection{Uncertainty in Exposure Assessment, Statistical Methods and Treatment of Confounders in Occupational Studies}

An additional source of uncertainty in dose-response assessment is that errors in measuring exposure in occupational epidemiology studies can dilute or bias the effects levels used to estimate the dose-response curve. For example, the key studies used to estimate dose-response curves for benzene and 1,3-butadiene have undergone revisions to 
their original exposure estimates, and these have changed the slopes of the estimated doseresponse curves. If the original study underestimated exposure, then the slope of the linear dose-response curve will be biased toward overestimation of risks - whereas if the study overestimated exposure, risk estimates will be biased towards underestimation. For 1,3butadiene, for example, changes in exposure assessment as well as statistical methods and treatment of confounding exposure to styrene led to a 60 -fold reduction in the slope of the dose-response curve (Texas Commission on Environmental Quality, 2008).

Major Assumption \# 8 Exposure estimates and statistical modelling to derive doseresponse are accurate

\begin{tabular}{|l|l|l|l|}
\hline $\begin{array}{l}\text { Source of } \\
\text { Uncertainty }\end{array}$ & Assumption & $\begin{array}{l}\text { Implication for } \\
\text { population average } \\
\text { risk }\end{array}$ & $\begin{array}{l}\text { Implication for } \\
\text { most exposed } \\
\text { individuals }\end{array}$ \\
\hline $\begin{array}{l}\text { Exposure errors in } \\
\text { dose-response } \\
\text { estimation }\end{array}$ & N/A & $\begin{array}{l}\text { Could overestimate } \\
\text { or underestimate } \\
\text { risk }\end{array}$ & $\begin{array}{l}\text { Could overestimate } \\
\text { or underestimate } \\
\text { risk }\end{array}$ \\
\hline
\end{tabular}

\subsection{Chemical Specific Risk Characterization}

\subsubsection{Benzene}

Benzene was the chemical with highest incremental lifetime cancer risk estimated at $9.09 \times 10^{-6}$. As discussed above, the location of the monitor creates uncertainty as to whether this estimate reflects the true risk faced by the population living near Chemical Valley. For individuals living closer to facilities than the monitor, this may underestimate risk; however, this would also depend on the source location, timing and weather conditions. The magnitude of this potential underestimation is difficult to predict without additional monitoring (see appendix 1). 
The shape of the dose-response curve is another source of uncertainty due to the high-to low dose extrapolation. There are competing scientific interpretations of the mode of action evidence to characterize the shape of benzene's dose-response curve, and this led the European Union's science panel to conclude that a large range of average lifetime continuous exposure concentrations, from $0.2 \mu \mathrm{g} / \mathrm{m}^{3}$ to $20 \mu \mathrm{g} / \mathrm{m}^{3}$ could plausibly represent an excess risk of contracting acute myeloid leukemia (AML) of one in a million (Comission of European Communities, 1998). This does not represent a range of variability in the true risk, but the range over which equally compelling scientific arguments could be made for a cancer risk representing one in a million.

The EPA's dose-response curve used linear-extrapolation because of the EPA's default policy to use linear extrapolation when a carcinogen's MOA is not sufficiently characterized (U.S. Environmental Protection Agency, 1998, 2005a). Due to uncertainty in the exposure estimates in the occupational study used to estimate the dose-response curve, the EPA's linear dose-response curve itself has a range of slope factors within a 95\% confidence interval for the unit inhalation risk $\left(2.2 \times 10^{-6} \mathrm{per} \mu \mathrm{g} / \mathrm{m}^{3}\right.$ to $\left.7.8 \times 10^{-6} \mathrm{per} \mu \mathrm{g} / \mathrm{m}^{3}\right)$. The unit inhalation risk estimate used in this thesis was the higher end of the range $\left(7.8 \times 10^{-6} \mathrm{per} \mu \mathrm{g} / \mathrm{m}^{3}\right)$. Using the lower end of this range, the risk estimate based on the Aamjiwnaang monitor is $2.56 \times 10^{-6}$, and the EPA states that there is no scientific evidence to suggest either end of this range is more or less accurate. This lower limit of the dose-response curve slope is what the MOECC used to derive its annual benzene AACQ of $0.45 \mu \mathrm{g} / \mathrm{m} 3$, which represents cancer risk of $1 \times 10^{-6}$. Using the MOECCs preferred slope, the annual mean at the Aamjiwnaang monitor represents a slight exceedance in risk above the $1 \times 10^{-6}$ level. 


\subsubsection{1,3-Butadiene}

1,3-butadiene had the next highest incremental lifetime cancer risk at $3.98 \times 10^{-6}$. Like benzene, the monitor location introduces uncertainty and could potentially bias this result toward underestimating the true risk. The US EPA's dose-response curve for 1,3-butadiene is based on an occupational cohort study that has been updated since the EPA's dose-response curve estimation. The update made improvements to exposure estimates which indicated exposure to the cohort was higher than had previously been reported (Sielken \& Valdez-Flores, 2015). The Texas Commission on Environmental Quality re-estimated the dose-response relationship using the updated exposure estimates, as well as different line-fitting techniques and assumptions, and derived an inhalation unit risk 5.0 x $10^{-7}$ - a slope 60 -times lower than the EPA's inhalation unit risk used in this thesis (Texas Commission on Environmental Quality, 2008). Using the TCEQ's unit risk, the 1,3butadiene ILCR at the Aamjiwnaang monitor is $6.63 \times 10^{-8}$.

Although it's beyond the scope of this thesis to weigh the scientific merit of the EPA's and TECQ's approaches, because the TECQ's uses updated and more detailed exposure estimates from the same study, on the surface, the TCEQ's inhalation unit risk would appear to be a more accurate estimate of risk, however, detailed review of the original study and methods used by both agencies would be required to confirm this.

\subsubsection{Carbon Tetrachloride}

The ILCR for carbon tetrachloride was estimated at $3.26 \times 10^{-6}$. The EPA's estimated dose-response relationship is based on a bioassay study in rats and mice and therefore 
included cross-species extrapolation which adds uncertainty to the assessment relative Benzene and 1,3-butadiene.

Unlike benzene or 1,3-butadiene which had a small but significant number of very high values, the carbon tetrachloride observations appeared to be normally distributed at the monitor, which could suggest its presence is from background concentrations, with less influence from the facilities in Chemical Valley. This is supported by the fact that carbon tetrachloride is long-lived in the atmosphere, and appears to be uniformly distributed in much of North America (McCarthy, Hafner, \& Montzka, 2006). McCarthy et al., (2006) also estimated that background concentrations of carbon tetrachloride were responsible for 99.5\% of urban concentrations of carbon tetrachloride in a ten-city study in the United States. This could suggest that its spatial distribution near Chemical Valley is relatively uniform as well, however this would need to be confirmed empirically. The production of carbon tetrachloride was banned under the Montreal Protocol, however, its use as a feedstock is permitted, and so it's presence could also originate from fugitive leaks from chlor-alkali processes (Hu et al., 2016). In Chemical Valley, Dow chemicals operated a choralkali plant, that was shut down over 2006-2008 and so it is possible that carbon tetrachloride is no longer used as a feedstock in Chemical Valley. This would need to be confirmed by the MOECC. As shown by (McCarthy et al., 2006) the cancer risk from carbon tetrachloride estimated in this study is in line with the average risk level found across the United States. 


\subsubsection{1,2-Dichloroethane}

1,2-dichloroethane had an estimated cancer risk of $1.81 \times 10^{-6}$. The US EPA estimated dose-response was from a study of male rats exposed via the oral route, which introduces both cross-species and cross-route uncertainty (U.S. Environmental Protection Agency, 1987). The TCEQ recently produced a dose-response curve estimate from an inhalation study of female rats with a slope 7.65 times lower than the EPA's estimation (Myers, 2016). When the TCEQ dose-response curve is applied to the mean 1,2dichloroethane concentration estimated in this thesis, the incremental lifetime cancer risk at the Aamjiwnaang monitor is $2.37 \times 10^{-7}$. Despite the cancer risk estimated at slightly higher than 1 x $10^{-6}$ using the EPA's inhalation unit risk, the concentration of 1,2Dichlorethane is much lower than found in some of the other studies of petroleum complexes where there appeared to be fugitive emissions (Cetin, Odabasi, \& Seyfioglu, 2003).

\subsubsection{Chromium}

Chromium's estimated lifetime incremental cancer risk was 9.1 x $10^{-6}$, however, there is a high degree of uncertainty with this estimate because of the large proportion on non-detect observations (60\%), the reporting of chromium in its elemental form and not in its most toxic species (chromium VI), and the use of a dose-response curve that has not been updated. Using the TCEQ’s inhalation unit risk, which was based on weighted results of two occupational studies that were not available at the time of the EPAs dose-response estimation (Haney, Erraguntla, Sielken, \& Valdez-Flores, 2014), the chromium cancer risk estimated at the Aamjiwnaang monitor is $1.74 \times 10^{-6}$. This lower estimate, in addition to the 
issues of speciation and non-detects create uncertainty with the risk estimate produced for this thesis, all in the direction of overestimating the cancer risk. Without speciated samples, it is difficult to understand the magnitude of this uncertainty, and the estimated incremental lifetime cancer risk of $9.1 \times 10^{-6}$ for chromium cannot be interpreted as a reliable estimate of the true health risk.

\subsubsection{PAHs}

The ILCR from PAHs was $4.91 \times 10^{-6}$, and this was calculated using Benzo[a]Pyrene as a surrogate for the entire PAH mixture. Although less commonly used in site-specific risk assessments than the toxic equivalency factor approach, it is based on a human occupational study of exposed coke-oven workers compared to the toxic equivalency factor approach, which is based on animal studies. Additionally there is debate as to whether the TEF approach underestimates risk compared to the surrogate whole-mixture approach (Boström et al., 2002; Pufulete et al., 2004).

One of the main sources of uncertainty in using $\mathrm{B}[\mathrm{a}] \mathrm{P}$ as an indicator of risk for the whole mixture of PAHs is that the environmental mixture may differ from the exposure mixture from which the dose-response curve was estimated. While this uncertainty could result in over or underestimation depending on the components of the mixture of interest, Petry, Schmid, \& Schlatter, (1996) demonstrated that the differences of mixtures of PAHs between different environments were relatively small, and would only effect risk estimates by a maximum factor 2.6 based on the environments considered in their study. Important to note is that the differences in all the environments surveyed resulted in greater risks than from the coke-oven environment, suggesting that the dose-response relationship from 
the coke-oven workers might underestimate risks. The results of a meta analysis of many occupational cohorts exposed to mixtures of PAHs published in Armstrong, Hutchinson, Unwin, \& Fletcher, (2004) indicate that the risks estimates based on coke-oven workers may overestimate the average risk across all occupational environments studied, however these results are not unexpected given the uncertainty involved in these studies.

Other sources of uncertainty in the assessment are the use of linear extrapolation in dose-response assessment and, that the concentrations of PAHs are estimated from the total suspended particulate, so it is unclear how much of the $\mathrm{PAH}$ and in particular $\mathrm{B}[\mathrm{a}] \mathrm{P}$ is from the respirable fraction. Additionally, since some of the values are below the method detection limit, this also introduces some uncertainty into the assessment. Although PAHs can be in both vapour and particle phase, the risks for this study are measured based on particulate, and especially for the fine fraction, particulate matter can be from local as well as transboundary sources.

\subsubsection{Criteria Air Contaminants}

That most of the criteria air contaminants fall in the orange area of the CCME's management system implies the need to reduce air concentrations in the area, at least partially on the basis of the reduction of health risk. This is particularly the case for ozone, which was in the red management zone for all years monitored. Unfortunately, due to the fact that regulatory agencies have not published concentration-response relationships for criteria air contaminants, and that dose-response relationships are not readily available in the scientific literature, it is not possible to quantify the risk of adverse health effects due to 
criteria air contaminants without extensive literature review that is beyond the scope of this thesis to conduct.

\subsubsection{Cumulative Exposure and Effects}

The results of this risk assessment show that at the Aamjiwnaang monitor, residents are exposed to many contaminants, which individually were measured at concentrations below those needed for chronic effects to manifest. For carcinogens, several were above the individual incremental lifetime cancer risk of $1 \times 10^{-6}$, however for all of these except Benzene, and Benzo[a]Pyrene (as a surrogate for PAHs), uncertainty as well as updates in dose-response assessment suggest that the cumulative cancer risk estimated at $3.33 \times 10^{-}$

5 should be interpreted with some caution. While cumulative hazard indexes are often calculated in risk assessments, there is little scientific basis for doing so, and it cannot be predicted whether this approach would over or underestimate the cumulative risk of these exposures (Callahan \& Sexton, 2007).

\subsection{Summary of Risk Characterization}

Most of the risk estimates in this thesis were either below traditional thresholds for concern within the risk-assessment community, or have updated dose-response curves that produce alternate risk estimates below these levels. Quantitative interpretation of criteria air contaminants is also limited by the lack of pre-established concentrationresponse curves, however the levels measured may merit future study.

The risk characterization discussed various sources of uncertainty, and showed that the location of the monitor, as well as uncertainty in high to low-dose extrapolation and 
exposure measurement in dose-response studies can have significant impacts on the risk estimates produced.

Given this discussion, the risk estimates for benzene and PAHs are above levels traditionally accepted for risk assessments but not by a large magnitude. 


\section{Chapter 6 Discussion}

\subsection{Summary, Response to Research Question \# 1}

The primary objective of this thesis was to use the Aamjiwnaang ambient air monitoring data to estimate health risk and determine whether emissions from multiple facilities in Chemical Valley result in increased risk to the population living nearby. For carcinogens, the results of the quantitative health risk assessment showed that for benzene, PAHs, and carbon tetrachloride, health risks were estimated above the 1 x 10-6 level, which has traditionally been considered a level of concern in health risk assessment. For 1,3-butadiene and 1,2-dichloroethane, the use of newer dose-response estimates reduced the ILCR from slightly above the $1 \times 10^{-6}$ to well below it.

Although it was beyond the scope of this thesis to assess criteria air contaminants with the same degree of precision as VOCs, metals and PAHs, all criteria air contaminants assessed were in CCME management zones for which reductions in concentrations are recommended, with ozone exceeding the highest guideline.

While these results suggest that the facilities in Chemical Valley are having an impact on air quality and resulting in health risk estimates above risk levels often used as standards in risk assessment, they are not significantly above these levels, making interpretation of the meaning of these risks difficult. This chapter will evaluate these results in the context of other air pollution hot spots, Ontario's risk-based policies and environmental conflicts in general. 


\subsubsection{Thesis Results relative to other Hotspots:}

Relative to other air pollution hotspots found in the literature review, the cumulative cancer risk measured in this thesis was lower by an order of magnitude (within the $1 \times 10^{-5}$ range compared to $1 \times 10^{-4}$ ), however, not all assumptions are the same across studies so the results aren't directly comparable. With the exception of Houston Texas, where benzene and cumulative cancer risk are both in the $1 \times 10^{-4}$ range in some locations, there were few air pollution hot spot studies where the incremental lifetime cancer risk attributed to Benzene was greater than $1 \times 10^{-5}$, despite traffic and industrial emissions being a significant source of benzene in many of these studies. That the cancer risk of benzene measured at the Aamjiwnaang monitor is in the same range as hotspots with significant traffic influence suggests that industry may be the important influence of health risk attributable to benzene for those living near Chemical Valley.

\subsection{Response to Research Question \# 2: Comparing Results to Ontario's Acceptable Risk Policies}

A secondary objective of this study was to examine Ontario's regulatory system to see if it has been effective in achieving its policy goals. Chapter 1 explained that although the MOECC has set out a risk-based environmental regulatory system, risk-based standards are applied only to a facility's modeled emissions plume and not the ambient air. This has led to questions as to whether emissions from multiple facilities would result in ambient air concentrations that put residents living near facilities at risk. The results from this thesis show that for Benzene and PAHs, incremental lifetime cancer risk was above $1 \times 10^{-6}$ with reasonable confidence in the assessments. When compared to Ontario's air quality standards, both benzene and benzo[a]pyrene exceed the standards. Since Ontario's risk- 
based regulatory system does not apply to ambient air, the legal implications of these exceedances are unclear, however, it appears that under Ontario's proposed regulation for cumulative effects, they will be considered acceptable.

As was discussed in the literature review section, understandings of "acceptable risk" are not universal, and an incremental cancer risk within the $1 \times 10^{-6}$ to $1 \times 10^{-5}$ range can be valued differently. Ontario's risk evaluation framework for air standards considers incremental lifetime cancer risk below $1 \times 10^{-6}$ as negligible risk, which is broadly acceptable (Ontario Ministry of the Environment and Climate Change, 2009). Risk levels greater than $1 \times 10^{-6}$ and up to $1 \times 10^{-4}$, are called the "region of concern". Applied to a facility's emissions, the region of concern is an area where a facility must take all reasonable steps to reduce its emissions to meet the $1 \times 10^{-6}$ standard, but which gives discretion to the MOECC to grant a facility an alternative standard. The alternative standard allows the facility to produce emissions above the $1 \times 10^{-6}$ standard but requires the facility to reduce its emissions to as low as reasonably achievable (ALARA) using technology benchmarking. This "region of concern" spans a 100-fold difference in risk estimates, and although there is no guidance to distinguish between risks at the lower and higher end of this range, it seems likely that the MOECC applies some discretion in setting and enforcing alternative standards over this 100 fold risk range.

Applied to Ontario's risk management framework, the results of this thesis are that the individual cancer risks due to benzene and PAHs fall at the lower end of the "region of concern". Given that ambient concentrations in Chemical Valley likely reflect emissions from more than one source, it is unclear whether ambient concentrations in the region of concern should trigger regulatory action by the MOECC. Although not yet adopted as a 
regulation, in November 2017, the MOECC proposed a regulatory framework for addressing cumulative effects from multiple facilities. The framework applies to two regions in Ontario: Sarnia/Corunna and Hamilton/Burlington. For Sarnia/Corunna, the framework applies to benzene only, and proposes using multi-facility air dispersion modelling to establish areas where ambient concentrations exceed Ontario's air quality standard (AAQC). For concentrations up to 10 times greater than the AAQC, no regulatory action is triggered except for "periodic evaluation by ministry". For concentrations that exceed the AAQC by 10 - 100 times, any new or expanding facility must include a technology benchmarking report in its application for an environmental compliance approval. There are several aspects of the proposed cumulative effects regulatory framework that imply the MOECC would not interpret the risks estimated in this thesis as requiring additional regulatory action. These are:

- The framework applies to new or expanding facilities only,

- The framework applies to benzene only,

- No action is required for the range of environmental concentrations measured in this thesis

Although this framework has not yet been adopted, as a statement of intention, it clearly communicates that although benzene and $\mathrm{B}[\mathrm{a}] \mathrm{P}$ levels are in the lower end of Ontario's "range of concern", the MOECC does not intend to take additional regulatory action.

\subsubsection{Emissions Reductions under Existing Regulations}

Should the MOECCs proposal to regulate cumulative effects be adopted and become law, it will not result in regulatory action to reduce emissions from currently operating 
facilities, but it is important to highlight that the years studied in this thesis occurred before the MOECCs risk-based benzene standard came into effect (July $1^{\text {st }} 2016$ ) for individual facilities. Seven facilities in Chemical Valley were not able to meet this standard and have been granted an alternative standard called the Petroleum Refining Technical standard, which encompasses technical requirements for reducing benzene emissions (Ontario Ministry of the Environment and Climate Change, 2016, 2017c). Given that these facilities are required to make technological improvements to reduce benzene emissions, benzene concentrations near Chemical Valley should fall over the coming years as a result of these requirements, and it will be important to verify this through monitoring. So while Ontario's proposal to regulate cumulative effects does not signify an intention to reduce the risk associated with benzene in the ambient air, regulatory measures already in effect, which apply to individual facilities' emissions may result in a reduction of benzene in the ambient air- assuming the technical measures in Ontario's Petrochemical Industry Standard are effective.

Additionally, PAHs were not included in the proposed regulatory framework and this is perhaps because PAHs are found in particulate matter, whose sources can be both local and trans-boundary, and since the cumulative effects framework uses modeled cumulative emissions, it likely does not include additional particulates from transboundary sources.

\subsection{Response to Research Questions \#2, \#3: Discussing Results Relative to Value- Concerns and Environmental Dispute Literature}

The results of this thesis demonstrate that although the location of the monitor creates some uncertainty for the population living closest to the facilities, the MOECC's 
regulation of Chemical Valley emissions has kept risk levels either below the province's negligible risk level, or at the lower end of the "area of concern" over the study period, and that new regulatory standards implemented on July $1^{\text {st }} 2016$ will likely reduce this risk. So although not perfect, overall, the MOECC appears to be achieving its risk related policy goals in the regulation of Chemical Valley. Within the risk-assessment, risk-management paradigm, therefore, it could be argued that despite some shortcomings, the MOECCs regulatory system is sufficiently protecting residents- however this is subject to discretion regarding the significance of risk within the $1 \times 10^{-5}$ to $1 \times 10^{-6}$ range.

Despite this, media reports critical of government regulation, including concerns over mismanagement expressed by the MOECC's own engineers have persisted—and this highlights an important question: why is there so much dissatisfaction with the MOECC when it appears to be meeting its risk-management policy goals? The literature review of environmental disputes hypothesizes that values such as fairness, and relationship factors such as trust, play a strong role in environmental conflict and that by excluding these factors, the risk-based framework itself may be exacerbating the conflict and resulting in unjust outcomes.

\subsubsection{Discussion of Results Within Criticism of the Risk Assessment - Risk Management Paradigm}

The literature review of the science-policy interface, environmental disputes and acceptable risks, predicted the outcome of this thesis relatively well in that it highlighted that science could not, by itself, either completely validate or repudiate the concerns of those involved in the environmental conflict. The risk assessment did not find excessively 
high risks, nor did it find risks to be at the "negligible" level— even by standards of "acceptable risk" within the traditional risk-management paradigm.

The dual meaning of risk as both a quantitative probability of occurrence based on evidence of physical phenomena, as well as intuitive reasoning based on values, implies that numerical statements of "acceptable risk" cannot be universal. This means that Ontario's policy of acceptable risk, may not match the values of those affected by the regulation of Chemical Valley. The risk-assessment - risk management paradigm therefore distributes risk to individuals or communities that they do not believe are acceptable. That this is an important feature of the conflict in Chemical Valley, is supported by early riskmanagement literature which prioritizes the ethical components of risk such as equity, consent and trust as being central drivers of a wide variety of risk-related social conflicts (Baxter, Eyles, \& Elliott, 1999; Bradbury, 1989; Gibbs, 1994; Jenkins-Smith \& Kunreuther, 2001; Otway \& Von Winterfeldt, 1982; Rayner \& Cantor, 1987; Slovic, 1993).

In 1987 Rayner and Cantor concisely summarized the importance of equity in risk management by transforming a familiar question in risk management, "how safe is safe enough?" into the question "how fair is safe enough?" This transformation captures the fact that for those involved in environmental conflict, values around "safe enough" are related to values about fairness. Research conducted by these authors found that constituencies in risk-related decisions are primarily concerned with the question: "Is the procedure by which collective consent is obtained for a course of action acceptable to those who must bear its consequences?"(Rayner \& Cantor, 1987). By this measure, regulation of the industrial facilities has clearly failed in Chemical Valley because the population living near 
facilities were never given opportunity to consent to development, and still do not have a share of decision-making power over regulation of the facilities that affect them.

\subsubsection{Managing uncertainty, fear and their impact on how to evaluate environmental policy}

Hammond, (2000) explains that when decisions are made involving risk and uncertainty, these decisions distribute both the quantitatively estimated risk, as well as the risk of errors in analysis and judgement due to uncertainty. For health risk assessment, this has been described as the risk of false negatives or false positives (Elliott \& Resnik, 2014). There are two implications of these insights with respect to these results: First, uncertainties in analysis, such as the monitor location, imposes a cost on those who bear this uncertainty. And this uncertainty has a cost on those individuals even if the expert judgement of a government scientist decides this uncertainty is not of a significant magnitude. The cost of this uncertainty is fear:

"Fear is a major impact of living in Chemical Valley. The applicants are continuously subjected to a vista of industrial facilities and the associated stacks, smells and sirens both from accidents and practice drills. Not only do they fear the daily, ongoing pollutant releases, the Applicants live in a constant state of emergency preparedness waiting for the next accidental release of dangerous levels of pollutants."

Lockridge et. al. vs. Ontario (2010)

This quote, from the notice of application by residents of Aamjiwnaang show that uncertainty is felt acutely, as fear, by the people involuntarily exposed to emissions. Therefore, in order to improve the situation for those exposed, uncertainty must be reduced in a meaningful way for them. Recent risk research, discussed earlier in this thesis, hypothesizes that risk has two components, both a rational and intuitive part, and that analytic reasoning cannot be effective unless it is guided by intuition (Slovic et al., 2004). 
Further, research has told us that this intuitive part of risk is experiential, and incorporates values such as fairness and trust. It seems clear from this research, and the experiential aspects of quote above, that the MOECC's regulatory system has failed to address aspects of the environmental dispute that matter for the population living near Chemical Valley, and that regulatory systems cannot be evaluated based on risk-levels alone. This result shows that the dispute in Chemical Valley aligns well with the large body of literature investigating environmental disputes, by confirming that environmental disputes occur when exposure to emissions are higher, but where risk-levels are not significantly higher than ranges considered acceptable by traditional risk-management policies.

\subsection{Environmental Racism and Indigenous Rights}

By permitting the emissions releases from Chemical Valley, Ontario's risk-based regulation allows for the distribution of the both estimated health risk, as well as the risk of errors in judgement to fall disproportionately on the residents living near the facilities. While the concentration of benzene at the Aamjiwnaang monitor is only slightly higher than the MOECCs standard for acceptable risk, it is the $6^{\text {th }}$ highest of 59 monitoring locations across Canada and two times higher than the concentrations measured in downtown Toronto (Galarneau et al., 2016; Ontario Ministry of the Environment and Climate Change, 2017c). Although the risk estimates produced by this thesis indicate ILCR in both locations are at the low end of the MOECCs area of concern $\left(9.1 \times 10^{-6}\right.$ in Aamjiwnaang compared to $4.6 \times 10^{-6}$ in Toronto), the qualitative differences of this risk are important to consider. 
That Ontario's risk management system continues to permit the distribution of risk and uncertainty disproportionately to an Indigenous population without its consent is particularly concerning. In the introduction, this thesis briefly discussed the court case in which applicants argued that Ontario's regulatory system enabled the burden of pollution to fall disproportionately on a First Nation's community. The results of this thesis reinforce this notion, because they show that the MOECC's regulation has allowed for higher exposure and higher risk to be distributed to an Indigenous population without its consent. A central insight from the literature review is that while quantitative differences in risk are important, so too are differences in fairness in who is exposed, and how they are exposed. This result needs to be discussed in the context of the environmental justice literature and colonialism, because it demonstrates that risk-based environmental policies can simultaneously result in risk-levels considered acceptable within the risk-management paradigm, while also authorizing the unequal distribution of risks and uncertainty to a community already subject to systemic oppression from the Canadian state and society at large. Further, since a central aspect of colonialism is the disruption of the connection between Indigenous peoples and their traditional land, the MOECCs acceptable risk policy can be seen to permit the continuation of this disruption if acceptable risk levels prevent residents from practicing their culture tied to the land (Arquette et al., 2002; Ranco \& Suagee, 2007; Richmond \& Ross, 2009; Torres, 1992; Westra, 1999; Wiebe, 2016b). Although the practice of risk assessment itself generates only technical estimates of risk, the way it fits into structural patterns of dominance and superiority of mainstream Canadian society over Indigenous peoples must be further examined. 


\subsection{Further Discussion and Improvements in MOECC Regulation in Chemical Valley}

Over the past 2 years, the MOECC has made several improvements to its air monitoring program of Chemical Valley including:

- The publication of mobile VOC monitoring data (Ontario Ministry of the Environment and Climate Change, 2017g),

- Upgrading the continuous VOC monitor at the Aamjiwnaang monitoring station, (Ontario Ministry of the Environment and Climate Change, 2017f)

- Increasing the frequency of 24 hour VOC sampling from every 12 days to every 6 days beginning in January 2016 (Aamjiwnaang First Nation, 2017)

- Introducing benzene emissions reductions and promising fence-line monitoring under the MOECCs petrochemical industry standard (Ontario Ministry of the Environment and Climate Change, 2017g)

All of these actions will hopefully reduce the quantitative health risk, as well as reduce uncertainty in estimating this risk in Chemical Valley. The MOECC has also reported that it has created a specialized team to work on monitoring and reducing risk due to Chemical Valley emissions, as well as communicating better with stakeholders (Ontario Ministry of the Environment and Climate Change, 2017f). These developments are positive efforts that should increase confidence and trust in the MOECC, while also resulting in reductions in health risk. They do not however, change the power relationship in the conflict for the residents near Chemical Valley because they still have no formal power to determine the risks to which they are exposed. 


\section{Chapter 7 Conclusion}

Using Ontario's Chemical Valley as a case study, this thesis investigated the use of the risk assessment - risk management paradigm in the regulation of an environmental conflict. The health risk associated with current ambient air concentrations of contaminants to the population living near Chemical Valley was estimated and compared to Ontario's policies for acceptable risk. No chemicals were close to established thresholds for chronic effects, however, benzene and PAHs had incremental lifetime cancer risks greater than 1 x 10-6; above Ontario's negligible risk level but below its upper limit where immediate regulatory action is required. Additionally, ozone exceeded the CCME's acceptable level and $\mathrm{PM}_{2.5}$ and $\mathrm{SO}_{2}$ were in the CCME's orange management level, which indicates pollutant levels should be reduced. Comparison of these results to Ontario's risk management policy showed that while above negligible levels, these risks only require discretionary regulatory action that does not guarantee reduction of risks to below Ontario's negligible levels.

The literature review in this thesis demonstrated that the second research question, regarding whether Ontario's regulatory system is sufficient to protect residents from combined facility emissions, involved two different definitions of risk: one quantitative and one qualitative. Based on the quantitative definition of risk, and acceptable risk levels conventionally used in the practice in risk assessment-risk management, risk levels estimated in this thesis are slightly above what is considered negligible for large populations, but not above levels which have traditionally resulted in immediate regulatory action. When environmental disputes are regulated based on quantitative criteria only, 
however, important value aspects of conflicts are excluded from consideration. Ontario's risk assessment - risk management based regulation of Chemical Valley, therefore, does not include important considerations such as Indigenous definitions of health, fairness, trust, the cost of uncertainty and errors in judgement, and the collective consent on behalf of those exposed to Chemical Valley emissions. The risk estimates generated by this thesis therefore do not provide a complete answer about the sufficiency of government regulation.

These findings helped answer the third research question: How does the practice of science in the regulation of Chemical Valley conform to its expected role based on theories of environmental disputes? The literature review hypothesized that science is a source of knowledge, as well as authority in environmental disputes, but also that science-based regulation can exclude important value components from decision-making and that this often contributes to conflict. This thesis makes contributions to research involving risk assessment and environmental policy by confirming this insight. An important factor referenced throughout this thesis is that many of the exposed individuals in Chemical Valley are Indigenous. Within the traditional risk assessment - risk management paradigm, this fact is not considered, however it is clearly an important aspect of this conflict. That Indigenous people are subject to historic and ongoing colonialism, have different conceptions of health, and have different relationships to land and the environment all suggest that the risk assessment - risk management paradigm, as practiced in Ontario fails to incorporate important values of the residents affected into policy making in Chemical Valley. That these residents have no formal means of incorporating their values in determining policy affecting their environment is an issue of justice, and may not be solved by more stringent risk-based regulation. 
Moving forward, this thesis has shown that the MOECC has taken important steps toward reducing air contaminant concentrations near Chemical Valley, and that these could result in reducing risk to levels considered negligible within the traditional risk management paradigm. Importantly however, this thesis has also demonstrated that the sufficiency of these reductions cannot be evaluated on the basis of science alone, and must also be evaluated based on how well it meets the needs of those exposed to Chemical Valley emissions. 


\section{Appendix 1: Assessment of continuous VOC monitor Data}

\section{Benzene:}

Below are several figures showing hourly benzene concentrations recorded at the Aamjiwnaang monitor. The figures show values below detection limit reported as zeros $(\mathrm{n}=8760$ per year, $87.32 \%$ non-detects in 2014). Because the experimental-grade continuous VOC monitor had an unknown method detection limit, this data could not be used to estimate long-term average concentration. The data shows a handful of incidents in each year during which concentrations at the monitor reached above $15 \mathrm{ppbv}$ or $48 \mu \mathrm{g} / \mathrm{m}^{3}$ $\left(1 \mathrm{ppb}=3.19 \mu \mathrm{g} / \mathrm{m}^{3}\right.$ assuming temp $=20^{\circ} \mathrm{C}$ and 1 atmosphere of pressure $)$. These spikes demonstrate the influence of industrial emissions, however, their impact on long-term concentrations is unclear because of the unknown method detection limit. Although these spikes are well below the EPAs acute exposure guideline levels ( $\mathrm{AEGL}$ Benzene $\left.=170 \mathrm{mg} / \mathrm{m}^{3}\right)$, a comprehensive assessment of acute effects from VOCs was beyond the scope of this thesis.

\section{Figure A1: 2014 Hourly Benzene Concentrations Recorded Aamjiwnaang Continuous VOC Monitor}

Benzene 2014

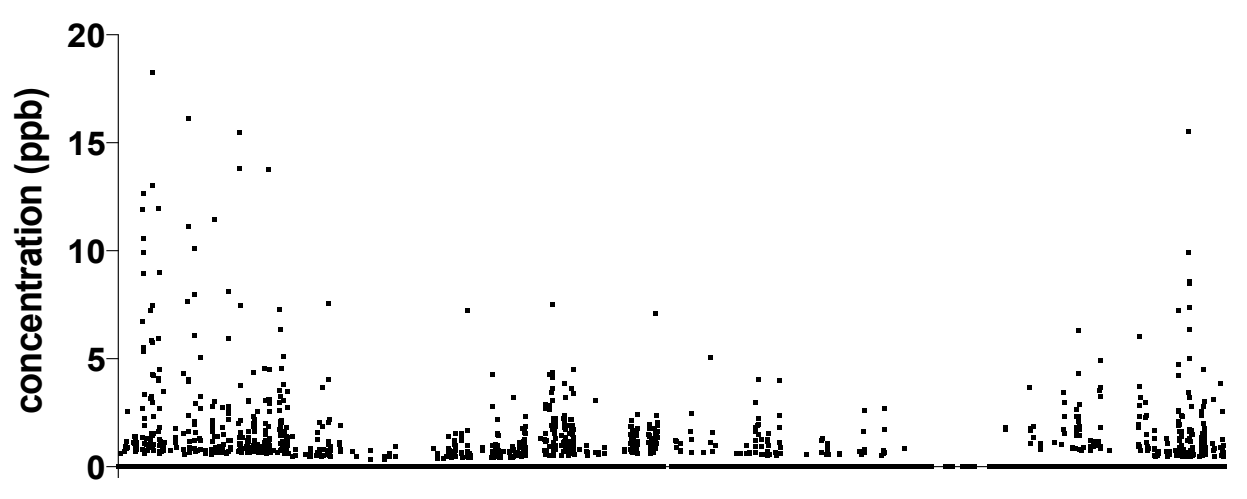

January 2014 - December 2014 
Figure A2: 2013 Hourly Benzene Concentrations Recorded Aamjiwnaang Continuous VOC Monitor

\section{Benzene 2013}

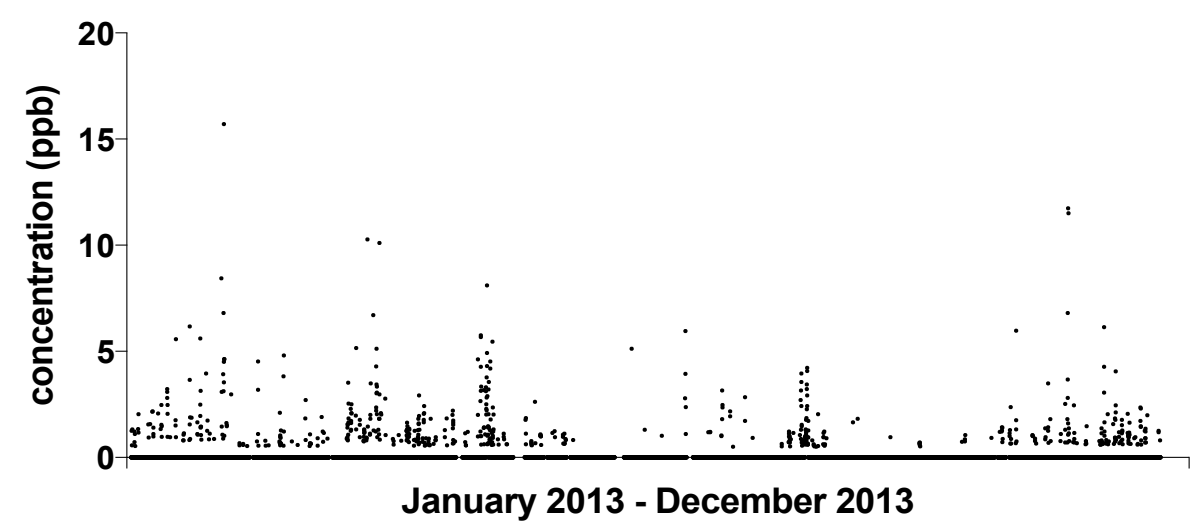

Figure A3: 2012 Hourly Benzene Concentrations Recorded Aamjiwnaang Continuous VOC Monitor

\section{Benzene 2012}

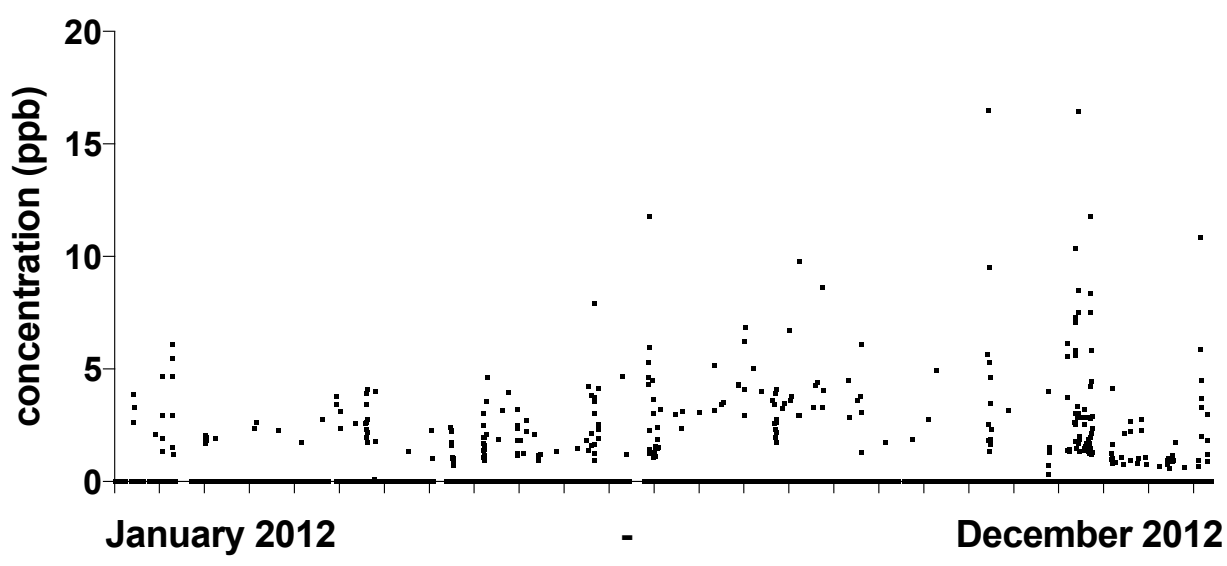

\section{1,3-butadiene:}

1,3-butadiene had very few values detected over the monitoring period, however, the presence of spikes, including on in which the maximum value reached $82.12 \mathrm{ppb}$ shows some industrial influence from leaks. 
Figure A4: 2014 and 2013 Hourly 1,3-butadiene Concentrations Recorded Aamjiwnaang Continuous VOC Monitor

1,3-butadiene 2014

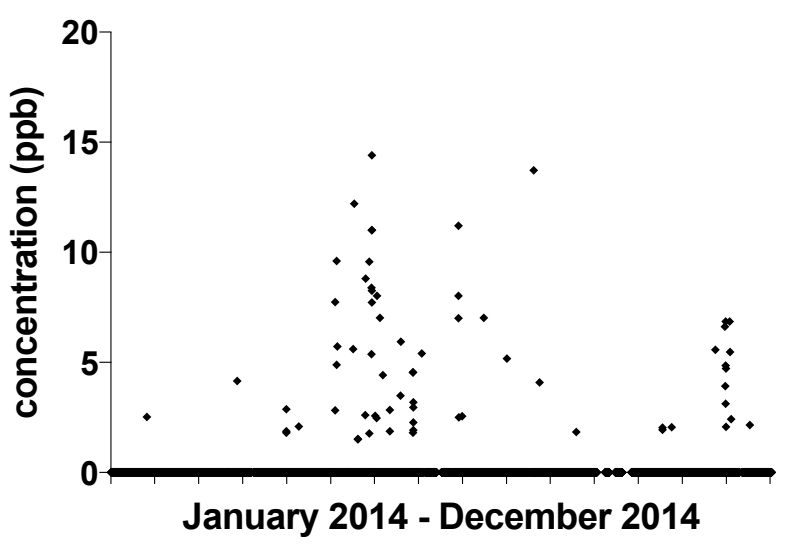

1,3-butadiene 2013

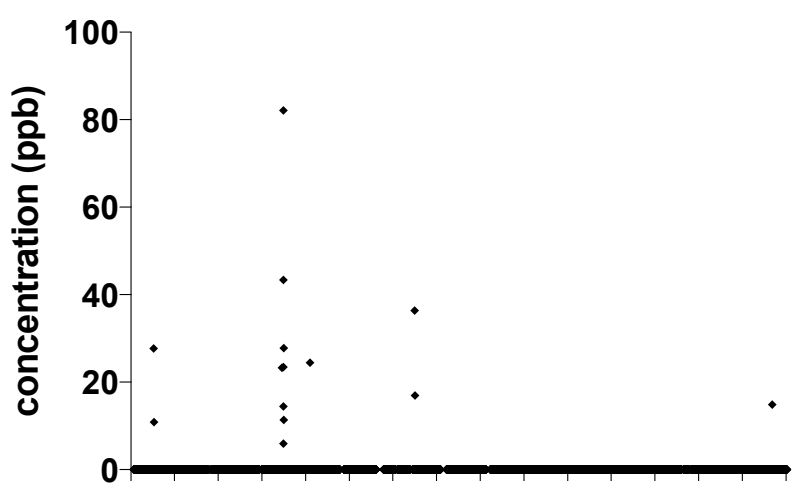

January 2013 - December 2013

\section{Summary of the MOECCs Mobile VOC Survey}

In 2015, the MOECC conducted a mobile VOC sampling program (see for detailed disscussion of methods Ontario Ministry of the Environment and Climate Change, 2017). The program took samples at 6 locations on the Aamjiwnaang reserve over a number of days. Table 1 below shows the results. The health centre is location of the Aamjiwnaang monitor, while the community centre is the location of the daycare. The administration building location represents the northern end of the reserve where there are some houses located along Tashmoo Ave. The concentrations are half-hour measurements and are not taken simultaneously but one after another. The results show that high concentrations of benzene were found at all three of these locations on two of the days, however, it is difficult to assess the extent to which the long-term Aamjiwnaang monitor is representative of longterm concentrations at other locations near Chemical Valley based on the data reported in the survey. 
Table A1: benzene concentrations measured in Ontario Ministry of the Environment and Climate Change, 2017

\begin{tabular}{|l|r|r|r|r|r|r|}
\hline \multicolumn{7}{|c|}{ Benzene (7) } \\
\hline All values in $\mathbf{~ g} / \mathbf{m}^{\mathbf{3}}$ \\
\hline Date & $\begin{array}{l}\text { Health } \\
\text { Centre }\end{array}$ & $\begin{array}{c}\text { Community } \\
\text { Centre }\end{array}$ & $\begin{array}{c}\text { Vidal St. } \\
\text { South }\end{array}$ & Cemetery & $\begin{array}{c}\text { Administration } \\
\text { Building }\end{array}$ & Scott Road \\
\hline 28-Jan & 15.88 & 17.20 & 20.07 & 25.08 & 29.04 & 10.16 \\
\hline 27-Feb & 11.40 & 12.56 & 17.69 & 6.99 & 12.63 & 4.55 \\
\hline 26-Mar & 2.25 & 1.16 & 9.89 & 1.70 & $\mathrm{n} / \mathrm{d}$ & 1.69 \\
\hline 29-Apr & 2.04 & 1.81 & 3.93 & 2.42 & 11.62 & 10.70 \\
\hline 22-May & 1.73 & $\mathrm{n} / \mathrm{d}$ & 0.97 & 0.36 & 10.44 & 1.54 \\
\hline 24-Jun & 0.86 & 0.70 & 5.57 & 0.47 & 0.55 & 3.25 \\
\hline 24-Jul & 1.65 & $\mathrm{n} / \mathrm{d}$ & 9.12 & 0.75 & 0.75 & 2.32 \\
\hline 27-Aug & $\mathrm{n} / \mathrm{d}$ & 1.44 & 15.18 & $\mathrm{n} / \mathrm{d}$ & $\mathrm{n} / \mathrm{d}$ & 9.57 \\
\hline 25-Sep & $\mathrm{n} / \mathrm{d}$ & $\mathrm{n} / \mathrm{d}$ & 6.23 & $\mathrm{n} / \mathrm{d}$ & $\mathrm{n} / \mathrm{d}$ & 0.38 \\
\hline 27-Oct & 4.30 & $\mathrm{n} / \mathrm{d}$ & 4.12 & $\mathrm{n} / \mathrm{d}$ & $\mathrm{n} / \mathrm{d}$ & 2.39 \\
\hline 20-Nov & $\mathrm{n} / \mathrm{d}$ & $\mathrm{n} / \mathrm{d}$ & $\mathrm{n} / \mathrm{d}$ & $\mathrm{n} / \mathrm{d}$ & $\mathrm{n} / \mathrm{d}$ & $\mathrm{n} / \mathrm{d}$ \\
\hline 18-Dec & 1.20 & 4.26 & $\mathrm{n} / \mathrm{d}$ & 0.17 & $\mathrm{n} / \mathrm{d}$ & $\mathrm{n} / \mathrm{d}$ \\
\hline
\end{tabular}


Figure A5: MOECC 2015 mobile monitoring survey locations.

Source: (Ontario Ministry of the Environment and Climate Change, 2017g)

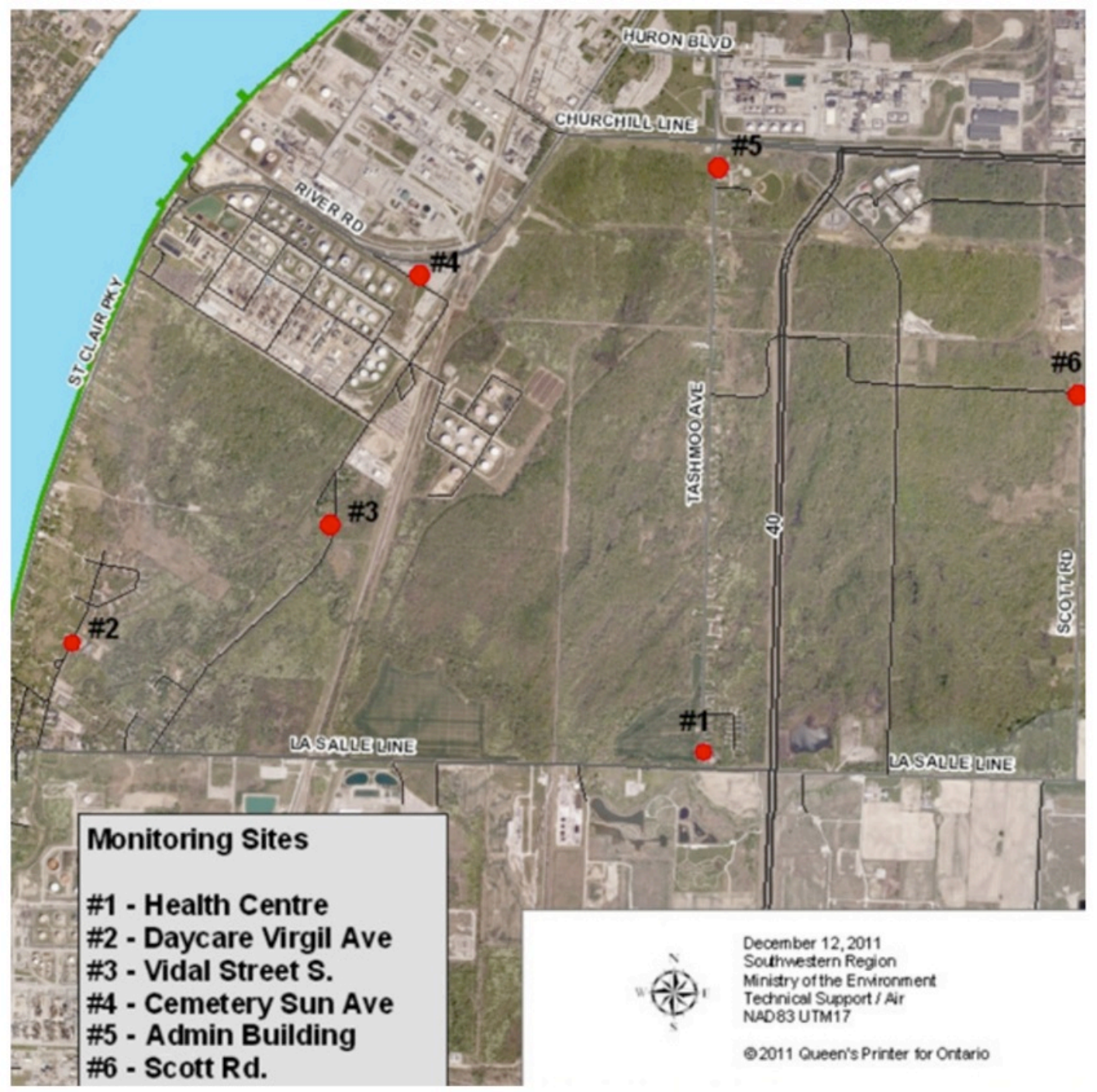




\section{Reference List:}

Aamjiwnaang Environment. (2010). Community History. Retrieved from http://www.aamjiwnaangenvironment.ca/history.html

Aamjiwnaang First Nation. (2017). Air Monitoring Reports. Retrieved January 2, 2017, from http://www.aamjiwnaang.ca/air-monitoring/

Agency for Toxic Substances and Disease Registry. (2013). Polycyclic Aromatic Hydrocarbons (PAHs).

Almanza, V. H., Molina, L. T., \& Sosa, G. (2012). Soot and $\mathrm{SO}_{2}$ contribution to the supersites in the MILAGRO campaign from elevated flares in the Tula Refinery. Atmos. Chem. Phys., 12(21), 10583-10599. https://doi.org/10.5194/acp-12-10583-2012

Armstrong, B., Hutchinson, E., Unwin, J., \& Fletcher, T. (2004). Lung Cancer Risk after Exposure to Polycyclic Aromatic Hydrocarbons: A Review and Meta-Analysis. Environmental Health Perspectives, 112(9), 970-978. https://doi.org/10.1289/ehp.6895

Arquette, M., Cole, M., Cook, K., LaFrance, B., Peters, M., Ransom, J., ... Stairs, A. (2002). Holistic risk-based environmental decision making: a Native perspective. Environmental Health Perspectives, 110(Suppl 2), 259-264. Retrieved from http://www.ncbi.nlm.nih.gov/pmc/articles/PMC1241171/

Atari, D. O. (2008). Spatial Variability of Ambient Nitrogen Dioxide and Sulfur Dioxide in Sarnia, "Chemical Valley," Ontario, Canada, 71(24), 1572-1581. Retrieved from http://resolver.scholarsportal.info/resolve/15287394/v71i0024/1572_svoanddisvoc .xml

Baltrènas, P., Baltrènaitė, E., Šerevičienė, V., \& Pereira, P. (2011). Atmospheric BTEX concentrations in the vicinity of the crude oil refinery of the Baltic region. Environmental Monitoring and Assessment, 182(1), 115-127. https://doi.org/10.1007/s10661-010-1862-0

Batterman, S., Su, F.-C., Li, S., Mukherjee, B., \& Jia, C. (2014). Personal Exposure to Mixtures of Volatile Organic Compounds: Modeling and Further Analysis of the RIOPA Data. Research Report (Health Effects Institute), (181), 3-63. Retrieved from http://www.ncbi.nlm.nih.gov/pmc/articles/PMC4577247/

Baxter, J. W., Eyles, J. D., \& Elliott, S. J. (1999). From Siting Principles to Siting Practices: A Case Study of Discord among Trust, Equity and Community Participation. Journal of Environmental Planning and Management, 42(4), 501-525. https://doi.org/10.1080/09640569911037

Bosco, M. L., Varrica, D., \& Dongarrà, G. (2005). Case study: Inorganic pollutants associated with particulate matter from an area near a petrochemical plant. Environmental Research, 99(1), 18-30. https://doi.org/http://dx.doi.org/10.1016/j.envres.2004.09.011

Boström, C.-E., Gerde, P., Hanberg, A., Jernström, B., Johansson, C., Kyrklund, T., ... Westerholm, R. (2002). Cancer risk assessment, indicators, and guidelines for polycyclic aromatic hydrocarbons in the ambient air. Environmental Health Perspectives, 110(Suppl 3), 451-488. Retrieved from http://www.ncbi.nlm.nih.gov/pmc/articles/PMC1241197/ 
Bradbury, J. A. (1989). The Policy Implications of Differing Concepts of Risk. Science, Technology, \& Human Values, 14(4), 380-399. https://doi.org/10.1177/016224398901400404

Brain, J., Kreyling, W., \& Godleski, J. (2014). Inhalation Toxicology. In W. Hayes \& C. Kruger (Eds.), Hayes' Principles and Methods of Toxicology (6th ed., pp. 1407-1465). CRC Press. Retrieved from https://www.crcpress.com/Hayes-Principles-and-Methods-ofToxicology-Sixth-Edition/Hayes-Kruger/p/book/9781842145364

Brown, J. S. (2009). Acute Effects of Exposure to Ozone in Humans. American Journal of Respiratory and Critical Care Medicine, 180(3), 200-201. https://doi.org/10.1164/rccm.200906-0834ED

Brown, J. S., Gordon, T., Price, O., \& Asgharian, B. (2013). Thoracic and respirable particle definitions for human health risk assessment. Particle and Fibre Toxicology, 10(1), 12. https://doi.org/10.1186/1743-8977-10-12

Burke, T. A. (2003). The Red Book and the Practice of Environmental Public Health: Promise, Pitfalls, and Progress. Human and Ecological Risk Assessment: An International Journal, 9(5), 1203-1211. https://doi.org/10.1080/10807030390247169

Buzcu, B., \& Fraser, M. P. (2006). Source identification and apportionment of volatile organic compounds in Houston, TX. Atmospheric Environment, 40(13), 2385-2400. https://doi.org/https://doi.org/10.1016/j.atmosenv.2005.12.020

Calebrese, E. J. (2014). Dose-Response: A Fundamental Concept in Toxicology. In C. Hayes, A. Wallace, Kruger (Ed.), Hayes' Principles and Methods of Toxicology (6th Ed., pp. 90132). London: CRC Press.

California Air Resources Board. (2017). Glossary. Retrieved October 29, 2017, from https://ww2.arb.ca.gov/about/glossary?f\%5B0\%5D=name\%3AT\#search_anchor

Callahan, M. A., \& Sexton, K. (2007). If Cumulative Risk Assessment Is the Answer, What Is the Question? Environmental Health Perspectives, 115(5), 799-806. https://doi.org/10.1289/ehp.9330

Canadian Council of Ministers of the Environment. (2012). Guidance Document on Achievement Determination Canadian Ambient Air Quality Standards for fine Particulate Matter and Ozone. Winnipeg. Retrieved from https://www.ccme.ca/files/Resources/air/aqms/pn_1483_gdad_eng.pdf

Caussy, D., Gochfeld, M., Gurzau, E., Neagu, C., \& Ruedel, H. (2003). Lessons from case studies of metals: investigating exposure, bioavailability, and risk. Ecotoxicology and Environmental Safety, 56(1), 45-51. https://doi.org/https://doi.org/10.1016/S01476513(03)00049-6

Cetin, E., Odabasi, M., \& Seyfioglu, R. (2003). Ambient volatile organic compound (VOC) concentrations around a petrochemical complex and a petroleum refinery. Science of The Total Environment, 312(1), 103-112. https://doi.org/http://dx.doi.org/10.1016/S0048-9697(03)00197-9

Chen, C.-L., Fang, H. Y., \& Shu, C.-M. (2005). Source Location and Characterization of Volatile Organic Compound Emissions at a Petrochemical Plant in Kaohsiung, Taiwan. Journal of the Air \& Waste Management Association, 55(10), 1487-1497. https://doi.org/10.1080/10473289.2005.10464741

Cheng, L., Fu, L., Angle, R. P., \& Sandhu, H. S. (1997). Seasonal variations of volatile organic 
compounds in Edmonton, Alberta. Atmospheric Environment, 31(2), 239-246.

https://doi.org/http://dx.doi.org/10.1016/1352-2310(96)00170-7

Cheremisinoff, N. P. (2002). Handbook of Air Pollution and Control. Woburn, MA: Elsevier Science.

Chow, J., \& Watson, J. (1998). Guideline on Speciated Particulate Monitoring. Research Triangle Park. Retrieved from https://www3.epa.gov/ttnamti1/files/ambient/pm25/spec/drispec.pdf

Comission of European Communities. (1998). Council Directive on Ambient Air Quality Assessment and Management Working Group on Benzene: Position Paper. Retrieved from http://ec.europa.eu/environment/air/pdf/ppbenzene.pdf

Covello, V. T., \& Merkhofer, M. W. (1993). Risk assessment methods : approaches for assessing health and environmental risks. New York: Plenum Press.

Crump, K. S. (1998). On Summarizing Group Exposures in Risk Assessment: Is an Arithmetic Mean or a Geometric Mean More Appropriate? Risk Analysis, 18(3), 293297. https://doi.org/10.1111/j.1539-6924.1998.tb01296.x

Crump, K. S. (2011). Use of threshold and mode of action in risk assessment. Critical Reviews in Toxicology, 41(8), 637-650.

https://doi.org/10.3109/10408444.2011.566258

Crump, K. S., Hoel, D. G., Langley, C. H., \& Peto, R. (1976). Fundamental Carcinogenic Processes and Their Implications for Low Dose Risk Assessment. Cancer Research, 36(9 Part 1), 2973 LP-2979. Retrieved from http://cancerres.aacrjournals.org/content/36/9_Part_1/2973.abstract

Cuclis, A. (2012). Why Emission Factors Don't Work at Refineries and What to do about it. In International Emissions Inventory Conference (p. 41). Tampa, Florida. Retrieved from https://www3.epa.gov/ttnchie1/conference/ei20/session7/acuclis.pdf

Cumming, R. B. (1981). Is Risk Assessment A Science? Risk Analysis, 1(1), 1-3. https://doi.org/10.1111/j.1539-6924.1981.tb01347.x

Dann, T. (2016). Integration of 2015 Odour Data for the Wood Buffalo Environmental Association (WBEA) Human Exposure Monitoring Program (HEMP). Ottawa.

Dayan, A. D., \& Paine, A. J. (2001). Mechanisms of chromium toxicity, carcinogenicity and allergenicity: Review of the literature from 1985 to 2000 . Human \& Experimental Toxicology, 20(9), 439-451. https://doi.org/10.1191/096032701682693062

Durie, M. (2004). Understanding health and illness: research at the interface between science and indigenous knowledge†. International Journal of Epidemiology, 33(5), 1138-1143. Retrieved from http://dx.doi.org/10.1093/ije/dyh250

Elliott, K. C., \& Resnik, D. B. (2014). Science, Policy, and the Transparency of Values. Environmental Health Perspectives, 122(7), 647-650. https://doi.org/10.1289/ehp.1408107

Environmental Commissioner of Ontario. (2014a). Managing New Challenges: Annual Report 2013/2014. Toronto. Retrieved from http://docs.assets.eco.on.ca/reports/environmental-protection/2013-2014/2013-14AR.pdf\#page $=116$

Environmental Commissioner of Ontario. (2014b). Managing New Challenges: Annual Report 2013/2014 Supplement. Toronto. Retrieved from 
http://docs.assets.eco.on.ca/reports/environmental-protection/2013-2014/2013-14AR-Supp.pdf

Fann, N., Gilmore, E. A., \& Walker, K. (2016). Characterizing the Long-Term PM2.5 Concentration-Response Function: Comparing the Strengths and Weaknesses of Research Synthesis Approaches. Risk Analysis, 36(9), 1693-1707. https://doi.org/10.1111/risa.12435

Finkel, A. M. (1989). Is Risk Assessment Really Too Conservative: Revising the Revisionists Symposium: Risk Assessment in Environmental Law. Columbia Journal of Environmental Law.

Flowers, L., Rieth, S. H., Cogliano, V. J., Foureman, G. L., Hertzberg, R., Hofmann, E. L., ... Schoeny, R. S. (2002). Health Assessment of Polycyclic Aromatic Hydrocarbon Mixtures: Current Practices and Future Directions. Polycyclic Aromatic Compounds, 22(3-4), 811-821. https://doi.org/10.1080/10406630290103960

Galarneau, E., Wang, D., Dabek-Zlotorzynska, E., Siu, M., Celo, V., Tardif, M., ... Jiang, Y. (2016). Air toxics in Canada measured by the National Air Pollution Surveillance (NAPS) program and their relation to ambient air quality guidelines. Journal of the Air \& Waste Management Association, 66(2), 184-200.

https://doi.org/10.1080/10962247.2015.1096863

Gibbs, L. (1994). Risk assessments from a community perspective. Environmental Impact Assessment Review, 14(5), 327-335. https://doi.org/https://doi.org/10.1016/01959255(94)90004-3

Gilbert, R. O. (1987). Statistical Methods for Environmental Pollution Monitoring. New York: Van Nostrand Reinhold Company Inc.

Ginsberg, G., Foos, B., Dzubow, R. B., \& Firestone, M. (2010). Options for incorporating children's inhaled dose into human health risk assessment. Inhalation Toxicology, 22(8), 627-647. https://doi.org/10.3109/08958371003610958

Graf, C. (2017, July 14). Indigenous Woman Suing Ontario Over "Chemical Valley" Pollution. Vice. Toronto.

Grant, C., R. Bloxam, S. G. (2009). Managing air pollution impacts to protect local air quality. WIT Transactions on Ecology and the Environment, 123, 141-150.

Greenwood, T. (1984). The Myth of Scientific Incompetence of Regulatory Agencies. Science, Technology, \& Human Values, 9(1), 83-96. Retrieved from http://www.jstor.org/stable/688995

Haller, S. F., \& Gerrie, J. (2007). The Role of Science in Public Policy: Higher Reason, or Reason for Hire? Journal of Agricultural and Environmental Ethics, 20(2), 139-165. https://doi.org/10.1007/s10806-006-9027-4

Hammond, K. R. (2000). Human judgment and social policy: Irreducible uncertainty, inevitable error, unavoidable injustice. Oxford University Press on Demand.

Haney, J. T., Erraguntla, N., Sielken, R. L., \& Valdez-Flores, C. (2014). Development of an inhalation unit risk factor for hexavalent chromium. Regulatory Toxicology and Pharmacology, 68(2), 201-211.

https://doi.org/https://doi.org/10.1016/j.yrtph.2013.12.005

Health Canada. (2010). Guidance on Human Health Detailed Quantitative Risk Assessment For Chemicals. Ottawa.

Health Canada. (2016). Human Health Risk Assessment for Ambient Nitrogen Dioxide. 
Ottawa. Retrieved from http://publications.gc.ca/collections/collection_2016/schc/H114-31-2016-eng.pdf

Hoyt, D., \& Raun, L. H. (2015). Measured and estimated benzene and volatile organic carbon (VOC) emissions at a major U.S. refinery/chemical plant: Comparison and prioritization. Journal of the Air \& Waste Management Association, 65(8), 1020-1031. https://doi.org/10.1080/10962247.2015.1058304

Hsu, Y.-M., Harner, T., Li, H., \& Fellin, P. (2015). PAH Measurements in Air in the Athabasca Oil Sands Region. Environmental Science \& Technology, 49(9), 5584-5592. https://doi.org/10.1021/acs.est.5b00178

Hu, L., Montzka, S. A., Miller, B. R., Andrews, A. E., Miller, J. B., Lehman, S. J., ... Tans, P. (2016). Continued emissions of carbon tetrachloride from the United States nearly two decades after its phaseout for dispersive uses. Proceedings of the National Academy of Sciences , 113(11), 2880-2885. Retrieved from http://www.pnas.org/content/113/11/2880.abstract

Infante, P. F. (2013). Benzene and leukemia, Pliofilm Revisited: I. An historical review of the leukemia deaths among Akron Goodyear Tire and Rubber Company Employees. International Journal of Occupational and Environmental Health, 19(3), 215-222. https://doi.org/10.1179/2049396713Y.0000000029

Jackson, D. D. (2010). Shelter in place : a First Nation community in Canada's Chemical Valley. Interdisciplinary Environmental Review, 11(4), 249-262.

Jarvis, I. W. H., Dreij, K., Mattsson, Å., Jernström, B., \& Stenius, U. (2014). Interactions between polycyclic aromatic hydrocarbons in complex mixtures and implications for cancer risk assessment. Toxicology, 321(Supplement C), 27-39. https://doi.org/https://doi.org/10.1016/j.tox.2014.03.012

Jasanoff, S. (1990). The Fifth Branch: Science Advisers as Policymakers. Cambridge: Harvard University Press.

Jenkins-Smith, H., \& Kunreuther, H. (2001). Mitigation and Benefits Measures as Policy Tools for Siting Potentially Hazardous Facilities: Determinants of Effectiveness and Appropriateness. Risk Analysis, 21(2), 371-382. https://doi.org/10.1111/02724332.212118

Jia, C., Batterman, S., \& Godwin, C. (2008). VOCs in industrial, urban and suburban neighborhoods, Part 1: Indoor and outdoor concentrations, variation, and risk drivers. Atmospheric Environment, 42(9), 2083-2100. https://doi.org/https://doi.org/10.1016/j.atmosenv.2007.11.055

Jia, C., D’Souza, J., \& Batterman, S. (2008). Distributions of personal VOC exposures: A population-based analysis. Environment International, 34(7), 922-931. https://doi.org/https://doi.org/10.1016/j.envint.2008.02.002

Jia, C., \& Foran, J. (2013). Air toxics concentrations, source identification, and health risks: An air pollution hot spot in southwest Memphis, TN. Atmospheric Environment, 81, 112-116. https://doi.org/https://doi.org/10.1016/j.atmosenv.2013.09.006

Jobson, B. T., Berkowitz, C. M., Kuster, W. C., Goldan, P. D., Williams, E. J., Fesenfeld, F. C., ... Riemer, D. (2004). Hydrocarbon source signatures in Houston, Texas: Influence of the petrochemical industry. Journal of Geophysical Research: Atmospheres, 109(D24), n/an/a. https://doi.org/10.1029/2004JD004887

Johansson, J. K. E., Mellqvist, J., Samuelsson, J., Offerle, B., Lefer, B., Rappenglück, B., ... 
Yarwood, G. (2014). Emission measurements of alkenes, alkanes, SO2, and NO2 from stationary sources in Southeast Texas over a 5 year period using SOF and mobile DOAS. Journal of Geophysical Research: Atmospheres, 119(4), 1973-1991. https://doi.org/10.1002/2013JD020485

Kalabokas, P. D., Hatzianestis, J., Bartzis, J. G., \& Papagiannakopoulos, P. (2001). Atmospheric concentrations of saturated and aromatic hydrocarbons around a Greek oil refinery. Atmospheric Environment, 35(14), 2545-2555. https://doi.org/https://doi.org/10.1016/S1352-2310(00)00423-4

Kelly, K. E. (1991). The myth of $10^{\wedge}(-6)$ as a definition of acceptable risk. In 84th annual meeting of the Air and Waste Management Association, Vancouver, BC, Canada. www. deltatoxicology. com/pdf/10-6. pdf (accessed 31/10/07).

Kentel, E., \& Aral, M. M. (2004). Probabilistic-fuzzy health risk modeling. Stochastic Environmental Research and Risk Assessment, 18(5), 324-338. https://doi.org/10.1007/s00477-004-0187-3

Koehler, J. J. (1993). The Influence of Prior Beliefs on Scientific Judgments of Evidence Quality. Organizational Behavior and Human Decision Processes, 56(1), 28-55. https://doi.org/http://dx.doi.org/10.1006/obhd.1993.1044

Koppenjan, J. F. M., \& Klijn, E.-H. (2004). Managing uncertainties in networks: a network approach to problem solving and decision making. Psychology Press.

Kotaś, J., \& Stasicka, Z. (2000). Chromium occurrence in the environment and methods of its speciation. Environmental Pollution, 107(3), 263-283. https://doi.org/https://doi.org/10.1016/S0269-7491(99)00168-2

Kraus, N., Malmfors, T., \& Slovic, P. (1992). Intuitive Toxicology: Expert and Lay Judgments of Chemical Risks. Risk Analysis, 12(2), 215-232. https://doi.org/10.1111/j.15396924.1992.tb00669.x

Lambton Community Health Study Board. (2010). Systemic Literature of Health Outcomes Associated With Living in Proximity to Petrochemical Facilities. County of Lambton.

Lin, T.-Y., Sree, U., Tseng, S.-H., Chiu, K. H., Wu, C.-H., \& Lo, J.-G. (2004). Volatile organic compound concentrations in ambient air of Kaohsiung petroleum refinery in Taiwan. Atmospheric Environment, 38(25), 4111-4122. https://doi.org/https://doi.org/10.1016/j.atmosenv.2004.04.025

MacDonald, E., \& Rang, S. (2007). Exposing Canada's Chemical Valley. Toronto. Retrieved from http://www.environmentalhealthnews.org/ehs/news/2012/2007-study.pdf

Mackenzie, C. A., Lockridge, A., \& Keith, M. (2005). Declining Sex Ratio in a First Nation Community. Environmental Health Perspectives, 113. https://doi.org/10.1289/ehp.8479

Mathewson, G. (2001, December 29). Water quality better in 2001: Air emissions were also lower during the past year. Sarnia Observer. Sarnia.

Mathewson, G. (2004). On the Front Line: Aamjiwnaang emergency response planner. Sarnia Observer. Sarnia. Retrieved from http://ezproxy.lib.ryerson.ca/login?url=https://search-proquestcom.ezproxy.lib.ryerson.ca/docview/348184142?accountid=13631

McCarthy, M. C., Hafner, H. R., \& Montzka, S. A. (2006). Background Concentrations of 18 Air Toxics for North America. Journal of the Air \& Waste Management Association, 56(1), 311. https://doi.org/10.1080/10473289.2006.10464436 
McClellan, R. O. (1999). KEYNOTE ADDRESS: HUMAN HEALTH RISK ASSESSMENT: A Historical Overview and Alternative Paths Forward. Inhalation Toxicology, 11(6-7), 477-518. https://doi.org/10.1080/089583799196880

McClellan, R. O. (2012). Role of science and judgment in setting national ambient air quality standards: how low is low enough? Air Quality, Atmosphere \& Health, 5(2), 243-258. https://doi.org/10.1007/s11869-011-0147-2

McCoy, B. J., Fischbeck, P. S., \& Gerard, D. (2010). How big is big? How often is often? Characterizing Texas petroleum refining upset air emissions. Atmospheric Environment, 44(34), 4230-4239. https://doi.org/http://dx.doi.org/10.1016/j.atmosenv.2010.07.008

McGarity, T. O. (2015). Science and Policy in Setting National Ambient Air Quality Standards: Resolving the Ozone Enigma Symposium: Science Challenges for Law and Policy. Texas Law Review.

McHale, C. M., Zhang, L., \& Smith, M. T. (2012). Current understanding of the mechanism of benzene-induced leukemia in humans: implications for risk assessment. Carcinogenesis, 33(2), 240-252. Retrieved from http://dx.doi.org/10.1093/carcin/bgr297

McIntosh, E. (2017a). Province to fund health study examining air pollution effects of Sarnia's Chemical Valley. Toronto Star. Toronto. Retrieved from https://www.thestar.com/news/canada/2017/10/16/province-to-fund-healthstudy-examining-air-pollution-effects-of-sarnias-chemical-valley.html

McIntosh, E. (2017b, October 17). Ontario government ignored health warnings from its own engineers about Sarnia's Chemical Valley, report claims. Toronto Star. Toronto. Retrieved from https://www.thestar.com/news/canada/2017/10/17/ontariogovernment-ignored-health-warnings-from-its-own-engineers-about-sarniaschemical-valley-report-claims.html

Mclaren, R., Liu, P. S. K., Brien, J. O., Mittermeier, R. L., Zhang, J., \& Marson, G. (2017). Differences between measured and reported volatile organic compound emissions from oil sands facilities. https://doi.org/10.1073/pnas.1617862114

Michaels, D. (2008). Doubt is their product: how industry's assault on science threatens your health. Oxford ; New York : Oxford University Press, 2008. Retrieved from https://search.library.wisc.edu/catalog/9910059325402121

Miller, L., Xu, X., \& Luginaah, I. (2009). Spatial Variability of Volatile Organic Compound Concentrations in Sarnia, Ontario, Canada. Journal of Toxicology and Environmental Health, Part A, 72(9), 610-624. https://doi.org/10.1080/15287390802706413

Miller, L., Xu, X., Wheeler, A., Atari, D. O., Grgicak-Mannion, A., \& Luginaah, I. (2011). Spatial variability and application of ratios between BTEX in two Canadian cities. TheScientificWorldJournal, 11, 2536-49. https://doi.org/10.1100/2011/167973

Miron, I., \& MacDonald, E. (2015). Charge laid against Shell Canada for refinery spill in "Chemical Valley." Retrieved October 21, 2017, from https://www.ecojustice.ca/charge-laid-against-shell-canada-for-refinery-spill-inchemical-valley/

Mo, Z., Shao, M., Lu, S., Qu, H., Zhou, M., Sun, J., \& Gou, B. (2015). Process-specific emission characteristics of volatile organic compounds (VOCs) from petrochemical facilities in the Yangtze River Delta, China. Science of The Total Environment, 533, 422-431. 
https://doi.org/https://doi.org/10.1016/j.scitotenv.2015.06.089

Murphy, C. F., \& Allen, D. T. (2005). Hydrocarbon emissions from industrial release events in the Houston-Galveston area and their impact on ozone formation. Atmospheric Environment, 39(21), 3785-3798. https://doi.org/https://doi.org/10.1016/j.atmosenv.2005.02.051

Myers, J. L. (2016). Development of an inhalation unit risk factor for ethylene dichloride. Inhalation Toxicology, 28(9), 403-409. https://doi.org/10.1080/08958378.2016.1188187

Nadal, M., Schuhmacher, M., \& Domingo, J. L. (2007). Levels of metals, PCBs, PCNs and PAHs in soils of a highly industrialized chemical/petrochemical area: Temporal trend. Chemosphere, 66(2), 267-276. https://doi.org/http://dx.doi.org/10.1016/j.chemosphere.2006.05.020

Nam, J., Webster, M., Kimura, Y., Jeffries, H., Vizuete, W., \& Allen, D. T. (2008). Reductions in ozone concentrations due to controls on variability in industrial flare emissions in Houston, Texas. Atmospheric Environment, 42(18), 4198-4211. https://doi.org/https://doi.org/10.1016/j.atmosenv.2008.01.035

National Research Council. (1983). Risk Assessment in the Federal Government: Managing the Process. (C. on the I. M. for A. of R. To, P. Health, \& C. on L. Sciences, Eds.). Washington, DC: National Research Council.

National Research Council. (1997). Environmental Epidemiology, Volume 2. Washington, DC: The National Acadamies Press. Retrieved from https://doi.org/10.17226/5804

National Research Council. (2011). Weight-of-Evidence Descriptions from US Environmental Protection Agency Guidelines. Washington, DC: National Academies Press (US). Retrieved from https://www.ncbi.nlm.nih.gov/books/NBK208232/\#ddd00159

Oiamo, T. H., Luginaah, I. N., Atari, D. O., \& Gorey, K. M. (2011). Air pollution and general practitioner access and utilization: a population based study in Sarnia, "Chemical Valley," Ontario. Environmental Health : A Global Access Science Source, 10(1), 71. https://doi.org/10.1186/1476-069X-10-71

Ontario Ministry of the Environment and Climate Change. (2007). Ontario Air Standard For Total Reduced Sulphur. Toronto. Retrieved from http://www.ontla.on.ca/library/repository/mon/20000/277839.pdf

Ontario Ministry of the Environment and Climate Change. (2009). Guideline for Implementation of Air Standards in Ontario. Toronto.

Ontario Ministry of the Environment and Climate Change. (2016). Petrochemical Industry Standard Under Ontario's Local Air Quality Regulation: Background and Rationale Document.

Ontario Ministry of the Environment and Climate Change. (2017a). Guideline A-10: Procedure for Preparing an Emission Summary and Dispersion Modelling (ESDM) Report. Toronto. Retrieved from https://www.ontario.ca/document/guideline-10procedure-preparing-emission-summary-and-dispersion-modelling-esdm-report-0

Ontario Ministry of the Environment and Climate Change. (2017b). Guideline A-12: Guideline for the Implementation of Air Standards in Ontario. Toronto. Retrieved from https://www.ontario.ca/page/guideline-12-guideline-implementation-air-standardsontario

Ontario Ministry of the Environment and Climate Change. (2017c). Proposal for Addressing 
Cumulative Effects in Air Approvals in Ontario Questions and Answers. Toronto.

Ontario Ministry of the Environment and Climate Change. (2017d). Rules on Air Quality and

Pollution. Toronto. Retrieved from https://www.ontario.ca/page/rules-air-qualityand-pollution

Ontario Ministry of the Environment and Climate Change. (2017e). Science Discussion Report on the Development for Air Standards for Sulphur Dioxide. Toronto. Retrieved from

http://www.downloads.ene.gov.on.ca/envision/env_reg/er/documents/2017/0130903_Discussion.pdf

Ontario Ministry of the Environment and Climate Change. (2017f). Technical Memorandum: Aamjiwnaang First Nation Community Air Monitoring Station 2015 Report. Toronto. Retrieved from http://www.aamjiwnaang.ca/wpcontent/uploads/2017/10/Aamjiwnaang-First-Nation-Air-Monitoring-2015Report.pdf

Ontario Ministry of the Environment and Climate Change. (2017g). Technical Memorandum Aamjiwnaang Air Quality Mobile Survey, 2015. London. Retrieved from http://www.aamjiwnaang.ca/wp-content/uploads/2017/10/Aamjiwnaang-mobilesurvey-2015_Final.pdf

Otway, H. J., \& Von Winterfeldt, D. (1982). Beyond acceptable risk: On the social acceptability of technologies. Policy Sciences, 14(3), 247-256. https://doi.org/10.1007/BF00136399

Ozawa, C. P. (1996). Science in Environmental Conflicts. Sociological Perspectives, 39(2), 219-230. https://doi.org/10.2307/1389309

Ozymy, J., \& Jarrell, M. L. (2011). Upset over Air Pollution: Analyzing Upset Event Emissions at Petroleum Refineries. Review of Policy Research, 28(4), 365-382.

https://doi.org/10.1111/j.1541-1338.2011.00502.x

Paustenbach, D. J., A. K. M. (2014). Practice of Exposure Assessment. In C. L. Hayes, A. Wallace, Kruger (Ed.), Hayes' Principles and Methods of Toxicology (6th Ed., pp. 454505). London: CRC Press.

Paustenbach, D. J. (2000). THE PRACTICE OF EXPOSURE ASSESSMENT: A STATE-OF-THEART REVIEW. Journal of Toxicology and Environmental Health, Part B, 3(3), 179-291. https://doi.org/10.1080/10937400050045264

Petry, T., Schmid, P., \& Schlatter, C. (1996). The use of toxic equivalency factors in assessing occupational and environmental health risk associated with exposure to airborne mixtures of polycyclic aromatic hydrocarbons (PAHs). Chemosphere, 32(4), 639-648. https://doi.org/https://doi.org/10.1016/0045-6535(95)00348-7

Plain, W, H. (2001, September 11). Resident wasn't warned of spill. Sarnia Observer. Sarnia. Pufulete, M., Battershill, J., Boobis, A., \& Fielder, R. (2004). Approaches to carcinogenic risk assessment for polycyclic aromatic hydrocarbons: a UK perspective. Regulatory Toxicology and Pharmacology, 40(1), 54-66. https://doi.org/https://doi.org/10.1016/j.yrtph.2004.04.007

Ramírez, N., Cuadras, A., Rovira, E., Borrull, F., \& Marcé, R. M. (2012). Chronic risk assessment of exposure to volatile organic compounds in the atmosphere near the largest Mediterranean industrial site. Environment International, 39(1), 200-209. https://doi.org/https://doi.org/10.1016/j.envint.2011.11.002 
Ramírez, N., Cuadras, A., Rovira, E., Marcé, R. M., \& Borrull, F. (2011). Risk Assessment Related to Atmospheric Polycyclic Aromatic Hydrocarbons in Gas and Particle Phases near Industrial Sites. Environmental Health Perspectives, 119(8), 1110-1116. https://doi.org/10.1289/ehp.1002855

Ranco, D., \& Suagee, D. (2007). Tribal Sovereignty and the Problem of Difference in Environmental Regulation: Observations on "Measured Separatism" in Indian Country. Antipode, 39(4), 691-707. https://doi.org/10.1111/j.1467-8330.2007.00547.x

Rappaport, S. M. (1991). Assessment of Long-term Exposures To Toxic Substances In Air. The Annals of Occupational Hygiene, 35(1), 61-122. Retrieved from http://dx.doi.org/10.1093/annhyg/35.1.61

Rappaport, S. M., Kupper, L. L., \& Lin, Y. S. (2005). On the Importance of Exposure Variability to the Doses of Volatile Organic Compounds. Toxicological Sciences, 83(2), 224-236. Retrieved from http://dx.doi.org/10.1093/toxsci/kfi039

Ras, M. R., Marcé, R. M., \& Borrull, F. (2009). Characterization of ozone precursor volatile organic compounds in urban atmospheres and around the petrochemical industry in the Tarragona region. Science of The Total Environment, 407(14), 4312-4319. https://doi.org/https://doi.org/10.1016/j.scitotenv.2009.04.001

Rayner, S., \& Cantor, R. (1987). How Fair Is Safe Enough? The Cultural Approach to Societal Technology Choice1. Risk Analysis, 7(1), 3-9. https://doi.org/10.1111/j.15396924.1987.tb00963.x

Rehwagen, M., Müller, A., Massolo, L., Herbarth, O., \& Ronco, A. (2005). Polycyclic aromatic hydrocarbons associated with particles in ambient air from urban and industrial areas. Science of The Total Environment, 348(1), 199-210. https://doi.org/http://dx.doi.org/10.1016/j.scitotenv.2004.12.050

Rhomberg, L. R., Goodman, J. E., \& Lewandowski, T. A. (2010). Risk Assessment. In Comprehensive Toxicology, Volumes 1-14 (2nd Edition). Elsevier. Retrieved from http://app.knovel.com/hotlink/pdf/id:kt0084CIYI/comprehensive-toxicology/riskassessment-2

Richmond, C. A. M., \& Ross, N. A. (2009). The determinants of First Nation and Inuit health: A critical population health approach. Health \& Place, 15(2), 403-411. https://doi.org/https://doi.org/10.1016/j.healthplace.2008.07.004

Rodricks, J. V., Gaylor, D. W., \& Turnbull, D. (2007). Quantitative Extrapolations in Toxicology. In W. Hayes (Ed.), Hayes' Principles and Methods of Toxicology (5th ed., pp. 453-471). Boca Raton: CRC Press.

Roeser, S., \& Pesch, U. (2015). An Emotional Deliberation Approach to Risk. Science, Technology, \& Human Values, 41(2), 274-297. https://doi.org/10.1177/0162243915596231

Salter, L. (1988). Mandated Science. https://doi.org/10.1007/978-94-009-2711-7_8

Sánchez de la Campa, A. M., Moreno, T., de la Rosa, J., Alastuey, A., \& Querol, X. (2011). Size distribution and chemical composition of metalliferous stack emissions in the San Roque petroleum refinery complex, southern Spain. Journal of Hazardous Materials, 190(1), 713-722. https://doi.org/http://dx.doi.org/10.1016/j.jhazmat.2011.03.104

Sarewitz, D. (2004). How science makes environmental controversies worse. Environmental Science \& Policy, 7(5), 385-403. https://doi.org/https://doi.org/10.1016/j.envsci.2004.06.001 
Sarnia-Lambton Econmic Partnership. (2015). Sarnia-Lambton Petrochemical and Refining Complex. Sarnia. Retrieved from http://www.viprail.com/S_L_PETROCHEM_BROCHURE.pdf

Sarnia-Lambton Econmic Partnership. (2017). Petrochemical and Refined Petroleum. Retrieved October 19, 2017, from http://www.sarnialambton.on.ca/keysectors/petrochemical-and-refined-petroleum

Sarnia Observer. (2003). System Fails Test. Sarnia Observer. Sarnia. Retrieved from https://search-proquestcom.ezproxy.lib.ryerson.ca/docview/348216289?accountid=13631

Schneiderman, M. A., Decouflé, P., \& Brown, C. C. (1979). THRESHOLDS FOR ENVIRONMENTAL CANCER: BIOLOGIC AND STATISTICAL CONSIDERATIONS. Annals of the New York Academy of Sciences, 329(1), 92-130. https://doi.org/10.1111/j.17496632.1979.tb15339.x

Sexton, K., Linder, S. H., Marko, D., Bethel, H., \& Lupo, P. J. (2007). Comparative Assessment of Air Pollution-Related Health Risks in Houston. Environmental Health Perspectives, 115(10), 1388-1393. Retrieved from http://www.jstor.org/stable/4626928

Shie, R.-H., Yuan, T.-H., \& Chan, C.-C. (2013). Using pollution roses to assess sulfur dioxide impacts in a township downwind of a petrochemical complex. Journal of the Air \& Waste Management Association, 63(6), 702-711. https://doi.org/10.1080/10962247.2013.780001

Sielken, R. L., \& Valdez-Flores, C. (2015). A comprehensive review of occupational and general population cancer risk: 1,3-Butadiene exposure-response modeling for all leukemia, acute myelogenous leukemia, chronic lymphocytic leukemia, chronic myelogenous leukemia, myeloid neoplasm and lymphoid neoplasm. ChemicoBiological Interactions, 241(Supplement C), 50-58. https://doi.org/https://doi.org/10.1016/j.cbi.2015.06.009

Simpson, I. J., Marrero, J. E., Batterman, S., Meinardi, S., Barletta, B., \& Blake, D. R. (2013). Air quality in the Industrial Heartland of Alberta, Canada and potential impacts on human health. Atmospheric Environment, 81, 702-709. https://doi.org/https://doi.org/10.1016/j.atmosenv.2013.09.017

Slob, W. (1999). Thresholds in Toxicology and Risk Assessment. International Journal of Toxicology, 18(4), 259-268. https://doi.org/10.1080/109158199225413

Slovic, P. (1993). Perceived Risk, Trust, and Democracy. Risk Analysis, 13(6), 675-682. https://doi.org/10.1111/j.1539-6924.1993.tb01329.x

Slovic, P. (1999). Trust, Emotion, Sex, Politics, and Science: Surveying the Risk-Assessment Battlefield. Risk Analysis, 19(4), 689-701. https://doi.org/10.1111/j.15396924.1999.tb00439.x

Slovic, P., Finucane, M. L., Peters, E., \& MacGregor, D. G. (2004). Risk as Analysis and Risk as Feelings: Some Thoughts about Affect, Reason, Risk, and Rationality. Risk Analysis, 24(2), 311-322. https://doi.org/10.1111/j.0272-4332.2004.00433.x

Slovic, P., Malmfors, T., Krewski, D., Mertz, C. K., Neil, N., \& Bartlett, S. (1995). Intuitive Toxicology. II. Expert and Lay Judgments of Chemical Risks in Canada. Risk Analysis, 15(6), 661-675. https://doi.org/10.1111/j.1539-6924.1995.tb01338.x

Slovic, P., Malmfors, T., Mertz, C. K., Neil, N., \& Purchase, I. F. H. (1997). Evaluating chemical risks: results of a survey of the British Toxicology Society. Human \& Experimental 
Toxicology, 16(6), 289-304. https://doi.org/10.1177/096032719701600601

Spears, T. (2005, September 9). Spill Angers Band. The Windsor Star. Windsor. Retrieved from http://ezproxy.lib.ryerson.ca/login?url=https://search-proquestcom.ezproxy.lib.ryerson.ca/docview/254646695?accountid=13631

Starr, C. (1969). Social Benefit versus Technological Risk. Science, 165(3899), 1232 LP1238. Retrieved from http://science.sciencemag.org/content/165/3899/1232.abstract

Suh, H. H., Bahadori, T., Vallarino, J., \& Spengler, J. D. (2000). Criteria air pollutants and toxic air pollutants. Environmental Health Perspectives, 108(Suppl 4), 625-633. Retrieved from http://www.ncbi.nlm.nih.gov/pmc/articles/PMC1637676/

Swenberg, J. A., Richardson, F. C., Boucheron, J. A., Deal, F. H., Belinsky, S. A., Charbonneau, M., \& Short, B. G. (1987). High- to low-dose extrapolation: critical determinants involved in the dose response of carcinogenic substances. Environmental Health Perspectives, 76, 57-63. Retrieved from http://www.ncbi.nlm.nih.gov/pmc/articles/PMC1474488/

Texas Commission on Environmental Quality. (2008). 1,3-Butadiene: Development Support Document.

Thepanondh, S., Varoonphan, J., Sarutichart, P., \& Makkasap, T. (2011). Airborne Volatile Organic Compounds and Their Potential Health Impact on the Vicinity of Petrochemical Industrial Complex. Water, Air, \& Soil Pollution, 214(1), 83-92. https://doi.org/10.1007/s11270-010-0406-0

Tiwari, V., Hanai, Y., \& Masunaga, S. (2010). Ambient levels of volatile organic compounds in the vicinity of petrochemical industrial area of Yokohama, Japan. Air Quality, Atmosphere \& Health, 3(2), 65-75. https://doi.org/10.1007/s11869-009-0052-0

Torres, G. (1992). Introduction: Understanding Environmental Racism Class, Race, and Environmental Regulation - Introduction. University of Colorado Law Review.

Travis, C. C., Richter, S. A., Crouch, E. A. C., Wilson, R., \& Klema, E. D. (1987). Cancer risk management A review of 132 federal regulatory decisions. Environmental Science \& Technology, 21(5), 415-420. https://doi.org/10.1021/es00159a001

Tsai, J.-H., Being-Hwa, P., Ding-Zang, L., \& Lee, C.-C. (1995). PAH characteristics and genotoxicity in the ambient air of a petrochemical industry complex. Environment International, 21(1), 47-56. https://doi.org/https://doi.org/10.1016/01604120(94)00037-8

U.S. Environmental Protection Agency. (1987). 1,2 Dichloroethane: Integrated Risk Information System, Chemical Assessment Summary. Washington, DC.

U.S. Environmental Protection Agency. (1992). Guidelines for Exposure Assessment. Washington, DC. Retrieved from https://cfpub.epa.gov/ncea/risk/recordisplay.cfm?deid=15263

U.S. Environmental Protection Agency. (1994). Methods for Derivation of Inhalation Reference Concentrations and Application of Inhalation Dosimetry. Washington, DC.

U.S. Environmental Protection Agency. (1998). Carcinogenic Effects of Benzene: An Update. Washington, DC. Retrieved from https://www.epa.gov/iris/supporting-documentsbenzene-cancer

U.S. Environmental Protection Agency. (2002a). A Review of the Reference Dose and Reference Concentration Process. Washington, DC. Retrieved from 
https://www.epa.gov/sites/production/files/2014-12/documents/rfd-final.pdf

U.S. Environmental Protection Agency. (2002b). Petroleum Refinery Source Characterization and Emission Model for Residual Risk Assessment.

U.S. Environmental Protection Agency. (2004). Chemicals Evaluated for Carcinogenic Potential. Retrieved from https://a816-

healthpsi.nyc.gov/ll37/pdf/carcclassJuly2004_1.pdf

U.S. Environmental Protection Agency. (2005a). Guidelines for Carcinogen Risk Assessment. Washington, DC.

U.S. Environmental Protection Agency. (2005b). Supplemental Guidance for Assessing Susceptibility from Early-Life Exposure to Carcinogens. Washington, DC.

U.S. Environmental Protection Agency. (2009a). Compilation of Air Pollutant Emission Factors (AP-42). Research Triangle Park. Retrieved from https://www.epa.gov/airemissions-factors-and-quantification/ap-42-compilation-air-emission-factors

U.S. Environmental Protection Agency. (2009b). Risk Assessment Guidance for Superfund Volume I: Human Health Evaluation Manual (Part F, Supplemental Guidance for Inhalation Risk Assessment). Washington, DC. Retrieved from https://www.epa.gov/risk/risk-assessment-guidance-superfund-rags-part-f

U.S. Environmental Protection Agency. (2010). Development of A Relative Potency Factor (RPF) Approach for Polycyclic Aromatic Hydrocarbon (PAH) Mixtures. Washington, DC.

U.S. Environmental Protection Agency. (2012). Advances in Inhalation Gas Dosimetry for Derivation of a Reference Concentration (RfC) and Use in Risk Assessment. Washington, DC.

U.S. Environmental Protection Agency. (2014). Additional Information, Adjustments and Special Cases for Dose-Response Values in Tables 1 and 2. Retrieved from https://www.epa.gov/fera/dose-response-assessment-assessing-health-risksassociated-exposure-hazardous-air-pollutants

U.S. Environmental Protection Agency. (2015). ProUCL Version 5.1 Technical Guide. Washington, DC.

U.S. Environmental Protection Agency. (2016). Nickel Compounds. Retrieved from https://www.epa.gov/sites/production/files/2016-09/documents/nicklecompounds.pdf

U.S. Environmental Protection Agency. (2017). Technical Overview of Volatile Organic Compounds. Retrieved February 28, 2018, from https://www.epa.gov/indoor-airquality-iaq/technical-overview-volatile-organic-compounds\#3

van den Hove, S. (2007). A rationale for science-policy interfaces. Futures, 39(7), 807-826. https://doi.org/https://doi.org/10.1016/j.futures.2006.12.004

Webster, M., Nam, J., Kimura, Y., Jeffries, H., Vizuete, W., \& Allen, D. T. (2007). The effect of variability in industrial emissions on ozone formation in Houston, Texas. Atmospheric Environment, 41(40), 9580-9593. https://doi.org/https://doi.org/10.1016/j.atmosenv.2007.08.052

Wei, W., Cheng, S., Li, G., Wang, G., \& Wang, H. (2014). Characteristics of ozone and ozone precursors (VOCs and NOx) around a petroleum refinery in Beijing, China. Journal of Environmental Sciences, 26(2), 332-342. https://doi.org/https://doi.org/10.1016/S1001-0742(13)60412-X

Weinberg, A. M. (1972). Science and trans-science. Minerva, 10(2), 209-222. 
https://doi.org/10.1007/BF01682418

Westra, L. (1999). Environmental Racism and the First Nations of Canada: Terrorism at Oka. Journal of Social Philosophy, 30(1), 103-124. https://doi.org/10.1111/00472786.t01-1-00007

Whipple, C. G. (1986). Dealing With Uncertainty About Risk in Risk Management. In Hazards: Technology and Fairness. Washington, DC: National Academies Press.

Wiebe, S. M. (2016a). Everyday Exposure: Indigenous Mobilization and Environmental Justice in Canada's Chemical Valley. UBC Press. Retrieved from http://ebookcentral.proquest.com.ezproxy.lib.ryerson.ca/lib/ryerson/detail.action?d ocID $=4689307$.

Wiebe, S. M. (2016b). Guardians of the environment in Canada's Chemical Valley. Citizenship Studies, 20(1), 18-33. https://doi.org/10.1080/13621025.2015.1075470

Williams, P. R. D., \& Paustenbach, D. J. (2002). RISK CHARACTERIZATION: PRINCIPLES AND PRACTICE. Journal of Toxicology and Environmental Health, Part B, 5(4), 337-406. https://doi.org/10.1080/10937400290070161

Wilson, K. (2003). Therapeutic landscapes and First Nations peoples: an exploration of culture, health and place. Health \& Place, 9(2), 83-93. https://doi.org/https://doi.org/10.1016/S1353-8292(02)00016-3

Wilson, W. E., Mage, D. T., \& Grant, L. D. (2000). Estimating Separately Personal Exposure to Ambient and Nonambient Particulate Matter for Epidemiology and Risk Assessment: Why and How. Journal of the Air \& Waste Management Association, 50(7), 1167-1183. https://doi.org/10.1080/10473289.2000.10464164

World Health Organization. (2000). Air Quality Guidelines for Europe. Retrieved from http://www.euro.who.int/_data/assets/pdf_file/0005/74732/E71922.pdf

World Health Organization. (2005). WHO Air quality guidelines for particulate matter, ozone, nitrogen dioxide and sulfur dioxide. Geneva.

World Health Organization. (2018). Constitution of WHO: principles. Retrieved February 12, 2018, from http://www.who.int/about/mission/en/

Wu, X. (May), Fan, Z. (Tina), Zhu, X., Jung, K. H., Ohman-Strickland, P., Weisel, C. P., \& Lioy, P. J. (2012). Exposures to volatile organic compounds (VOCs) and associated health risks of socio-economically disadvantaged population in a "hot spot" in Camden, New Jersey. Atmospheric Environment (Oxford, England : 1994), 57, 72-79. https://doi.org/10.1016/j.atmosenv.2012.04.029

Yassaa, N., \& Cecinato, A. (2005). Composition of torched crude oil organic particulate emitted by refinery and its similarity to atmospheric aerosol in the surrounding area. Chemosphere, 60(11), 1660-1666. https://doi.org/https://doi.org/10.1016/j.chemosphere.2005.02.041

Zhu, X., Fan, Z. (Tina), Wu, X., Meng, Q., Wang, S., Tang, X., ... Lioy, P. (2008). Spatial variation of volatile organic compounds in a "Hot Spot" for air pollution. Atmospheric Environment (Oxford, England : 1994), 42(32), 7329-7338. https://doi.org/10.1016/j.atmosenv.2008.07.039 


\section{Glossary}

Air pollution hot spot: Locations in which emissions from specific sources may expose individuals and population groups to elevated risks of adverse health effects and contribute to the cumulative health risks of emissions from other sources in the area (California Air Resources Board, 2017)

Canadian Charter of Rights and Freedoms: A bill of rights, entrenched in the Constitution of Canada, which guarantees civil rights to everyone in Canada.

Environmental Bill of Rights (EBR): Ontario legislation passed in 1993 giving Ontario citizens rights to participate in environmental decision making, including the right to request investigations of pollutant releases.

Environmental Racism: For this thesis it the idea that environmental policies can have a subordinating impact on racial groups and implies a focus on the distributional impacts of environmental policies (see Torres, 1992).

Hazard (chemical): Any chemical with the potential to cause harm to human and biological systems. A hazard is considered to produce risk only if an exposure pathway to humans exists, and if exposure creates the possibility of harm.

Hazard Quotient (HQ): The form of risk estimate for non-cancer effects, which is derived by dividing the estimated environmental exposure by a Reference Concentration (RfC) that represents an estimate of continuous inhalation exposure to the human population that is likely to be without an appreciable risk of health effects

Incremental lifetime cancer risk (ILCR): The incremental risk of death due to cancer over a lifetime associated with a specific exposure scenario.

National Pollutant Release Inventory: A database collected and maintained by Environment Canada of voluntarily reported annual pollutant releases to air, water and land by Canadian industrial facilities.

Point Of Impingement (POI): Any point on the ground or on a building located beyond an emitting facility's property boundary where either the maximum concentration of a given pollutant is expected to occur, or where the concentration of a given pollutant is expected to exceed Ontario's general air quality standards.

Risk: In quantitative risk assessment, the numerical probability that this harm will occur, however, as the literature review in this thesis discusses, there are multiple definitions of risk that are important to consider (see literature review for a detailed discussion). 
Risk-assessment - risk management paradigm: The use of risk assessment and risk management, as traditionally practiced by the U.S. EPA and the MOECC.

Science-policy interface: Any time or situation in which scientific knowledge is used to inform or influence a policy decision.

Statistical Power: In statistical hypothesis testing, statistical power is the probability of rejecting the null hypothesis when the null hypothesis is not true. At any level of statistical significance, the statistical power of the study is dependent on sample size, the prevalence of exposure, and rareness of the disease-and depending on study type, the length of time required for health effects to manifest (National Research Council, 1997).

Toxic Release Inventory: A database collected and maintained by the U.S. Environmental Protection Agency of voluntarily reported annual toxic pollutant releases to the environment by U.S. industrial facilities.

Volatile organic compounds (VOCs): For this thesis the U.S. Environmental Protection Agency definition is used: "Any compound of carbon, excluding carbon monoxide, carbon dioxide, carbonic acid, metallic carbides or carbonates and ammonium carbonate, which participates in atmospheric photochemical reactions, except those designated by EPA as having negligible photochemical reactivity. Volatile organic compounds, or VOCs are organic chemical compounds whose composition makes it possible for them to evaporate under normal indoor atmospheric conditions of temperature and pressure." (U.S. Environmental Protection Agency, 2017)

Polycyclic Aromatic Hydrocarbons (PAHs): PAHs are a class of organic compounds, which are solids with low volatility at room temperature, have relatively high molecular weights and are produced by incomplete combustion or high-pressure processes (Agency for Toxic Substances and Disease Registry, 2013). 